\title{
Review of Energy Storage Systems in Regenerative Braking Energy Recovery in DC Electrified Urban Railway Systems: Converter Topologies, Control Methods \& Future Prospects
}

\author{
Danlami Sadiq ${ }^{1}$, Muhamad Mansor ${ }^{1}$, Yong Jia Ying ${ }^{1}$, Vigna K. Ramachandaramurthy ${ }^{1}$, M.A \\ Hannan ${ }^{1}$, Mohd. Azrin Mohd Azau', Muhamad Safwan Abd Rahman', Azri Husni bin Hasani², \\ Nur A. Salim ${ }^{3}$. \\ ${ }^{1}$ Dept of Electrical \& Electronics Engineering, College of Engineering, Universiti Tenaga Nasional, Kajang \\ 43000, Selangor, Malaysia. \\ ${ }^{2}$ URND Sdn Bhd, Universiti Tenaga Nasional, Kajang, Malaysia. \\ ${ }^{3}$ Faculty of Electrical Engineering, Universiti Teknologi MARA, Shah Alam, Shah Alam, Malaysia. \\ Corresponding Author: Danlami Sadiq (Danlami.Sadiq@uniten.edu.my)
}

Funding information: Long Term Research Grant Scheme (LRGS) under the Ministry of Education, Malaysia, Grant Number: LRGS/1/2018/UNITEN/01/1/2

\begin{abstract}
Electrified urban railway systems are large consumers of energy in urban areas and thus, there is a need for energy saving measures in this transportation sector. Recuperation of train's regenerative braking energy (RBE) is one of the best ways for attaining high levels of energy efficiency in this area. Energy Storage Systems (ESSs) prove to be the most practical and viable solution for maximizing the RBE utilization in urban railway systems. In the existing related reviews of ESSs, few papers covered the review of ESS technologies or converter interface. However, a comprehensive review is needed in this regard. This paper discusses an overview of urban railway electrification, and detail review for the three ESS components - ESS Technologies, Bidirectional DC-DC Converters (BDCs), and Controller Unit. This study concludes that among the storage technologies, supercapacitor ESS appears to be the most suitable followed by Lithium-ion batteries and flywheels. For BDC, cascaded BDC is the most suitable followed by dual active bridge. For control methods, fuzzy logic and artificial intelligent are recommended among other control strategies. Thus, the key contribution of this paper is the comprehensive review and analyses of the ESS's components in the recovery of RBE in urban railways.
\end{abstract}

Keywords: Energy Saving; Energy Storage Technologies; Control System; Energy Management; DCDC Power Converters; Bidirectional Power Flow; Regenerative Braking Energy; Urban Railway Systems. 


\section{Introduction}

Electric railway system has become a major means of transporting people and goods, especially in the urban and suburban areas, and as such contributes greatly to the reduction of traffic and environmental pollution $\left(\mathrm{CO}_{2}\right.$ emission in particular) [1], [2]. Therefore, the electric traction system has uncompromised advantages more especially in densely populated areas like in the urban and suburban cities where the rapid transit systems are found and where the safety, protection, high level of performances, environmental protection, and cost effectiveness of service must be assured [3].

Currently, there is a fast development of electric railway transport system because of the rapid growth of the worldwide populations. As a result, this has led to high increase of energy consumption as well as the environmental pollutions. Therefore, increasing the energy efficiency of rail transit systems is crucial in order to achieve high reduction in energy consumption and $\mathrm{CO}_{2}$ emissions, [3]-[5]. Generally, in urban railway systems, electric rail vehicle has four working conditions, those are acceleration, moving with constant speed (coasting), braking process, and stopping mode, [6]-[9]. In the acceleration process, the train draws large amount of electric energy from the railway substation via the catenary line or third rail. This is the power required to speed up the vehicle to reach the constant speed. During the coasting mode, negligible energy is consumed. Whereas in the braking mode, the vehicle continuously slows down its speed to a final stop point at a station (deceleration process).

Nowadays, most electric trains are equipped with dynamic system of braking which enable them to convert their kinetic energy developed during motion into electricity. This is achieved in deceleration process during which, the traction of the electric motors behave as generators, [6], [10]-[13]. The electrical energy produced is called regenerated braking energy which is fed back into the traction network (DC-link). During the braking process, the regenerated energy is directly supplied to the train's auxiliaries onboard via the traction network for direct consumption while the excess is sent back to the catenary line or third rail for other vehicles in the same power supply network to utilize during their acceleration process. Otherwise, this surplus energy is lost in the form of heat by dissipating it into a bank of resistors located onboard of the train or at the substation (this is called rheostatic braking), [4], [10], [14]-[17]. Note that, there is an issue with regard to feeding back the regenerated braking energy 
to the catenary line in DC supply substation (non-inverting substation) if there are no simultaneous accelerating vehicles to consume such energy, [18]. Hence, this result into catenary line/third rail overvoltage which has the potential to damage the traction network equipment such as the electric motors' power converters and the others [6], [10], [14]. It is for this reason that the urban railway DC distribution network is said to be non-receptive, which means not all the times the regenerated energy is fully consumed by other accelerating vehicles. Therefore, the fundamental solution being only to send the regenerated braking energy to the catenary line network on a condition that there exists another accelerating vehicles in the same power supply network to consume it, otherwise rheostatic braking is applied to waste the energy in the form of heat [6]. However, rheostatic braking method has some negative effects especially in the underground metro systems or tunnels where the excess heat produced by the onboard resistors causes excessive warmness within the surrounding whose level needs to be controlled by additional ventilation facilities (hence, additional cost involved), [10].

In order to overcome the above challenges, the regenerated braking energy needs to be maximized while at the same time the number of the onboard resistors is reduced. To achieve this, three major solutions have been studied and proposed regarding the utilization of regenerative braking energy as mostly found in the literature [5], [6], [10], [19]-[25]. The solutions are:

\section{i. Timetable Optimization \\ ii. Reversible Substation \\ iii. Energy Storage System}

The first solution being improving the DC distribution network receptivity by bringing in more loads into the system network demanding excess energy for their acceleration process while at the same time the braking processes of other trains are occurring. This solution is called Timetable Optimization as shown in Fig.1 [5], [26]-[29]. 


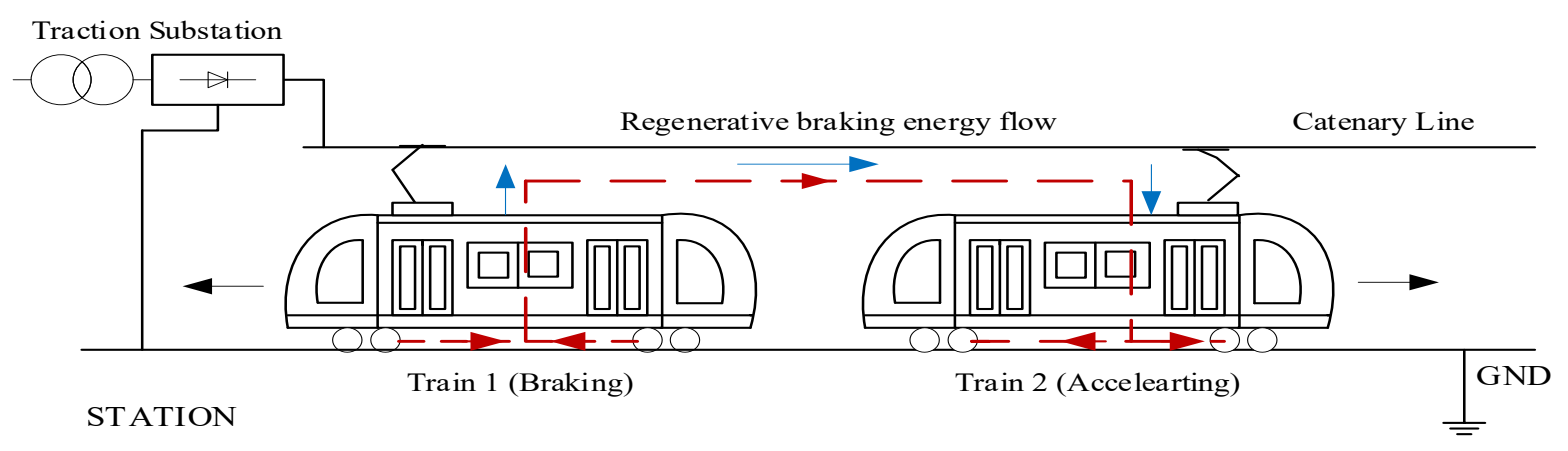

Fig. 1. Timetable Optimization Method (Exchange of regenerative braking energy between trains), [10]

This method allows a simultaneous exchange of the regenerated braking energy among the vehicles. Research studies in this field have confirmed that energy consumption reduction of up to $14 \%$ could be achieved with this method [30]. This method is regarded to be the cheapest way of utilizing regenerative braking energy compared to ESS and reversible methods. However, it requires reliable driving strategies and control systems to achieve schedule strategies and an unplanned occurrence of events for example accidents or delays. Moreover, this solution suffers difficulties in synchronizing accelerating and decelerating vehicles due to many uncertainties which occur in the system schedules. Hence in some cases, the energy is not being fully recovered and therefore wasted in the onboard resistors [6], [10]. The second solution is to improve the receptivity of the DC distribution network. This can be achieved by making the $\mathrm{DC}$ substation to become an inverting one i.e. to connect $\mathrm{DC}-\mathrm{AC}$ inverter in parallel with the unidirectional power supply rectifier circuit so that the regenerative braking energy could be fed directly to the AC grid as shown in Fig. 2 [5], [6], [19], [31]-[37].

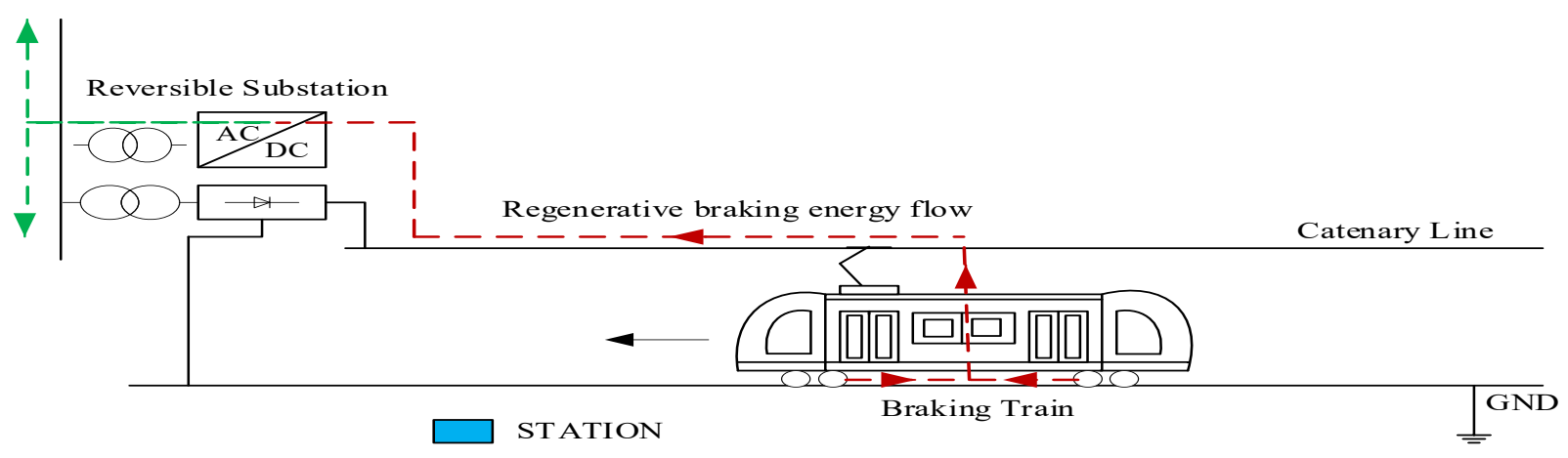

Fig. 2. Reversible Substation (Sending back regenerated energy to power grid) 
This method is called reversible or inverting substation. This method presents a relatively high energy efficiency compared to ESSs because of lower losses involved [6]. Moreover, minimal maintenance and space are required, and high reliability in terms of safety. However, reversible substations do not allow for vehicle's autonomous driving (driving freely without power supply from the substations as ESSs do). This method cannot provide catenary line voltage regulation as well as reduction in power peaks and demand. They have inherent harmonics on both sides of the bidirectional inverter, [10]. With this method, the energy consumption reduction of around $11 \%$ could be achieved [38]. The third solution is the use of Energy Storage Systems (ESSs) placed onboard of the vehicle or at the substation/ trackside in order to accumulate the excess regenerated braking energy and release it later during the vehicle's acceleration process as shown in Fig. 3, [14], [19], [39]-[46].

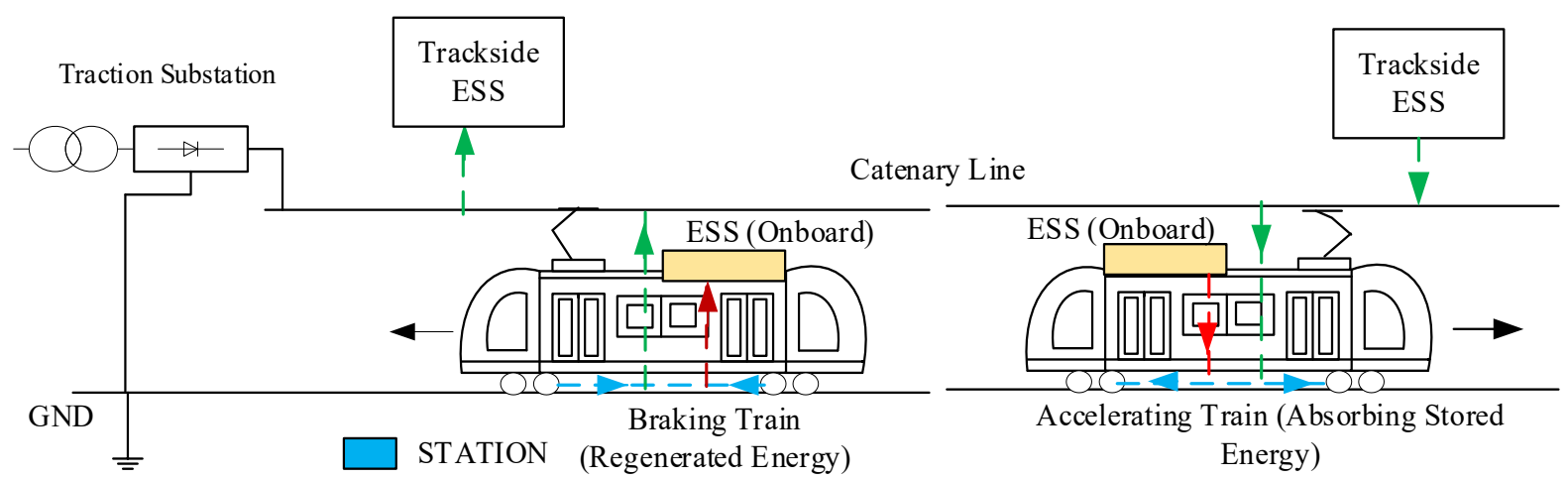

Fig. 3: Energy Storage System Method. (a) Green line for Wayside ESS (b) Red Line for Onboard ESS

With this solution, the total energy consumption required by the vehicle from the substation during the acceleration process is greatly reduced. The benefits of using energy storage systems in storing the regenerated energy are not only for total energy consumption reduction but also for providing reduction in peak power and demand, catenary-line voltage stabilization, compensation of power and energy, and enables the vehicles to have autonomous driving (called catenary-free driving) where a vehicle can continue to run freely without having to connect to the catenary line for power supply [14], [47], [48]. Autonomous driving is advantageous in urban cities where it is not possible to install the catenary lines network because of the existence of aesthetic or historic structures. With this method, as confirmed by a few studies, an energy saving of up to $35 \%$ could be achieved [49]-[54]. The most widely used energy storage devices for such applications include batteries, supercapacitors, flywheels, and hybrid energy 
storage systems. It could be observed that, a more practical and viable solution to maximize the regenerative braking energy is by the use of ESS especially in the urban railway system where acceleration and braking processes of trains occur at high frequency and in excess [10].

The aim of this paper is to provide a literature review on the applications of the most widely used energy storage technologies in recovering regenerative braking energy in urban rail transit system, and to review various topologies of bidirectional DC-DC power converters, and control strategies/energy management applied to both the converters and the energy storage devices. Various applications and detail descriptions of the technologies have been reviewed as presented by research studies and industrial implementation in maximizing the utilization of the regenerative braking energy. Moreover, advantages and disadvantages of the energy storages technologies, power converter topologies and control methods have been presented and analysed for various applications.

The organization of the remaining part of the paper is as follows. In section 2, an overview of railway electrification system, and urban rail transit system have been presented. In section 3, detail description of energy storage technologies, advantages/disadvantages and their applications in urban railway systems are presented and analysed. The techno-economic comparative assessment/analysis and the use of Ragone plot are also presented. Moreover, the ESSs installation configurations are discussed and analysed as presented commercially by the industries and academic research efforts. In section 4, detail descriptions, uses and advantages/disadvantages of various topologies of bidirectional DC-DC power converters as applied in the recovering process of the regenerative braking energy are presented. In section 5, the descriptions and usage of control methods and energy management as applied to the ESSs and bidirectional DC-DC converters in various application types are presented. In sections 6 , discussion and recommendation of the most suitable energy storage technology, dc-dc power converter and control method are presented based on the comparative analysis and assessment. In section 7, challenges and future research direction are outlined. Finally, section 8 concludes the paper. 


\section{Overview of Urban Railway and Railway Electrification Systems}

\subsection{Railway Electrification with System Integration}

Generally, railway electrification systems are of two types which are AC and DC electrification systems and each with its different voltage amplitudes and frequencies [55], [56]. The AC system supply voltages include $15 \mathrm{kV}$ at $16.7 \mathrm{~Hz}$ and $25 \mathrm{kV}$ at $50 \mathrm{~Hz}$ or $60 \mathrm{~Hz}$ while for the DC systems supply voltages are $600 \mathrm{~V}, 750 \mathrm{~V}, 1500 \mathrm{~V}$ and $3000 \mathrm{~V}$. Depending upon the speed profile requirements and travelling distance, AC electrification system is usually employed for long distance travel and high speed profiles electric railway vehicles [57]-[60]. One good advantage of the AC systems is that it exhibits very low power losses compared to the DC system due to the smaller value of currents that can be transmitted over a long distance [61]. In AC systems, as shown in Fig. 4, the power is mostly supplied to the vehicle via overhead catenary line and the examples of vehicles used for this application include high-speed trains and locomotives.

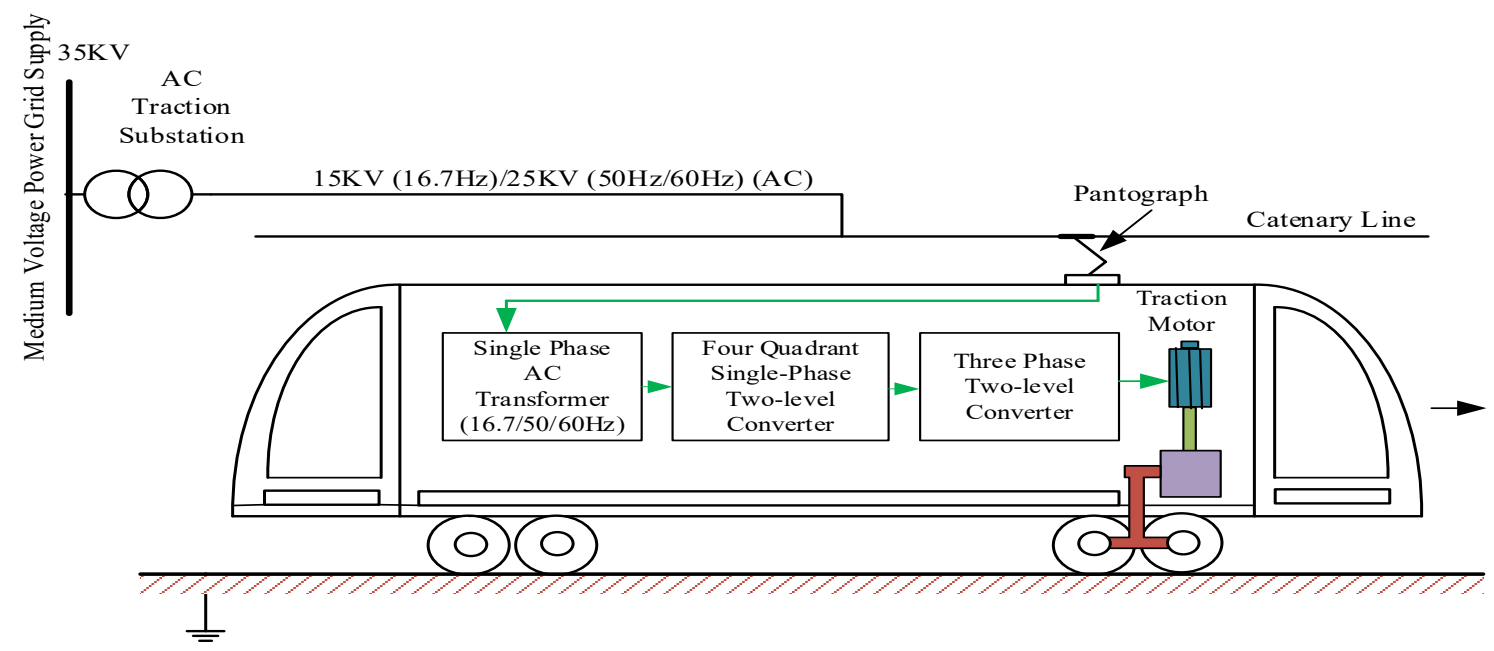

Fig. 4: AC Railway Electrification System with Train System integration [62].

On the other hand, DC electrification system as shown in Fig. 5 is employed for low-speed profiles and shorter distances, and for this reason it is the most preferred option in urban railway system. 


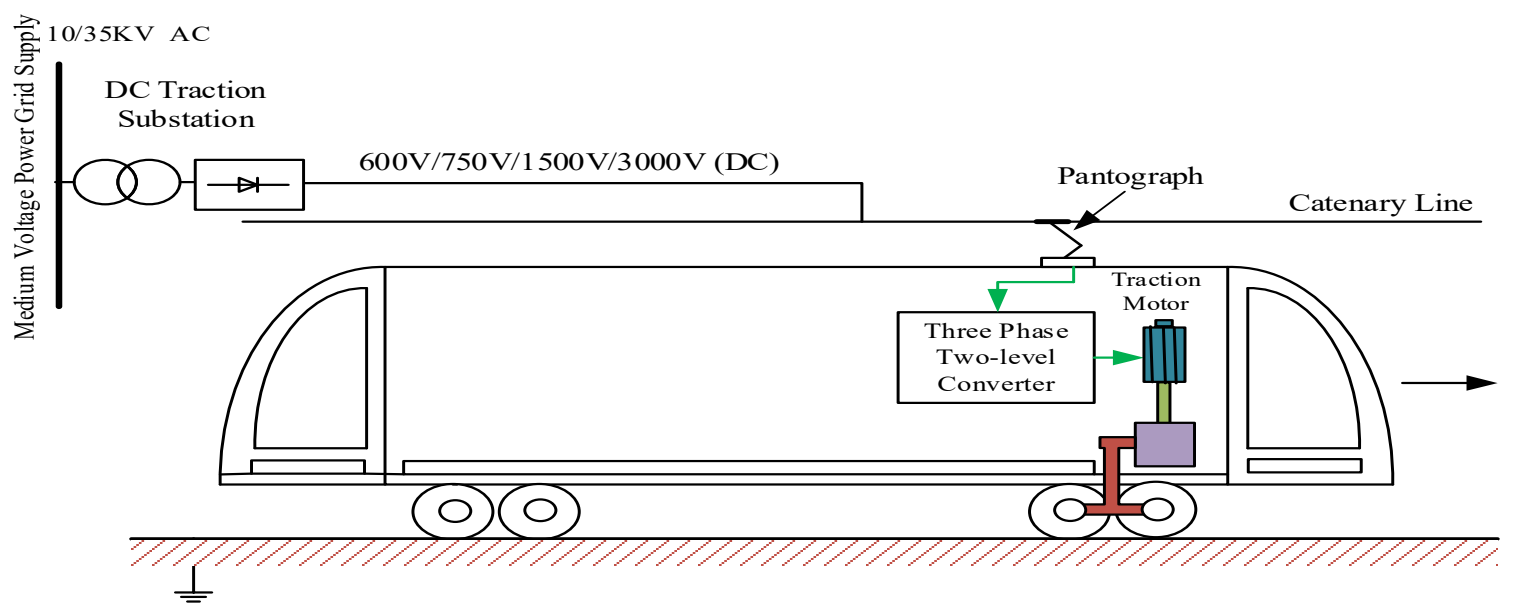

Fig. 5: DC Railway Electrification System with Train System integration

Examples for this application are trams, light rail vehicles, and metro systems. For DC systems, the power is conveyed by either the overhead line catenary or the third rail [55]-[58].

In an urban rail transit system, the main load is the electric train with electric motors attached to the train. The power required to drive the electric motors is supplied from the catenary line or third rail through a bidirectional power electronic converter (three phase two level converter). In both AC and DC supply systems, the power is conveyed to the traction network (DC-link) via a device called pantograph which is located on top of the train. A high-speed circuit breaker (HSCB) is connected in between the pantograph and the traction network for protection purposes [3], [6]. For DC systems, the DC supply goes straight to the traction motors via the power converter and to the train's auxiliaries. In the case of AC supply, the power passes through a step-down AC transformer located inside the train, then through a four quadrant two level rectifier, and then to the traction network. Normally a filter consisting of an inductor and a capacitor is placed between the traction network and input supply for filtering the high frequency harmonics generated by the power converter due to its high switching frequencies [3], [59], [62]. The return (ground path) of the supply is connected by one of the rails. The electric motors produce the required torque and speed in order to provide the traction force to drive the train along the rails and being controlled by the power converter with a proper control circuit. Typical power converters applicable in DC railway traction system are the DC-AC converter (inverter) and DCDC converters. Two types of electric motors are used to provide the required traction force and these 
are the DC motors and AC induction motors (three-phase). The former is usually controlled by a resistor bank together with a DC-DC converter while the latter is by a DC-AC converter (inverter) only. The traction force produced by the electric motors is transmitted to the vehicle wheels on the traction rails via a gearbox in order to move the vehicle along the rail track at a required speed, [6], [61]-[68].

\subsection{Overview of Urban Railway Systems}

Worldwide, in most of the major cities especially in the developed countries, there are urban railway networks and city bus services that serve as public transportation systems. The urban rail transit network consists of suburban and regional rail networks, light rail transit systems, metro systems and trams. Nowadays, almost all the urban railway networks run wholly on electricity supply and the power is taken from various distributed traction power supply substations (TPSSs) located at specified intervals, [69].

The urban or suburban rail transport system usually spans a distance of up to $50 \mathrm{~km}$ from the city centres and utilizes the railway line routes connecting both the urban and suburban areas. The regional railway transport system spans a distance of up to $150 \mathrm{~km}$ from the urban city centres and utilizes the railway lines routes connecting urban and peri-urban areas. The tramway transport systems consist of a tram also known as streetcar, trolley car, tramcar or simply trolley. Tram is a rail car that moves or runs alongside public transport streets and in some countries along separate ways. Tramways provides services of transporting people or goods in urban and suburban areas. The approximate length of a typical tramcar is around $30 \mathrm{~m}$ and can carry up to 300 people at a time. The metro transport system also known as subway, rapid transit system, underground or tube is a rail transit system with higher passenger capacity and frequency of operation and they run on independent rails/guides that are wholly separated from all other forms of traffics. The light rail transit system (LRT), as the name implies, is a type of urban and suburban railway transport service that uses equipment and infrastructures that are less heavier compared to those for metro systems and other heavier rail vehicles such as high-speed rail vehicles or locomotives. It provides benefits of higher flow rates and revenue speed and minimizes interference with other vehicles movement and pedestrians. It has a moderate passenger capacity compared to metro system and trams [55]-[59], [70]-[74]. 


\section{Energy Storage Solutions in Recuperation of Regenerative Braking Energy}

The recent developments in power electronic converters and energy storage technologies have enable energy storage systems to become one of the most practical and viable solutions for recovering the regenerative braking energy in electric railway vehicles and road electric vehicles [10], [39], [40], [75][77]. Depending on the electric railway applications, in most cases, they are considered as the most accepted solution for increasing energy efficiency and reliability of the electrified urban railway systems [39]. As explained earlier, in addition to the total energy consumption reduction, the advantages of the ESSs that make them have such outstanding performances in recuperating regenerative braking energy are the peak power demand reduction in both urban railway and the power utility systems, catenary-line voltage stabilization, compensation of power and energy, and catenary-free driving. Since the ESSs provide an excellent recovery of the braking energy, the heat being wasted in the onboard or wayside braking resistors is highly minimized and hence the additional costs of equipment required for ventilation systems is greatly reduced, [78]-[81]. Two ways of using the ESSs in the urban rail system are by installing them either in mobile form or at stationary. The former, which is generally called onboard configuration is the one in which the ESSs are being conveyed along with the vehicle either at the roof top or under the floor of the train. This gives the opportunity for the trains to accumulate their regenerative energy directly and re-use the energy later during their acceleration processes. On the other hand, the stationary ESSs are placed along trackside or at substations (also called wayside configuration) and they are used to recover and store the excess regenerated braking energy from the catenary line and deliver back to the other trains during their acceleration processes [6], [10], [39].

The following sub-sections give the details of the content under this main section. To start with, the detail descriptions of ESS's components including their functions are presented. Next, is the detail discussions of the most widely used energy storage technologies in recovering regenerative braking energy in urban railway system including Ragone plot and their techno-economic comparisons. Finally, the two installation configurations of the ESSs are presented together with their application examples in urban railway systems. 


\subsection{The Energy Storage System Components}

Generally, as can be found in both industrial applications and academic research studies, the energy storage system comprises three major components namely an energy storage device (ESD), an electronic power converter, and a controller (control unit) [10]. The combination of these three components forms the electrical energy storage system and together they are used to perform several functions. The energy storage device converts electrical energy from a power source in order to store it into another form (electrochemically, mechanically, thermal, electromagnetically, and etc), and converts it back to its original form (electrical energy) whenever required [10], [82]-[85]. The power converter primarily performs the function of providing efficient flow of electrical energy between the power source (in this case the DC-link/Traction Network) and the energy storage device. It also serves as an interface between the two [39]. Fig. 6 below shows the ESS components.

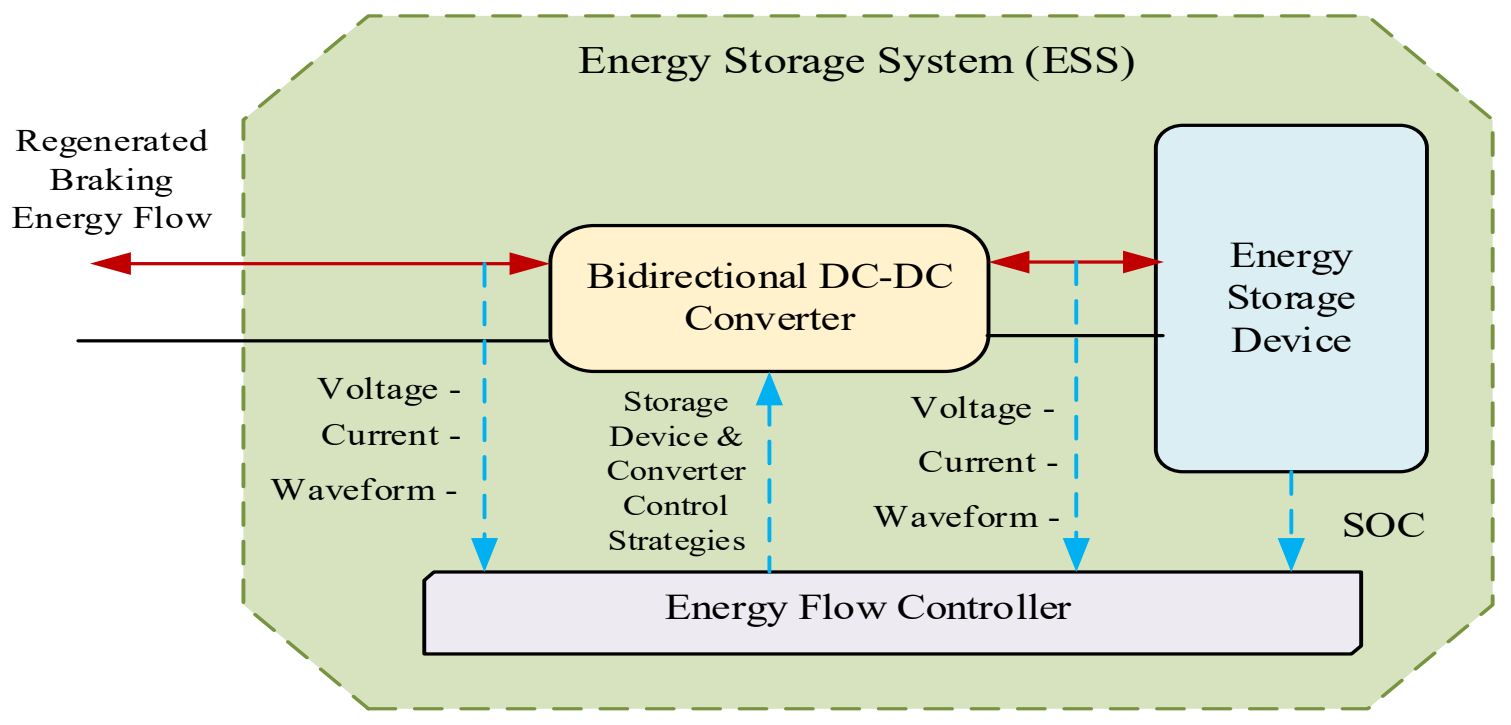

Fig. 6: Energy Storage System (ESS) Components [10].

It should be noted here that for applications in recovering of regenerative braking energy, the converter has to provide a bidirectional energy flow (to and from the energy storage device) and also ensures that the DC-link electrical parameters are aligned with those for the energy storage device parameters such as the voltage and current. For this type of application, the power converter being used is called a bidirectional DC-DC converter for all battery and supercapacitors energy storage devices while it is a bidirectional AC-DC converter in the case of a flywheel energy storage system. It should be noted here 
that from now henceforth, bidirectional DC-DC converter will be considered because for most applications in railway recuperation of regenerative braking energy, batteries and supercapacitors are the most commonly used energy storage devices. The controller which is the control unit for the system performs the functions of managing the energy storage device's charging and discharging processes during the energy flow conditions. This is done in an efficient manner in order to minimize losses. Moreover, the controller carries out this function according to the energy storage device's major working parameter called the state of charge (SOC - minimum, maximum and nominal values) with respect to the traction network (DC-link) voltage. The charging and discharging of the energy storage device are based on specified threshold values of the DC-link voltages [10], [39], [62].

The details of the mentioned components with their various functions, applications, topologies, types, technologies, and etc are covered in section 3.2 (Energy Storage Technologies), section 4 (DC-DC Power Converter Topologies) and section 5 (Control Strategies/Energy Management and bidirectional Converter Control).

\subsection{Energy Storage Technologies and their Applications in Urban Railway System}

In this section, descriptions and applications of the most commonly used energy storage technologies (batteries, supercapacitors, flywheels and hybrid energy storage systems) applied to urban rail transit system in regenerative braking energy recovery are discussed. The techno-economic comparisons among the technologies are presented, as well as their pictorial graph comparisons in terms of power and energy densities called Ragone plot.

The electrical energy storage technologies are the means in which electrical energy can be stored by converting it into electrochemically, potentially, kinetically, electromagnetically, and etc as it is not possible to store the energy in its original form. When the electrical energy is required from the storage device, the stored energy is then converted back into electrical form in order to perform a required operation, [39], [75]. The examples of energy storage technologies include batteries, flywheels, supercapacitors, superconducting, hydrogen fuel cells, and etc. Generally, ESSs are basically required for back-up power supply i.e. when there is a need to supply electrical loads in the absence of mains 
power supply or in the event of system maintenance/fault occurrence or during off-peak periods in renewable energy microgrids or when there is a need for short-term free movement of vehicles with onboard ESS or when it is necessary to get additional power supply if the available primary power supply cannot meet a certain demand [10], [75], [83], [86].

Therefore, in order to get ESS optimal performance for a particular application, selection of the best energy storage technology is crucial. To realize this, some factors are considered in aiding the ESSs design which consists of the number of charging and discharging cycles that a storage device can withstand during its lifetime; the device storage capacity in terms of energy capacity and energy density and power rating of the storage device i.e. the maximum current that it can handle from the mains supply, and the others [10], [39].

\subsubsection{Batteries Energy Storage System Technologies (BESS)}

Batteries are the earliest energy storage devices which store electrical energy by reversible electrochemical reactions between an anode and cathode within an electrolyte solution. With this, a reversible means of converting energy from one form (electrical) to another (chemical) is achieved [75], [86]. Batteries features are known for many decades and depending on the chemistry involved (types of electrodes and electrolyte), they offer different operational characteristics. Brief descriptions of battery technologies that are most commonly used in urban railway system applications are outlined.

\subsubsection{Lead-acid Batteries (PbA)}

This battery technology has been the oldest among all the electrochemical (rechargeable) batteries [87][89]. These lead-acid batteries are the most widely used for different applications. They have both the highest operational efficiency $(70 \%-90 \%)$ and cell voltage [90], [91]. The batteries have two types of electrodes namely cathode $\left(\mathrm{PbO}_{2}\right.$ - Lead Oxide) and anode $(\mathrm{Pb}$ - Lead metal). They are immersed in a diluted electrolyte solution called sulfuric acid $\left(\mathrm{H}_{2} \mathrm{SO}_{4}\right)$. Fig. 7 shows the charging and discharging chemical reactions of a Lead-acid battery. During the discharging condition, both cathode and anode become lead sulphate while the solution turns into water during charging process [92], [93]. 

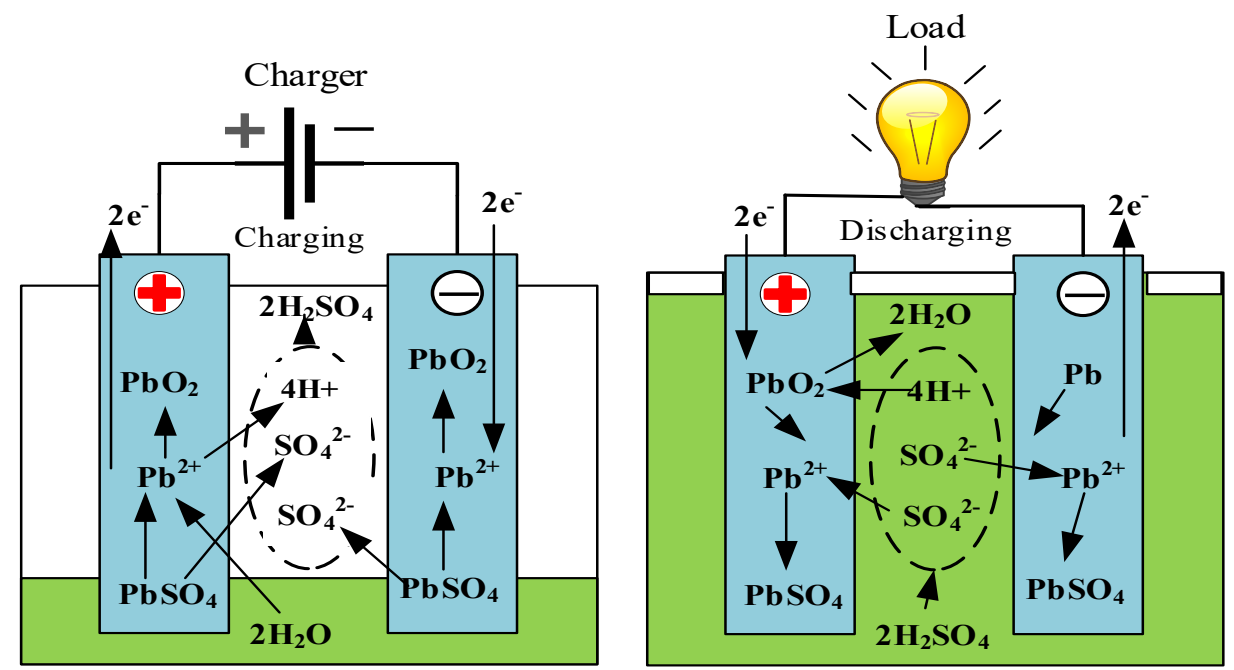

Fig. 7: Lead-Acid Battery (chemical reactions during charging and discharging conditions) [86].

Advantages and Disadvantages: The advantages of this type of batteries are, they have high power density over other types, high operational reliability, low cost in terms of watt-hour (Wh), long history with wide development and high efficiency. The disadvantages are, the batteries have poor performance at low temperature, limited life-time, low energy densities, contribute to environmental pollution, and etc. [87]-[91].

Applications: The lead-acid batteries have a long history of applications in power utilities and other applications for back-up power supplies. Due to their poor energy densities, short lifetime, cost of maintenance, and etc, they are generally being used in applications where low energy density and short lifetime are not major concerns. However, in the early 80 's, they were used in a railway system in Japan where the Japanese National Railway installed lead-acid batteries with total voltage of almost $1600 \mathrm{~V}$ at Nakajima substation. The purpose of such installation was to compensate for a voltage drop along the supply line from the substation, and this project was successful for a duration of three years [94].

In order to further upgrade the lead-acid batteries to enable them to fit in traction systems, both their power and energy densities need to be increased. In that regard, some research studies are ongoing to change the lead electrodes with carbon material [10]. 


\subsubsection{Nickel Metal Hydride Batteries (Ni-MH)}

The Ni-MH battery uses nickel hydroxide as its positive electrode, metal alloy as the negative electrode and both of them are immersed in an electrolyte solution of alkaline. These batteries are the earliest advanced rechargeable batteries with low maintenance and high reliability [95], [96]. From 1991 to date, the energy densities of Ni-MH increased from around $55 \mathrm{Wh} / \mathrm{kg}$ to about $100 \mathrm{~W} / \mathrm{kg}$ whereas the power densities have increased from about 200 to $1300 \mathrm{~W} / \mathrm{kg}$ over the last two decades [10], [97]. Fig. 8 shows the chemical reaction during charging and discharging operations.
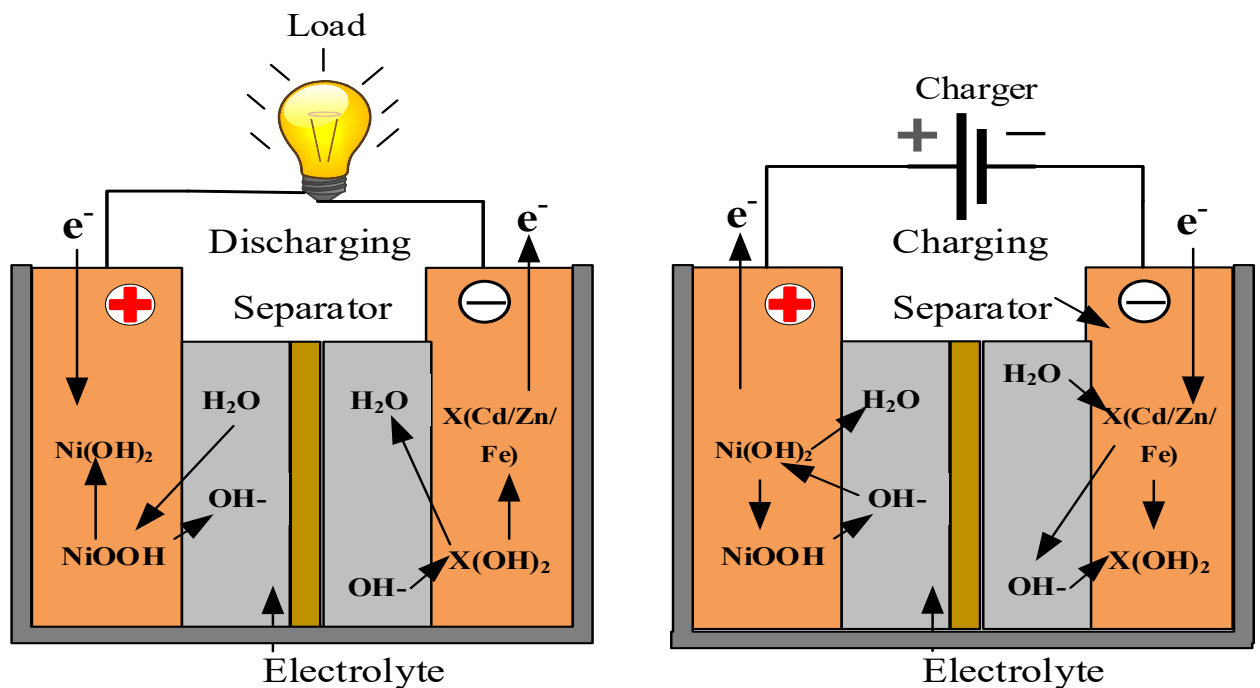

Fig. 8: Ni-MH Battery (chemical reactions during charging/discharging conditions) [86].

Advantages and Disadvantages: The advantages of Ni-MH batteries are as the followings. Compared to Lead-acid batteries, they have high power and energy densities and also with longer lifetime. Moreover, they have higher charging and discharging current, and low impact to environmental pollution. The disadvantages include low efficiency, costlier in terms of Watt-hour (Wh) and maintenance compared to lead-acid batteries. They also have a low resistance and present high rate of self-discharge. Hence, their terminal voltage is $1.2 \mathrm{~V}$. For this reason, they have to be connected in series to build up an ESSs with high nominal voltage, [62], [95]-[99]

In order to overcome the Ni-MH high discharge rate, some novel separators are recommended in their formation [10]. 
Applications: Ni-MH had first been implemented in the nineties in hybrid electric cars. Unlike leadacid batteries, in $2006 \mathrm{Ni}-\mathrm{MH}$ batteries were applied in traction rail vehicles in terms of energy consumption reduction where they were used in a tramcar called Citadis in Nice, France. A railway manufacturing company known as Alstom did the installation of such batteries as an onboard energy storage system which enabled the tramcar to a have catenary-free driving with a speed of $32.19 \mathrm{Km} / \mathrm{h}$ and covered a distance of a half of a kilometre [100]. the batteries were also used at a substation in Japan called Komagawa installed by Osaka Municipal Transportation Bureau (OMTB) with power and energy densities of $5.5 \mathrm{MW}$ and $576 \mathrm{kWh}$ respectively. The essence of this batteries installation was for energy consumption reduction, [101]. In 2012, a light rail vehicle called SWIMO, Japan was tested by Kawasaki in order to enable the vehicle to have an autonomous driving (catenary-free). The vehicle's ESS was charged to maximum from the catenary line voltage $(600 \mathrm{~V})$ for 5 minutes and the vehicle covered a distance of $10 \mathrm{~km}$ freely [94].

\subsubsection{Lithium-based batteries (Li-ion)}

The lithium-ion batteries have excellent characteristics over all the other types of batteries, and these are because of their high energy and power densities. As shown in Fig. 9, a Li-ion battery is formed from a lithium metal oxide being the positive electrode, and a titanate/carbon material as the negative electrode and both are placed in an electrolyte of liquid/gel/solid.

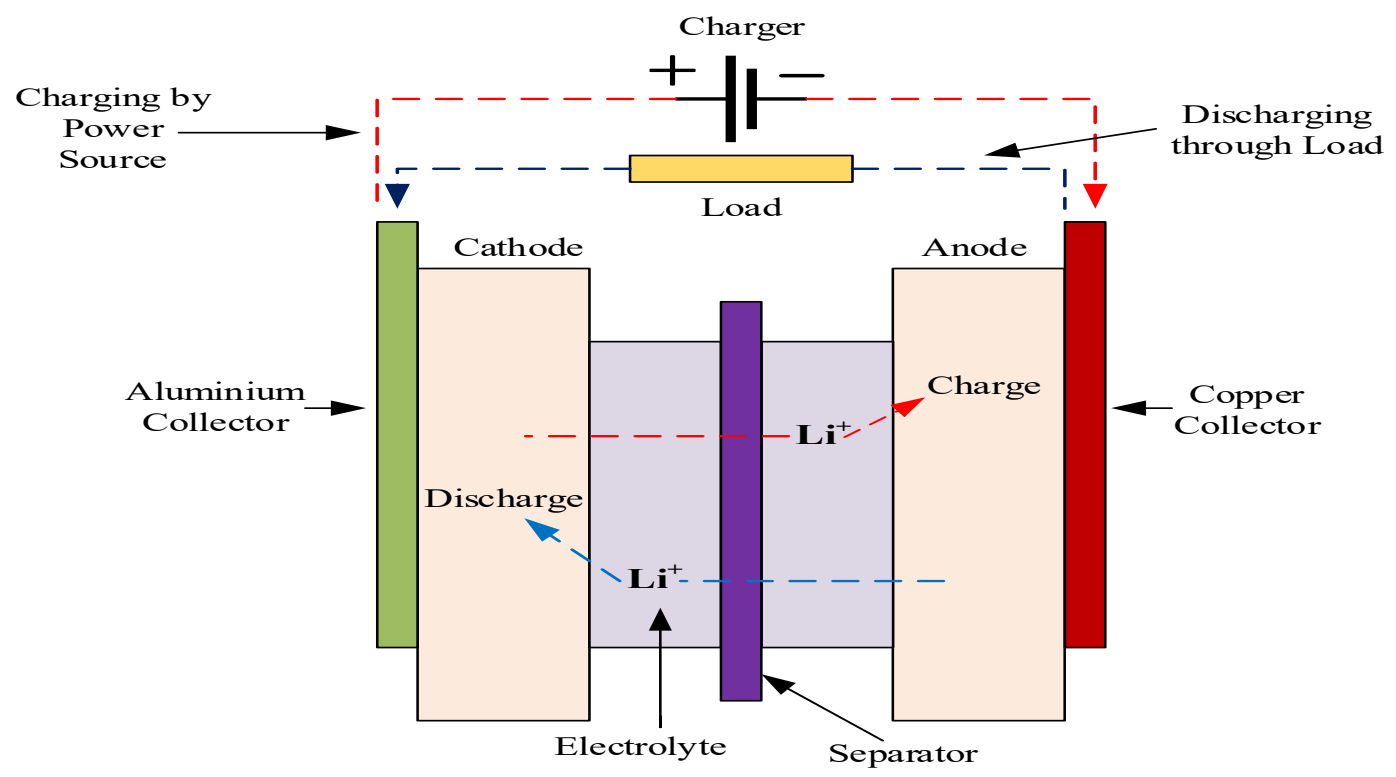

Fig. 9: Lithium-ion Cell internal components [62]. 
The electrolyte is made from lithium salts and organic solvents, [62], [102], [103]. There are different types of Li-ion batteries and the types depend on the compositions of the electrolyte and the different combinations of the metal oxides that form the two electrodes (anode and cathode), [102], [104]-[106].

Advantages and Disadvantages: The advantages of Li-ion batteries compared to other types of batteries are, they have higher relative energy and power densities, smaller in sizes and weigh lighter, wider range of operating temperature $\left(-20^{\circ} \mathrm{C}\right.$ to $\left.60^{\circ} \mathrm{C}\right)$, higher efficiency, longer operating cycles (longer lifetime), they cost lesser in terms of maintenance and they have zero memory effect. In addition, their cells have a high nominal voltage at3.6V hence high voltage ratings of energy storage systems can be designed with just few numbers of the cells [62], [102]-[105], [107], [108]. The disadvantages are, the batteries have higher relative cost per watt-hour (Wh) due to the costs of the protection circuits and packaging, the battery pack requires a battery management system to maintain the safe operating temperatures, state of charge (SOC) and nominal voltages [106], [108].

It should be noted that even with the mentioned excellent characteristics that make Li-ion the best among all other battery chemistries, there are ongoing research studies to improve their performances and to reduce the cost by combining nanostructure and electrochemical materials [108].

Applications: Generally, because of their excellent characteristics, Li-ion batteries are being used in many areas such as aerospace, hybrid and electric cars, power utilities (for power quality support) and in some devices like mobile phones, laptops, tables, and etc [62].

In electrified railways, Li-ion batteries have profound applications in areas like energy saving, voltage drop, autonomous driving (catenary-free), and etc. In energy saving area, Li-ion batteries were installed in electric railway systems in Japan for energy saving purpose as discussed in [94] and [109]. The authors outlined the installation modes which took place in two stages. The first stage called temporary batteries while the second as permanent batteries. Moreover, for catenary line voltage stabilization (due to voltage fluctuations) and voltage drop compensation, stationary lithium-ion batteries were installed in 2006 in Shin-Hikida substation. In 2013, lithium ion batteries with a total power rating of $2000 \mathrm{~kW}$ 
and rated capacity of $76 \mathrm{kWh}$ were also installed at Haijima substation for voltage stabilization and voltage drop compensation [110].

For catenary-free applications, $\mathrm{Li}$-ion batteries are the best solution because of their high energy density as they allow the train to travel for a long distance before the batteries reach their safe minimum state of charge $\left(\mathrm{SOC}_{m i n}\right)$. Li-ion batteries allow tramcars to run freely (without having power from substations) and pass through all areas in urban city centres where it is not possible to run overhead catenary lines power supply because of aesthetic and historic structures. For this type of application, the batteries must be carried onboard of the tramcar, [10].

\subsubsection{Sodium-Sulphur Batteries (NaS)}

The Sodium Sulphur battery operation depends on the movement of sodium ions between its electrodes as can be seen in Fig. 10 below. The NaS battery has sulphur in liquid form (molten) as its positive electrode while sodium also in liquid form (molten) as its negative electrode, and both electrodes are kept apart by an electrolyte called beta alumina ceramic [111].

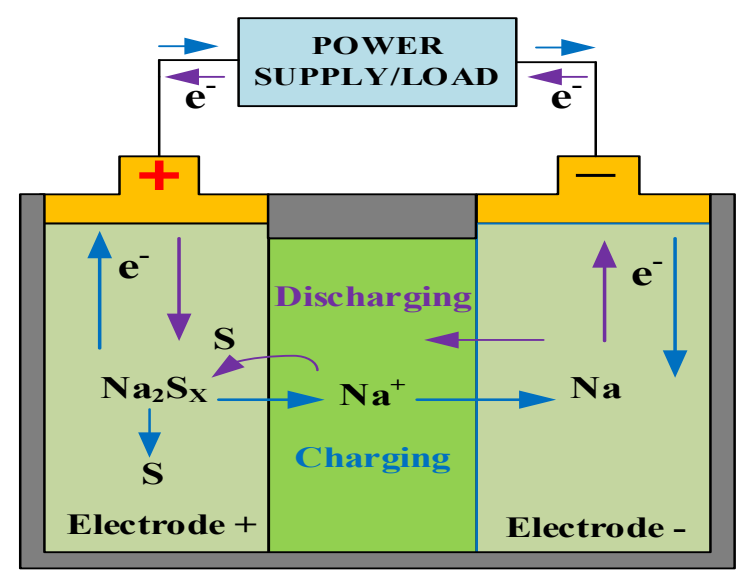

Fig. 10: NaS Battery (chemical reactions during charging and discharging conditions) [86].

During the discharge operation of $\mathrm{NaS}$ battery, $\mathrm{Na}^{+}$ions pass through the electrolyte alumina ceramic (the electrolyte) thereby combines with the sulphur to form polysulphides $\left(\mathrm{Na}_{2} \mathrm{~S}_{4}\right)$. This reaction is reversible during the charging period. When connected to an external circuit during discharging period, a $2 \mathrm{~V}$ potential difference is obtained at its terminal [112]. 
Advantages and Disadvantages: The advantages of NaS batteries are, they have high energy density $(150 \mathrm{Wh} / \mathrm{kg}-240 \mathrm{Wh} / \mathrm{kg})$ and power density $(90 \mathrm{~W} / \mathrm{kg}-230 \mathrm{~W} / \mathrm{kg})$, high efficiency in the range of $75 \%$ $-90 \%$, and they have longer relative lifetime. They exhibit some disadvantages, these are, their reaction processes work at a high temperature typically between $300^{\circ} \mathrm{C}$ and $350^{\circ} \mathrm{C}$ which consequently develop a high self-discharge rate, they have relatively high cost and environmental issues compared to some other types of batteries. Moreover, a ventilating equipment is required to cool the battery during operation due to high operating temperature [112]-[115].

It is also worth to mention the other type of sodium-based battery, sodium nickel chloride battery $\left(\mathrm{NaNiCl}_{2}\right)$, also known as ZEBRA cell. The detail of this battery is not explained here as it shares some similar operating characteristics and applications with the $\mathrm{NaS}$ but with few differences for example, it has a positive electrode that is nickel chloride and with electrolyte that is sodium chloroaluminate. However, both of the cells have similar kind of negative electrodes (liquid sodium metal) [112], [116], [117].

Applications: NaS batteries produced by a company named ShangHai NaS are for commercial purpose to be used for grid services. However, their applications in electrified railway systems are limited since they have a drawback of producing heat while in operation that lowers their performances in terms of peak power demand reduction and for power quality applications [112].

A summary of comparisons in terms of the advantages, disadvantages and applications for each type of battery energy storage technologies is presented in Table 1. 
Table 1: A summary of battery technologies comparisons for urban railway applications

\begin{tabular}{|c|c|c|c|c|c|c|}
\hline $\mathrm{S} / \mathrm{N}$ & Battery Type & Advantages & Disadvantages & Applications & Comments & References \\
\hline 1 & $\begin{array}{l}\text { Lead-acid Battery } \\
(\mathrm{PbA})\end{array}$ & $\begin{array}{l}\cdot \text { - High power density } \\
\text { - High operational reliability } \\
\text { - High efficiency } \\
\text { - Low cost per watt-hour } \\
\text { - Long history }\end{array}$ & $\begin{array}{l}\text { - Poor performance at low temperature } \\
\text { - Limited life-time } \\
\text { - Low energy density } \\
\text { - Environmental pollution } \\
\text { - Low number of cycle operation }\end{array}$ & $\begin{array}{l}\text { - For back-up power supplies in railway } \\
\text { stations \& power utilities. } \\
\text { - Voltage drop compensation along } \\
\text { supply line at Nakajima Substation in } \\
\text { Japan in the } 80 \text { 's. }\end{array}$ & $\begin{array}{l}- \text { To further upgrade the batteries } \\
\text { power and energy densities, } \\
\text { researches are ongoing to change } \\
\text { the lead electrode with carbon } \\
\text { material so that they can get } \\
\text { applications in traction systems. }\end{array}$ & $\begin{array}{c}\text { [10], [87], [88], [89], [90], } \\
\text { [91], [94]. }\end{array}$ \\
\hline 2 & $\begin{array}{l}\text { Nickel Metal } \\
\text { Hydride Batteries } \\
\text { (Ni-MH) }\end{array}$ & $\begin{array}{l}\text { - Long life time } \\
\text { - High power \& energy densities } \\
\text { - High charging \& discharging } \\
\text { current } \\
\text { - Low environmental pollution } \\
\text { - High number of cycle operation }\end{array}$ & $\begin{array}{l}\text { - Low efficiency } \\
\text { - Low resistance } \\
\text { - High rate of self-discharge } \\
\text { - High cost per watt-hour }\end{array}$ & $\begin{array}{l}\text { - For energy consumption reduction in } \\
\text { Citadis tramcar in Nice, France in } 2006 . \\
\text { - For onboard ESS to enable a tramcar } \\
\text { have catenary-free driving. } \\
\text { - For energy consumption reduction at } \\
\text { Komagawa in Japan } \\
\text { - In } 2012 \text { in Japan at SWIMO LRT for } \\
\text { catenary-free driving. }\end{array}$ & $\begin{array}{l}\text { In order to overcome the high } \\
\text { discharge rate, novel separators are } \\
\text { now recommended in their } \\
\text { formation. }\end{array}$ & $\begin{array}{l}\text { [10]. [62], [94], [95], [96]. } \\
{[97],[98],[99],[100] .[101]}\end{array}$ \\
\hline 3 & $\begin{array}{l}\text { Lithium-ion } \\
\text { Batteries (Li-ion) }\end{array}$ & $\begin{array}{l}\text { - High energy density } \\
\text { - Smaller in sizes \& weigh less } \\
\text { - Wider operating temparature } \\
\left(-20^{\circ} \mathrm{C}-60^{\circ} \mathrm{C}\right) \\
\text { - High number of cycle operation } \\
\text { - Low maintenance cost } \\
\text { - High cell's nominal voltage } \\
\text { (3.6V). }\end{array}$ & $\begin{array}{l}\text { - High cost per watt-hour } \\
\text { - Requires BMS (Battery Management } \\
\text { System) to maintain the operating } \\
\text { temperature, SOC and nominal } \\
\text { votages }\end{array}$ & $\begin{array}{l}\text { - For energy saving purpose in Japan in the } \\
\text { form of temporary and permanent batteries. } \\
\text { - For catenary line voltage stabilization \& } \\
\text { voltage drop compensation as installed in } \\
2006 \text { at Shin-Hikida railway substation, } \\
\text { Tsurugu city, Japan. } \\
\text { - In } 2013 \text {, installation of the batteries at } \\
\text { Haijima substation with power and rated } \\
\text { capacity of } 2000 \mathrm{~kW} \& 76 \mathrm{kWh} \text { for voltage } \\
\text { regulation \& voltage drop compensation. } \\
\text { - For catenary-free driving as onboard ESS } \\
\text { in city centers }\end{array}$ & $\begin{array}{l}\text { - Despite their excellent } \\
\text { characteristics, there is ongoing } \\
\text { research to further improve their } \\
\text { performance as well as reduce } \\
\text { their high cost by combining } \\
\text { nanostructure and } \\
\text { electrochemical materials. }\end{array}$ & $\begin{array}{c}\text { [10], [62], [94], }[102],[103], \\
\text { [104], [105], [106], [107], } \\
{[108],[109],[110]}\end{array}$ \\
\hline 4 & $\begin{array}{l}\text { Sodium-Sulphur } \\
\text { Batteries (NaS) }\end{array}$ & $\begin{array}{l}\text { - Long life time } \\
\text { - High energy density }(150 \mathrm{Wh} / \mathrm{kg} \\
-240 \mathrm{Wh} / \mathrm{kg}) \\
\text { - High power density }(90 \mathrm{~W} / \mathrm{kg} \text { - } \\
230 \mathrm{~W} / \mathrm{kg}) \\
\text { - High efficiency }(75 \%-90 \%)\end{array}$ & $\begin{array}{l}\text { - High operating temper ature }\left(300^{\circ} \mathrm{C} \text { - }\right. \\
\left.350^{\circ} \mathrm{C}\right) \\
\text { - Requires Ventilating equipment } \\
\text { due to high operating temperature } \\
\text { - High cost } \\
\text { - Environmental pollution }\end{array}$ & $\begin{array}{l}\text { - Mostly for use in grid services } \\
\text { - Limited application in electric railway } \\
\text { system because of the heat produced } \\
\text { during operation. }\end{array}$ & $\begin{array}{l}\text { - Another sodium-based battery } \\
\text { called ZEBRA cell (sodium } \\
\text { nickel choloride battery with } \\
\text { similar characteristics. } \\
\text { - Current researches ongoing to } \\
\text { reduce their high operational } \\
\text { temperatures. }\end{array}$ & $\begin{array}{c}\text { [112], [113], [114], [115], } \\
\text { [116], [117] }\end{array}$ \\
\hline
\end{tabular}

\subsubsection{Other Potential Battery Technologies}

In addition to the previously discussed battery technologies, there are some other types of batteries that could be used in electrified urban railway systems such as, flow batteries (redox flow batteries) and metal-air batteries. The flow batteries have excellent characteristics such as negligible self-discharge with a long lifetime of operation but they still have some drawbacks such as high relative cost and with low energy density. On the other hand, the metal-air batteries have some reasonable advantages like having high energy density at relatively lower cost but the disadvantage is, they present low energy efficiency. The metal-air batteries are used in some applications for examples in electric cars and mobile electronic devices [112], [113].

\subsubsection{Supercapacitors Energy Storage System Technologies (SESS)}

A supercapacitor is a device which operates based on electrostatic field principle to store energy in the same way a conventional electrolytic capacitor does. However, it has a very high energy density compared to electrolytic capacitors [62]. It is also called ultracapacitor - UC, pseudo capacitor or electrochemical double layer capacitor - EDLC. As shown in Fig. 11, it consists of three main components which are two electrodes, a separator and electrolyte solution. It stores energy using 
electrostatic charge transfer between the electrolyte and the two electrodes without chemical reactions taking place (unlike batteries).

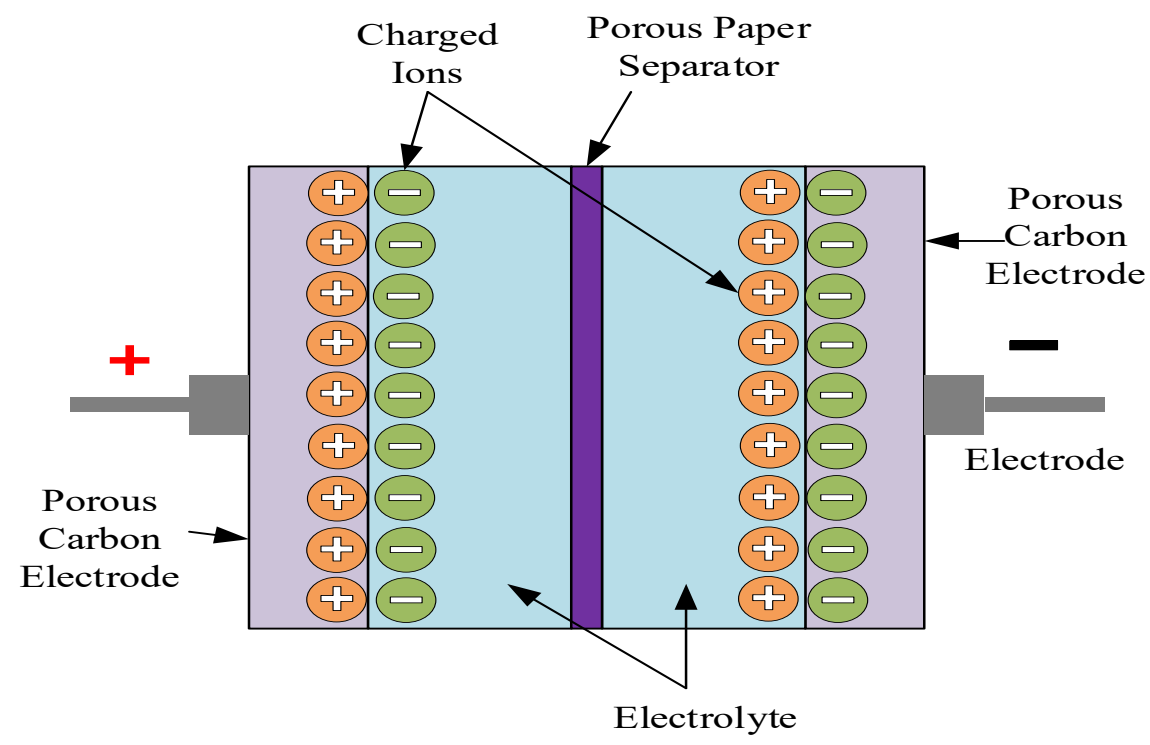

Fig. 11: Schematic of Supercapacitor Energy Storage Technology, [83].

A typical supercapacitor consists of two double layer capacitors adjoined to one another in a package. The complete cell has two porous electrodes made of carbon deposited aluminium with a separator between them (foil paper) and all are immersed in an electrolyte solution called organic acetonitrile,[10], [118]-[120].

Advantages and Disadvantages: The major advantages of supercapacitors are, they have a very high lifecycle (typically $10^{6}$ charging and discharging cycles), they have a high-power density above 4000W/kg; having high rate of charging and discharging; high efficiency (approximately 95\%) due to the very low internal resistance, they can operate between wide temperature range $\left(-40^{\circ} \mathrm{C}\right.$ to $\left.+65^{\circ} \mathrm{C}\right)$. Moreover, their state of charge (SOC) is easily obtained from the potential difference between its two terminals. On the other hand, the drawbacks are, the supercapacitors have a low energy density compared to other batteries that is $0.5 \mathrm{Wh} / \mathrm{kg}-10 \mathrm{Wh} / \mathrm{kg}$ where the lowest energy density in batteries being the lead-acid battery has $30 \mathrm{Wh} / \mathrm{kg}-40 \mathrm{Wh} / \mathrm{kg}$. They also suffer from high self-discharge rates due to leakage currents sensitive to overcharging which damage them easily, frequent vibrations, poor storage, high cycling current, and etc which actually affect their lifecycle [6], [10], [120]. 
Applications: The reason why supercapacitors become highly required in energy storage systems is because of their excellent characteristics of being able to withstand high rate of charging and discharging cycles without affecting their efficiency. Moreover, because of their high-power density coupled with the fact that they can be discharged and charged very fast, they can therefore supply high power peak demand. These useful features enable them to have wide range of applications in hybrid power systems, electric transportation systems such as electric cars and trains for harvesting of regenerative braking energy which occurs at high power levels and for short periods (few seconds). Moreover, they are used in line voltage regulation due to the intermittent fluctuations caused by the regenerative braking energy $(10-25 \mathrm{sec})[62],[121]-[123]$.

It should be noted that, in regenerative braking energy applications, the supercapacitors are interfaced with a $\mathrm{DC} / \mathrm{DC}$ power converter (bi-directional) that controls the power flows between them and the DC-link. A controller manages the operations of the supercapacitor and the converter [62]. The subsequent paragraph discusses some applications of supercapacitors energy storage technologies in electrified railway systems.

Supercapacitors can be found in many applications ranging from high power applications at power grid, electric vehicles to electrified railway systems. Some of the applications in electrified railway system for recuperating of regenerative braking energy are: In [124], a siemens SITRAS wayside ESS was used in Toronto LRT for the purpose of energy consumption reduction where the ESS voltage rating was at $600 \mathrm{~V}$. In another Siemens SITRAS application, a wayside supercapacitor ESS was used in Cologne public transport, Germany for the purpose of energy saving and voltage regulation. An energy saving of up to $37 \%$ was achieved [125]. In [126], two supercapacitor ESSs of the same energy density of $2.8 \times 10^{-4} \mathrm{MWh}$ were placed under the floor of a railway passenger car for the purpose of minimizing the use of the conventional friction braking in the event of failure of the train to send back regenerative braking energy to the supply substation. The result confirmed that the supercapacitors were both able to save regenerative braking energy of $8 \%$ from the electric drives of the train. In another application, modules of supercapacitors were used in a Korean metro system, Daejeon Rapid Transit, for the purpose of energy consumption reduction and voltage regulation. Both of the supercapacitors' modules were 
having an energy and power densities of approximately $10 \mathrm{kWh}$ and $1.9 \mathrm{MW}$ respectively. The results of this application confirmed that the catenary line voltage was stabilized at a nominal of $1.5 \mathrm{kV}$ DC [127]. A MITRAC energy saver being an onboard supercapacitors ESS installation is used mainly for energy saving and autonomous driving [128]. In one of the applications, it was installed on an LRT vehicle in Mannheim, Germany and used for up to five years. In such application, an energy consumption was reduced by $30 \%$. Moreover, the result of the installation test revealed that up to half of the current peak demand and voltage drop had been curtailed [129].

\subsubsection{Flywheels Energy Storage System (FESS)}

Flywheel ESS is a type of mechanical energy storage system consists of an electrical machine that has a stator and a rotor, friction bearings, rotating cylindrical mass, AC/DC power electronic converter (bidirectional) and a rugged housing as shown in the Fig. 12.

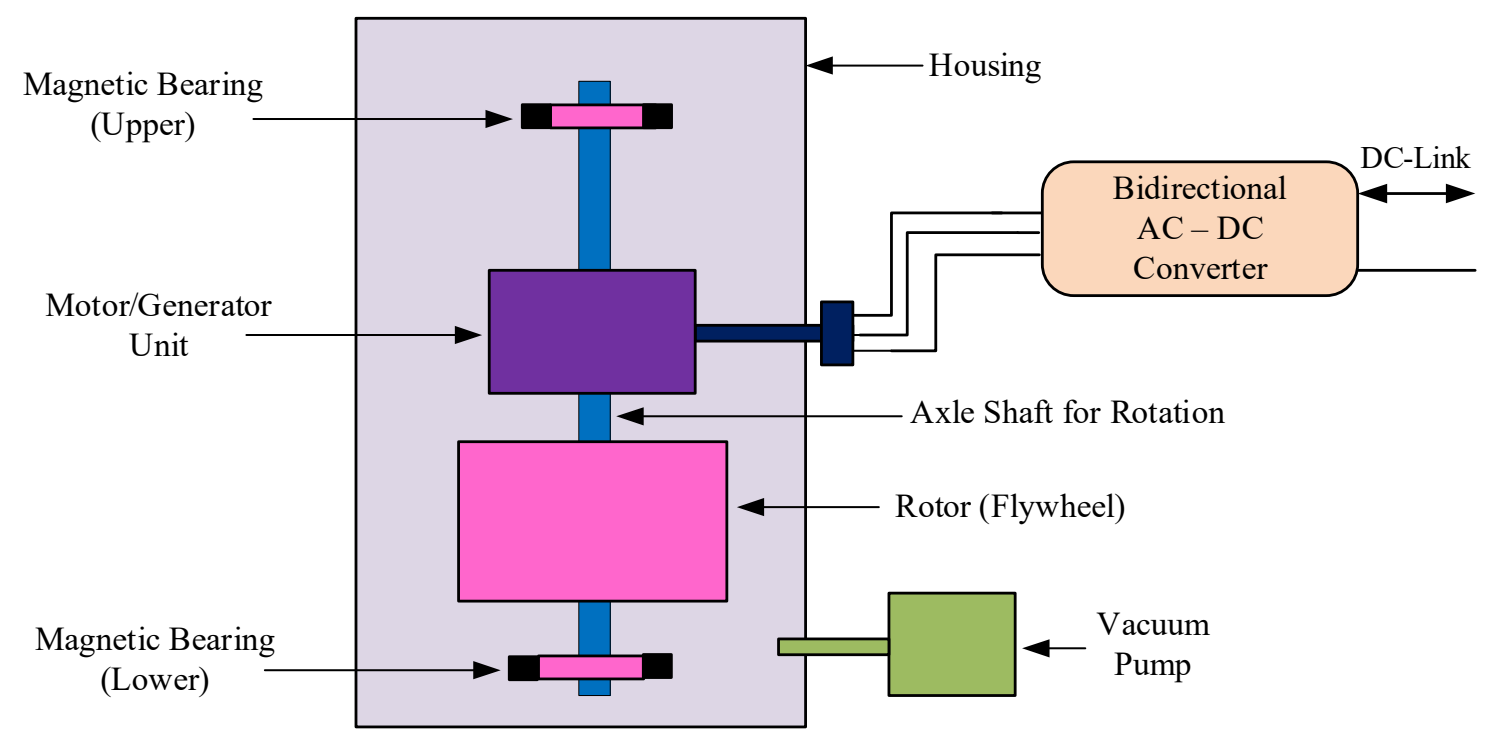

Fig. 12: Flywheel Energy Storage System (FESS) [114], [130].

Essentially, it operates based on the principle of converting electrical energy into kinetic energy and vice-versa. The cylindrical mass is attached to the rotor while the rotor is suspended by the bearings. The flywheel rotor is made of combination of carbon and fibre materials. Although the composite materials reduce the flywheel's inertia, a very high rotational speed of the rotor is attained. In order to 
reduce the flywheel's internal losses by providing low frictions, the bearings are made from magnetic material, [75], [86], [131], [132].

During the flywheel ESS operation, the electric machine acts as a motor by receiving an electrical energy via the power converter interface thus spinning the cylindrical mass at a very high speed hence enabling it to acquire the kinetic energy in proportion to the amount of electrical energy received [130]. During discharging state, however, the stored kinetic energy is converted back into electrical energy by decelerating rotor torque and at this instant the electrical machine behaves as a generator (i.e. supply electrical power back through the power electronic converter) [10], [39], [132], [133].

Advantages and Disadvantages: The flywheel ESSs have high relative efficiency with high power and energy densities Similar to supercapacitors, flywheel ESSs have a high charging and discharging frequency, they have minimal adverse effects to the environment, their SOC can be obtained easily by determining the flywheel's angular velocity, and they can operate over a wide temperature range. The first major drawback of using flywheels is that they are very much heavier compare to all other ESSs. They are sensitive to overloading which can easily cause them to explode into pieces although advanced rotors are made from fibre materials which are less risky compared to those made from metal materials. Their internal friction make them to have high rate of self-discharge, [39], [75], [86], [132], [134].

Applications: Flywheel ESSs can be considered equal or next best to supercapacitors in terms of suitability in high power applications and electrified transportation systems especially in railway systems due to some of their excellent characteristics. However, when they are carried onboard, they easily develop a high rate of self-discharge when the train changes in its direction. Moreover, flywheel ESSs have heavier weight and occupy much space, hence these factors become major issues in railway applications especially when they are carried onboard. Another big threat in their applications for railways system is, they pose the risk of explosion [10], [131], [133], [134].

Nevertheless, flywheels can be found in some applications as discussed in reference [135] where the flywheel energy storage system was used in a light rail transit (LRT) system for the purpose of energy consumption reduction. The results showed that an energy saving of $31 \%$ was achieved with an energy 
capacity of $2.9 \mathrm{kWh}$ and rated power of $725 \mathrm{~kW}$ respectively. In another application, a flywheel storage system was tested in Hanover, Germany by Pillar for the purpose of energy consumption reduction. In this test, an energy saving of $462 \mathrm{kWh}$ per annum was achieved at the flywheel rated power capacity of $2 \times 10^{-1} \mathrm{MW}$ and energy capacity of $1500 \mathrm{Wh}$ [136]. In [137], a flywheel energy storage system was applied to achieve a voltage stabilization at Kehin electric railway system in Japan whose rated power was $3000 \mathrm{~kW}$ and energy capacity of $0.025 \mathrm{MW}$. In the USA, the flywheel energy storage system was used at Los Angeles metro system for energy saving purpose. The storage rated power was at $2000 \mathrm{~kW}$, and energy capacity of around $8 \mathrm{kWh}$ [131]. A flywheel energy storage system with rated power of $1000 \mathrm{~kW}$ was installed by Urenco Power Utility company at Far Rockaway, New York, USA for the purpose of power peak shaving. An energy saving of up to $25 \%$ was achieved in this system, [130].

\subsubsection{Hybrid Energy Storage Systems (HESS)}

\subsubsection{Hybrid Electrical Energy Storage System (HEESS)}

The idea behind hybridization of two or more energy storage systems is to derive the best benefits of each individual storage technology so as to achieve the overall combined performances in a single system. This is called hybrid energy storage system (HESS). It is known that no any single ESS can provide the best characteristics required in a particular application, hence the reason for using HEESs technology. In HEESs, a combined high power and energy densities, high efficiency, long lifecycle of operations, fast response, and etc can be achieved altogether [138]. Different combinations of hybrid electrical energy storage systems can be achieved by using combinations of either Supercapacitor/Battery or Supercapacitor/Flywheel or Battery/Flywheelor Supercapacitor/Battery/Flywheel. However, the most common HEES in many applications is the hybrid of Supercapacitor/Battery [101], [138].

Advantages and Disadvantages: The advantages of HEESs are high energy saving of braking energy, line voltage stabilization, and the combined benefits such as high efficiency, high energy and power densities, long lifetime, and etc. There is an improvement in safety and protection of one of the ESSs. For instance, in supercapacitor/battery HEES, the battery lifetime is extended due to protection of their 
cells against damage as a result of having lower charging current. The performance of HESS is always better compared to a single ESS. However, HEESs also have some drawbacks such as having a complex control strategy as two or more different ESSs are used thus increased in maintenance and cost are inevitable, [139]-[141].

Applications: There are some applications of HEESs in electrified railway systems as discussed in the following references. In [142], Sitras hybrid energy storage by Siemens was used to reduce a tramcar energy consumption during acceleration and also enabled it to have autonomous driving. In such application, the HESS was installed on the tramcar consisted of NiMH battery and a module of supercapacitors in order to obtain both high energy and power densities. The design of the HESS was done in such a way that the NiMH battery ESS with the capacity of $18 \mathrm{kWh}$ was used to provide the tram with a long-distance catenary-free driving and to supply power to the cooling and heating systems required for the passengers. While the supercapacitors ESS with the lowest capacity of around $2 \mathrm{kWh}$ was used to provide the stored energy to the tram during its acceleration mode. The recharging of the Sitras energy storage system was both done during the tram braking or at the substation charging point. In [143], an onboard Sitras energy storage system was used in Portugal on a tram known as Combino plus MTS in the year of 2008. The HESS enabled the tram to have autonomous driving for a distance of about $2.4 \mathrm{~km}$ and the system has a minimal adverse impact to the environment.

A summary of comparisons in terms of the advantages, disadvantages and applications for each type of energy storage technologies are presented in Table 2. 
Table 2: A summary of energy storage technologies comparisons for urban railway applications

\begin{tabular}{|c|c|c|c|c|c|}
\hline $\mathrm{S} / \mathbf{N}$ & Battery Type & Advantages & Disadvantages & Applications & References \\
\hline 1 & Li-ion Battery ESS & $\begin{array}{l}- \text { High energy density } \\
\text { - Smaller in sizes \& weigh less } \\
\text { - Wider operating temparature }\left(-20^{\circ} \mathrm{C}-\right. \\
\left.60^{\circ} \mathrm{C}\right) \\
\text { - High number of cycle operation } \\
\text { - Low maintenance cost } \\
\text { - High cell's nominal voltage }(3.6 \mathrm{~V}) \text {. }\end{array}$ & $\begin{array}{l}- \text { High cost per watt-hour } \\
\cdot \text { - Requires BMS (Battery Management } \\
\text { System) to maintain the operating } \\
\text { temperature, SOC and nominal } \\
\text { votages }\end{array}$ & $\begin{array}{l}\text { - For energy saving purpose in Japan in the form of temporary } \\
\text { and permanent batteries. } \\
\text { - For catenary line voltage stabilization \& voltage drop } \\
\text { compensation as installed in } 2006 \text { at Shin-Hikida railway } \\
\text { substation, Tsurugu city, Japan. } \\
\text { - In } 2013 \text {, installation of the batteries at Haijima substation } \\
\text { with power and rated capacity of } 2000 \mathrm{~kW} \& 76 \mathrm{kWh} \text { for } \\
\text { voltage regulation \& voltage drop compensation. } \\
\text { - For catenary-free driving as onboard ESS in city centers }\end{array}$ & $\begin{array}{c}\text { [10], [62], [94], [102], [103], } \\
\text { [104], [105], [106], [107], } \\
\text { [108], [109], [110] }\end{array}$ \\
\hline 2 & Supercapacitor ESS & $\begin{array}{l}\text { - Very high power density }(>4000 \mathrm{~W} / \mathrm{kg}) \\
\text { - High life cycle (typically } 1 \text { million } \\
\text { charging \& discharging cycles) } \\
\text { - High efficiency }(\approx 95 \%) \\
\text { - Wide operatinng temperature }\left(-40^{\circ} \mathrm{C} \text { to }\right. \\
\left.+65^{\circ} \mathrm{C}\right) \\
\text { - High rate of charging \& discharging } \\
\text { cycles) } \\
\text { - Easy to calculate SOC }\end{array}$ & $\begin{array}{l}\text { - Very Low energy density } \\
(0.5 \mathrm{Wh} / \mathrm{kg} \text { - } 10 \mathrm{Wh} / \mathrm{kg}) \\
\text { - Sensitive to overcharging } \\
\text { - High rate of self-discharge (leakage } \\
\text { current) } \\
\text { - Sensitive to vibration, poor storage, } \\
\text { high cycling current, etc }\end{array}$ & $\begin{array}{l}\text { - Suitable applications for hybrid power systems \& electric } \\
\text { transportation systems } \\
\text { - For line voltage regulation as caused by regenerative braking } \\
\text { energy. } \\
\text { - For energy consumption reduction at } \\
\text { at Toronto LRT using Siemens SITRAS wayside ESS. } \\
\text { - For energy saving \& voltage regulation using wayside } \\
\text { supercapacitor ESS at Cologne transport, Germany in which } \\
37 \% \text { energy saving achieved. }\end{array}$ & $\begin{array}{l}\text { [6], [10], [62], [120], [121], } \\
\text { [122], [123], [124], [125], } \\
\text { [126], [127], [128], [129]. }\end{array}$ \\
\hline 3 & Flywheel ESS & $\begin{array}{l}\text { - High efficiency } \\
\text { - High power \& energy densities } \\
\text { - High charging \& discharging frequency } \\
\text { - Less effect in terms of environmental } \\
\text { pollution } \\
\text { - Operating over wide range of temperature }\end{array}$ & $\begin{array}{l}\text { - Weigh high compared to other ESS } \\
\text { - Sensitive to overload which can lead to } \\
\text { their explosion } \\
\text { - High rate of self-discharge due to } \\
\text { internal friction }\end{array}$ & $\begin{array}{l}\text { - For energy consumption reduction as used in an LRT where } \\
\text { a } 31 \% \text { energy saving was achiedved. } \\
\text { - For energy saving purpose as used in Hanover, Germany by } \\
\text { Pillar where a } 462 \mathrm{kWh} \text { per annum saving was achieved. } \\
\text { - For voltage stabilization purpose at Kehin electric railway } \\
\text { system, Japan with a rated power of } 3000 \mathrm{~kW} \& 0.025 \mathrm{MW} \\
\text { energy capacity. } \\
\text { - For energy saving purpose where a } 1000 \mathrm{~kW} \text { was installed at } \\
\text { Far Rockaway, New York, USA by Urenco Power Utility } \\
\text { where an enegy saving of up to } 25 \% \text { was achieved. }\end{array}$ & $\begin{array}{c}\text { [10], [39], [75], [86], [130], } \\
\text { [131], [132], [133], [134], } \\
\text { [135], [136], [137]. }\end{array}$ \\
\hline 4 & Hybrid ESS & $\begin{array}{l}\text { - High power \& energy densities } \\
\text { - High energy saving } \\
\text { - Line voltage stabilization } \\
\text { - High efficiency } \\
\text { - Long lifetime } \\
\text { - Improved safety \& protection }\end{array}$ & $\begin{array}{l}\text { - Complex control strategy } \\
\text { - High cost } \\
\text { - increase in maintenance cost }\end{array}$ & $\begin{array}{l}\text { - Sitras HESS by Siemens (NiMH battery \& Supercapacitors) } \\
\text { used onboard a tramcar for energy consumption reduction \& } \\
\text { for autonomous driving. The NiMH capacity was } 18 \mathrm{kWh} \\
\text { while the supacitory was } 2 \mathrm{kWh} \text {. } \\
\text { - An onboard HESS used in a Combino plus MTS tramcar in } \\
\text { Portugal in } 2008 \text { for autonomous driving where a } 2.4 \mathrm{~km} \\
\text { distance was covered. }\end{array}$ & $\begin{array}{c}\text { [139], [140], [141], [142], } \\
{[143] .}\end{array}$ \\
\hline
\end{tabular}

\subsubsection{Lithium-ion Capacitor ( $\mathrm{LiC})$}

Lithium-ion capacitor ( $\mathrm{LiC}$ ) is a newly developed hybrid energy storage technology and manufactured as a single energy storage device combining both the good characteristics of lithium-ion batteries and supercapacitors. As already indicated, lithium-ion battery has high energy density but low power density while supercapacitor has high power density but low energy density [144]. The idea behind LiC is to have a single unit energy storage device to combine these two characteristics (high energy and high power densities) [145], [146].

The chemical reaction in Lithium-ion capacitors occurs when adsorption and desorption processes take place at the positive electrode surface while at the same time at the negative electrode, the cations redox chemical reaction occurs. Therefore, a high energy density and high-power density are obtained in the $\mathrm{LiC}$ as a result of the ionic adsorption in the supercapacitor double layer and the redox chemical reaction due to the lithium-ion part [145], [147]. 


\subsubsection{Techno - economic Comparison and Assessment of ESSs for Urban Railway Applications}

The selection of suitable energy storage technologies reviewed in the previous sub-section depends on the technical characteristics and the costs. Table 3 shows, in order to derive the comparisons and assessments, various criteria are needed such as the storage devices energy and power densities, efficiency, life-time for operation, life cycle, capital cost investment, self-discharge, depth of discharge, durability, size (the weight to volume ratio), time of discharge, and response rate (note that only the main characteristics are considered in Table 3) [39],[148].

The type of installation configuration is also one of the criteria for the comparisons and assessments. For instance, for onboard type of ESSs installation mode, criteria such as ESSs size in terms of weight and volume or space are to be considered so that an ESS is carefully selected for specific application [10], [148], [149]. Another criterion for comparisons and assessments is the application response rate categorise into short or long duration (during charging and discharging of the ESS). The first category being the urban rail transit systems which have high and fast response rate to charging and discharging of regenerative braking energy because of the frequent and numerous braking phases that occur, and hence are classified under short - duration applications. While applications such as renewable energy system where the response rate is not that high due to longer charging and discharging rate and load shifting, they are therefore classified under long duration applications. [10], [150].

To start with, the energy and power densities are among the main characteristics to be considered in selecting ESSs for electric railway system applications. For onboard ESS applications the size is one part of the main criteria as space and weight are of great concerns. From the Table 3, it could be observed that batteries indicate to have the highest energy density ( $\mathrm{Wh} / \mathrm{kg}$ ) over supercapacitors and flywheels [151]. The lithium-ion batteries have a high energy capacity and they occupy less volume and this make them highly suitable for onboard applications. In the case of power densities, supercapacitors and flywheels have higher ratio power to weight values $(\mathrm{W} / \mathrm{kg}$ ) over batteries with flywheels having higher energy capacity. Efficiency is an important parameter to be considered and it indicates the amount of 
energy to be discharged by the ESS during charging and discharging cycles as lower efficiency signifies lower energy delivered. The efficiency of an ESS is a function of the energy storage cost. Supercapacitors, flywheels, and lithium are batteries that have the high efficiencies $(\approx 95 \%)$. It should also be noted that self-discharge parameter has similar effect as the efficiency, which higher rates of self-discharge have adverse impacts on the ESS cost since the total stored energy is reduced, [39], [152]. Despite flywheels having a high self-discharge rate, they can be fitted in urban rail applications as the energy storage duration requirements is for a short duration. This is due to the frequent charging and discharging cycles. Another important characteristic is the ESSs durability where it could be seen that batteries (lead-acid, nickel metal hydride, and sodium - sulphur) have much lower charge - discharge life-cycles compared to supercapacitors, advanced lithium-ion and flywheels that have higher number of charge - discharge cycles. It should be noted that this parameter is very important to be considered in urban railway applications because of the high number of charging and discharging cycles [10], [153], [154].

Another critical and important criterion to be considered at selecting the ESSs is the cost of the system which is expressed in terms of the total cost per energy stored and cost per rated power of the ESS measured in $\$ / \mathrm{kWh}$ and $\$ / \mathrm{kW}$ respectively. The selection of the ESS based on total cost per energy and per rated power is done without compromising the efficiency. It could be observed that the supercapacitors and flywheels are cheaper than batteries (lead-acid, nickel metal hydride, and sodium - sulphur) when cost $/ \mathrm{kW}$ is considered. While in terms of cost $/ \mathrm{kWh}$, batteries are the cheapest. Moreover, it should be noted that ESS costs also depend upon the types of application to be used e.g., for applications in power systems or railway or renewable energy systems. Reference [151] carried out a study on cost comparative analysis of ESSs for different types of applications. For instance, the cost of ESS for a particular (short or long duration) application depends on the rate of utilization of the stored energy in the operation. In urban railway systems where the stored energy in the ESSs is being discharged so frequently, then cost per/unit power output is to be considered. On a contrary, where the stored energy in the ESS stays for a longer duration then the cost/unit energy is to be considered. Based 
on this, batteries are the most cost effective for longer storage durations while supercapacitors and flywheels are for the shorter storage durations [10], [39], [151].

Table 3 presents the techno-economic comparisons of the energy storage technologies covered in this section.

\begin{tabular}{|c|c|c|c|c|c|c|c|c|c|c|}
\hline \multirow{2}{*}{$\mathrm{S} / \mathbf{N}$} & \multirow{2}{*}{ PARAMETER } & \multirow{2}{*}{$\begin{array}{c}\text { UINIT OF } \\
\text { MEASUREMENT } \\
\text { (UoM) }\end{array}$} & \multicolumn{7}{|c|}{ ENERGY STORAGE TECHNOLOGIES } & \multirow[b]{2}{*}{ References } \\
\hline & & & Lead-acid Batteries & $\begin{array}{l}\text { Nickel Metal } \\
\text { Hydrite (Ni-MH) } \\
\text { Batterries }\end{array}$ & $\begin{array}{l}\text { Sodium Sulphur } \\
\text { (Nas) Batteries }\end{array}$ & $\begin{array}{l}\text { Lithium ion (Li-ion) } \\
\text { Batteries }\end{array}$ & Supercapacitors & $\begin{array}{l}\text { Lithium Ion (Li-ion) } \\
\text { Capacitors }\end{array}$ & Flywheels & \\
\hline 1 & Specific Energy & Whkg & $20-50$ & $60-80$ & $120-240$ & $75-200$ & $1-6$ & $10-15$ & $5-100$ & \\
\hline 2 & Specific Power & W/kg & $25-300$ & $200-250$ & $120-230$ & $100-350$ & $500-5000$ & $500-5000$ & $1000-5000$ & \\
\hline 3 & Efficiency & $\%$ & $70-90$ & $65-70$ & $70-90$ & $90-100$ & $90-100$ & $90-100$ & $90-95$ & \\
\hline 4 & Discharge Time & Seconds & $1-3600$ & $1-3600$ & $1-3600$ & $1-3600$ & $0.1-60$ & $0.1-1000$ & $0.1-60$ & \\
\hline 5 & Durability & Number of Cycles & $200-2000$ & $1500-3000$ & $2000-3000$ & $1000-10,000$ & $<1,000,000$ & $<1,000,000$ & $40,000,000$ & 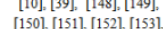 \\
\hline 6 & Self-discharge & $\%$ day/Wh & $0.5-3$ & $1 \cdot 2$ & 20 & $1-3$ & $2-4$ & $1 \cdot 2$ & 100 & {$[150]=[151],[152],[153]$} \\
\hline 7 & Self-discharge & $\%$ day/Wh & $0.5-3$ & $1 \cdot 2$ & 20 & $1-3$ & $2-4$ & 1.2 & 100 & \\
\hline 8 & Capital Cost of Energy & skWh & $50-150$ & $245-1250$ & $300-550$ & $270-1000$ & $350-2100$ & & $1050-5000$ & \\
\hline 9 & Capital Cost of Power & skw & $200-700$ & $400-1200$ & $1050-3000$ & $950-1350$ & $100-350$ & & $300-400$ & \\
\hline 10 & Environmental Impact & & High & Moderate & Low & Low & Low & Low & Negligible & \\
\hline
\end{tabular}

\subsubsection{Ragone Plot}

Another method in selecting a suitable type of an energy storage system for an application is by the use of Ragone plot. In the techno-economic comparisons done in the previous section, hybrid electrical energy storage system is not included as it is not a single entity energy storage device. Therefore, the Ragone plot includes the hybrid ESS to further shows its position with respect to other ESSs. Essentially, Ragone plot characterised energy storage devices on the basis of their specific energy and power densities. The plot shows the HESS abilities in meeting various applications demand of energy accumulation capacities and power transfer rates. As can be seen Fig. 13, the logarithmic axes of the plot indicates that the batteries have energy densities of up to $100 \mathrm{kWhkg}^{-1}$ but with low power densities while supercapacitors with high power densities of up to $1 \mathrm{kWkg}^{-1}$ but with low energy densities. Other energy storage devices are shown to fall within different energy - power densities regions which also signify for specific type of application based on energy and power requirements [101], [75],[155]. Fig. 13 below shows Ragone plot for various energy storage devices. 


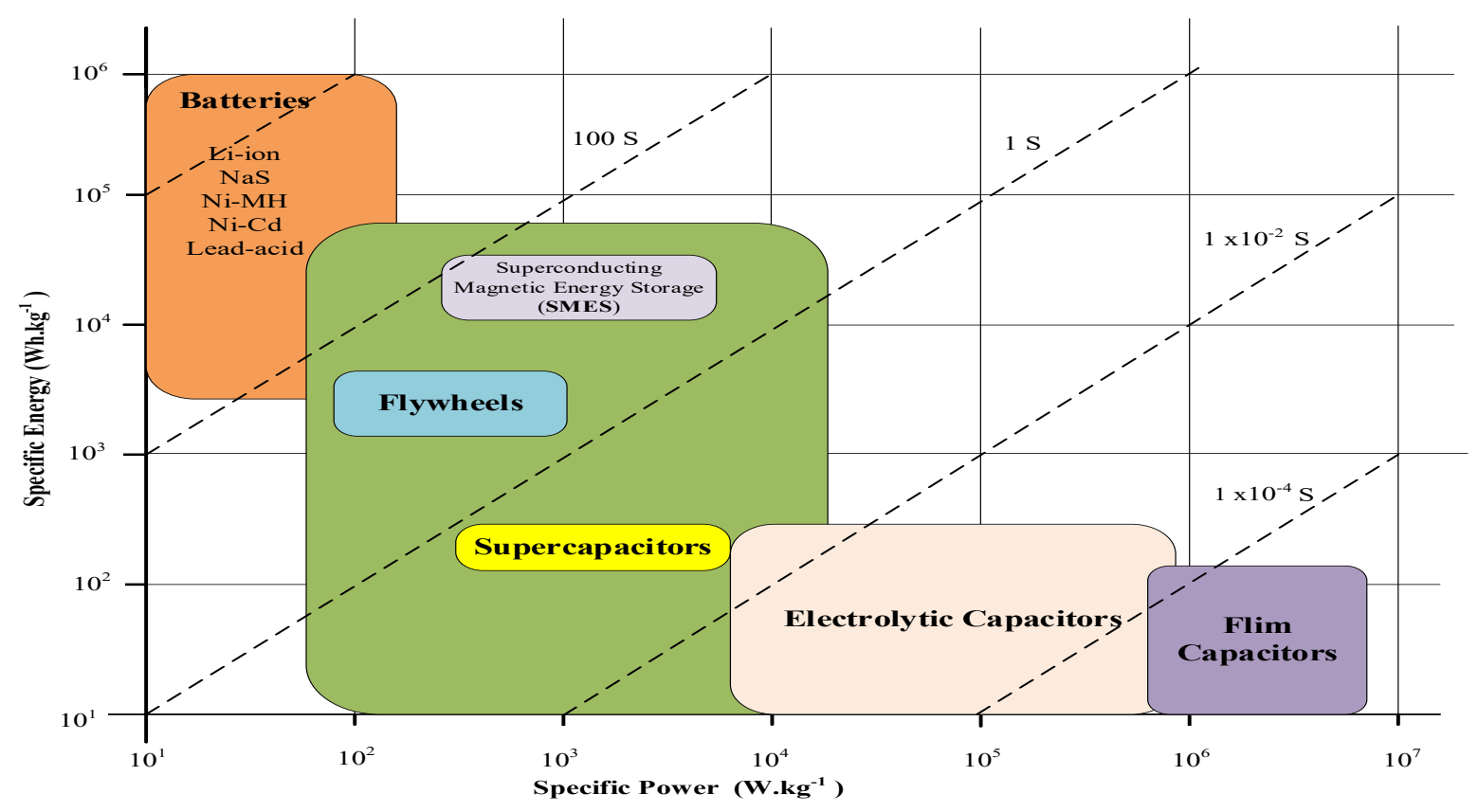

Fig. 13: Ragone Plot showing features of various Energy Storage Devices [75], [101], [156].

The Ragone plot for actual energy storage devices being used in electric railway systems including hybrid ESS is shown in Fig. 14.
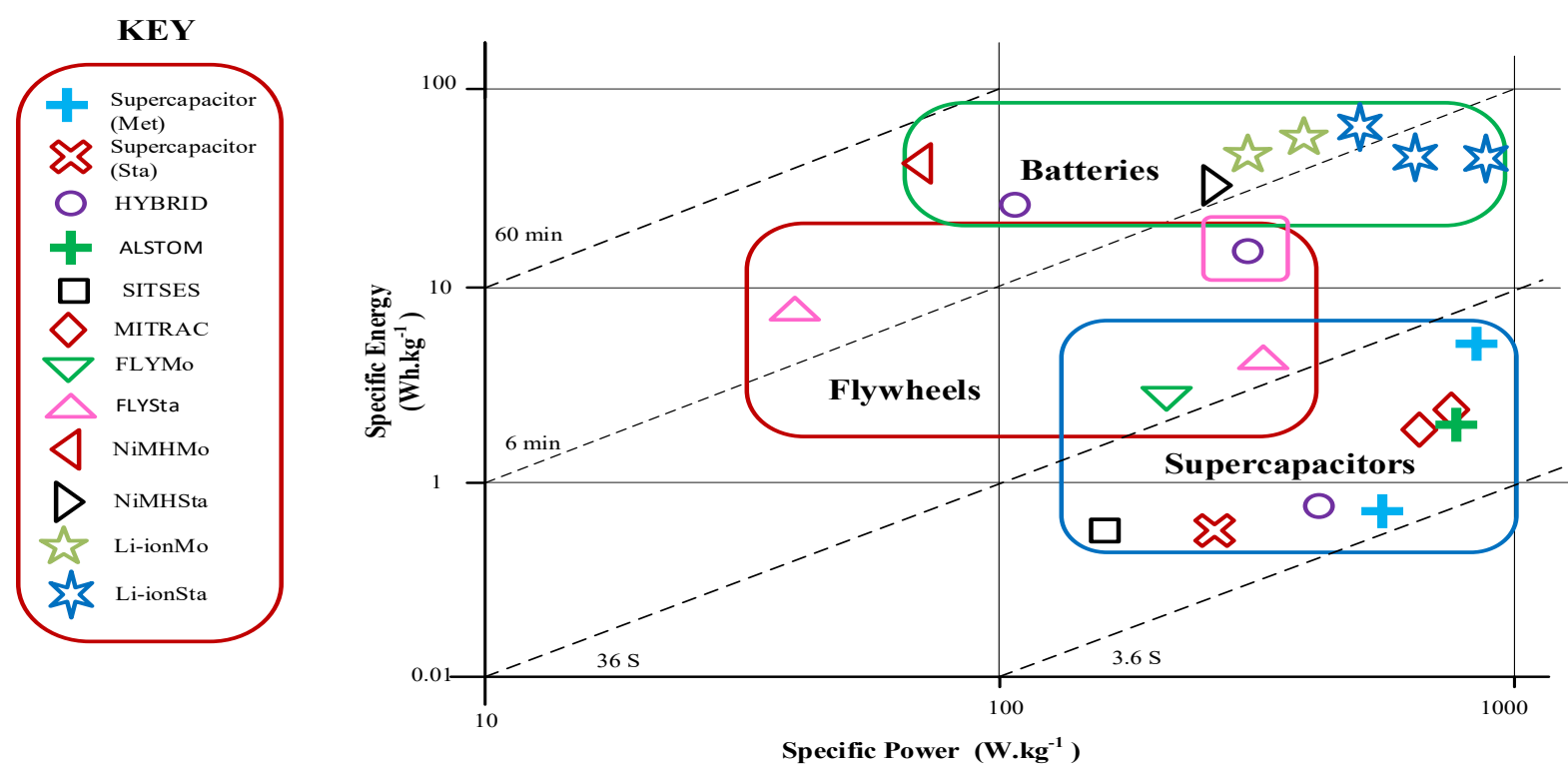

Fig. 14: Ragone plot of actual energy storage technologies used in urban railway system [101] [156].

On the logarithmic plane, the time is represented by the slope lines and deduced from the ratio of the energy storage device's energy and power densities which also signifies the device discharge time. It 
could be observed that $\mathrm{Li}$ - ion batteries with discharging time of around 5 minutes could be used for long duration applications. Flywheels have discharging time of around 1 minute for onboard installation while between a range of around $1-10$ minutes for the trackside installation. Supercapacitors have a fast discharging time of around $4-35$ seconds. The hybrid energy storage system by Siemens called SITRAS consists of nickel metal hydride and supercapacitor. The $\mathrm{Ni}-\mathrm{MH}$ batteries have a discharging time around 10 minutes while the supercapacitors with the value around 10 seconds [101].

Base on the plot, it is evident that supercapacitors have the fastest discharging time over batteries and flywheels in both installation modes (stationary and onboard) and therefore highly preferable for urban railway applications to be used for energy consumption reduction and autonomous driving (catenary free driving) [101], [155]. The discharging time for flywheels is in between the supercapacitors and the batteries and this qualifies them to be used for urban railway applications except for mobile (onboard) configuration due to their large sizes, cost of maintenance and risk of shattering in the event of explosion. For the use of batteries, they are most preferable for wayside/trackside installations. However, their shorter life-cycle operation compared to supercapacitors and flywheels make them not suitable in electrified urban railway applications. The hybrid energy storage systems appear to be the most suitable ESSs nowadays in urban railway systems especially in mobile configuration due to their good performance over supercapacitors or batteries as separate ESS. However, the costs implications and complex control strategies are to be incurred [101], [155], [156].

\subsection{Installation Configurations for Energy Storage Systems in Urban Rail Transit System}

\subsubsection{Onboard Energy Storage System Mode}

By onboard installation it means that the ESS is placed on the vehicle's roof or under the floor. Fig. 3 in section 1 shows the onboard energy flow where the red dashed lines represent the regenerative braking energy flow from the vehicle to the ESS and release back from the ESS to the vehicle during acceleration process. The main objectives of this installation mode are, firstly, to store the vehicle's regenerative braking energy and releases it later during acceleration phase. Secondly, this mode of installation is for power peak reduction during the vehicle's acceleration hence reducing the total power 
drained from the traction substation. It stabilises the catenary line voltage during acceleration phases. Finally, it allows the vehicle to have catenary - free driving [62], [157] Some research studies on onboard ESSs found that an energy saving about 14\% to 34\% could be achieved when onboard ESSs are deployed in urban railway applications [158], [159].

Advantages and Disadvantages: The onboard ESS advantages are, the peak power shaving during the vehicle's acceleration resulting in total energy cost reduction. The onboard ESS regulates the catenary line voltage's fluctuations which is caused during the vehicle's acceleration and braking phases. Moreover, the onboard ESS enables the vehicle to have an autonomous driving in the event of power outage from substations, pantograph failure, or passing through city centres where no catenary lines are available. One of the major drawbacks of onboard ESS is that it increases the vehicle's total weight by an average of 3 ton and this depends on the ESS's total size. Due to this increase in weight, the vehicle's energy consumption also increases. For this reason, it is actually the best to make provision for an approximate onboard ESS space and sizing during the vehicle design rather than retrofitting an existing one , [157], [160], [161].

\subsubsection{Wayside Energy Storage Mode}

Unlike onboard ESSs, in wayside ESSs (also known as trackside or stationery), the installation mode is stationary or at the ground level, and the ESSs capture and store the excess regenerated braking energy in the electric section (catenary line/third rail) provided by any braking vehicle in the same network. When any vehicle in the electric network brakes, the catenary line voltage increases and hence the ESSs stores the surplus braking energy (charging mode) whereas when the line voltage decreases due to any vehicle accelerating in the network, the ESSs discharges the stored braking energy (discharging mode) to aid the acceleration process as well as to maintain the line voltage threshold value. The installation of wayside is done either at a substation or at a trackside close to the train stations where the electric section experiences much fluctuations due to several braking and acceleration processes [160]-[162]. Fig. 3 in section 1 shows the trackside (wayside) energy flow where the green dashed lines represent regenerative braking energy flow from the vehicle to the catenary line and then to the ESS before it is released back to the catenary line for other vehicles absorb during their acceleration phases. 
Advantages and Disadvantages: One of the advantages is, the wayside ESSs bring significant of cost savings due to power peaks shaving in the entire electrical network due to the vehicles' accelerations. The wayside ESSs regulate the fluctuations of the catenary line voltage caused by the braking and accelerating vehicles [6], [163]. The wayside ESSs have more freedom of space and size allocation for the energy storage devices. Moreover, in case of a substation power supply failure, a vehicle can reach the nearest destination by getting the supply from the catenary line via the wayside ESSs. However, the wayside ESSs present lower efficiency because of the $I^{2} R$ losses along the catenary line (from the vehicle supplying the regenerative energy to the ESSs location) [157], [164], [165].

\section{Power Converter Topologies for ESSs in Regenerative Braking Energy Recovery}

The DC-DC power converters form a part of the ESSs in the recuperation process of the regenerative braking energy. In railway system networks, power converters are required to interface the energy storage devices to the traction network (DC-link) where all other power converters are connected to. One of the main functions of the power converters is to match the characteristics of the regenerated energy to the energy storage device working parameters including the voltage and current, and to provide an efficient energy flow in both directions (bi-directional) [10], [62], [166]. Depending on the energy storage technology and application, when making a topology selection for the bidirectional DCDC power converter, some important working parameters for the converters need to be considered. Those parameters are high efficiency, fast response, ability to withstand frequent and high-power peaks, working over a wide temperature range, small in size and light weight (particularly in the case of onboard ESSs applications), providing autonomous driving capability when the need surges (also in onboard applications) and the power converters must able to provide the required voltage level $(600,750,1500$ or $3000 \mathrm{~V})$ to the DC-link [62], [167], [168].

The bidirectional DC-DC power converters are categorized into isolated and non-isolated. Generally, the non-isolated converters are used when the transfer voltage ratio is small (usually $<4$ by 1 ) and the galvanic isolation is not necessary [62]. Due to these features, non-isolated DC-DC power converters do not have problems associated with magnetic interference, and their dimensions are small and lightweight. There are three main converter configurations namely buck (for stepping down voltage), 
boost (for stepping up voltage) and buck-boost (for stepping up or down voltage) [168]. On the other hand, the isolated converters are used when galvanic/dielectric isolation is required and high voltage transfer ratio is required. In such converters, the DC voltage is first converted into $\mathrm{AC}$, then passes a high frequency transformer, and finally converted back to DC. The high frequency transformer provides the magnetic isolation medium between the two linking voltages. For this reason, such converters are heavier and larger, [169], [170], [171].

In recuperating the regenerative braking energy using ESSs applications, the most commonly used bidirectional DC-DC converters are discussed in the following subsections.:

\subsection{Non-Isolated Buck-Boost Bi-directional DC-DC Converter.}

As shown in Fig. 15, this converter topology (also known as half-bridge DC-DC converter) consists of two power semiconductor switches (IGBTs), one inductor and it is used when galvanic isolation is not needed.

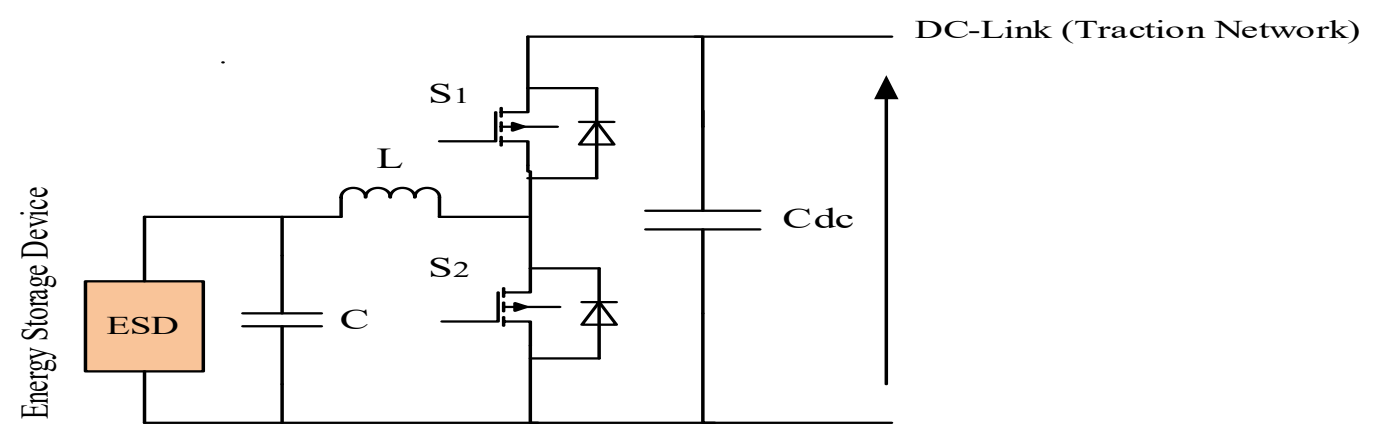

Fig. 15: Non-Isolated Buck-Boost Bi-directional DC-DC Converter [168],[172].

It controls the power flow between two different voltage levels of DC buses (the high side and low side). The energy storage device is usually connected to the low DC bus of the converter whereas the energy source (in this case, regenerated braking energy from the traction DC-link) is connected to the high DC bus. During the dynamic braking, regenerated energy flows from the DC-link to the energy storage device, and in this mode, the converter acts as a buck converter, in which the transistor switch $\mathrm{S} 1$ conducts while $\mathrm{S} 2$ is off and the inductor works as a filter. In the reverse energy flow, the converter acts as a boost converter i.e. transistor switch $\mathrm{S} 2$ is on while $\mathrm{S} 1$ is off, and the ESS sends the stored 
energy to the DC-link to facilitate vehicle's acceleration. In each of the operation, the duty cycle for each transistor switch controls the amount of energy flow to the ESS or to the DC link [62], [173], [172].

One of the advantages of this topology is that, it has less effect in the energy storage device deterioration despite the high switching frequency ripples being produced by the current at the converter output as discussed in [174], Another advantage is that it is simple, has smaller size and lighter weight and his topology has high efficiency ( $\geq 90 \%$ ). On the other hand, the use of this topology makes the ESS lacks of galvanic isolation from the DC link. This results in high switching losses and its inability to increase its voltage level during boost mode as required [175], [176].

\subsection{Multiphase Buck-Boost Bi-directional DC-DC Converter}

In order to have a high-power capacity and to reduce the converter output current ripple without necessarily increasing the switching frequency and the inductor value, a multiphase converter is employed that is the interleaved buck-boost DC-DC converter which consists of two or more of the buck-boost converters. The buck-boost converters are arranged in parallel as shown in Fig.16. With such arrangement of the phases, the control signals for the semiconductor switches are displaced by a phase shift angle of $360^{\circ} / \mathrm{N}$ where $\mathrm{N}$ stands for the number of the phases.

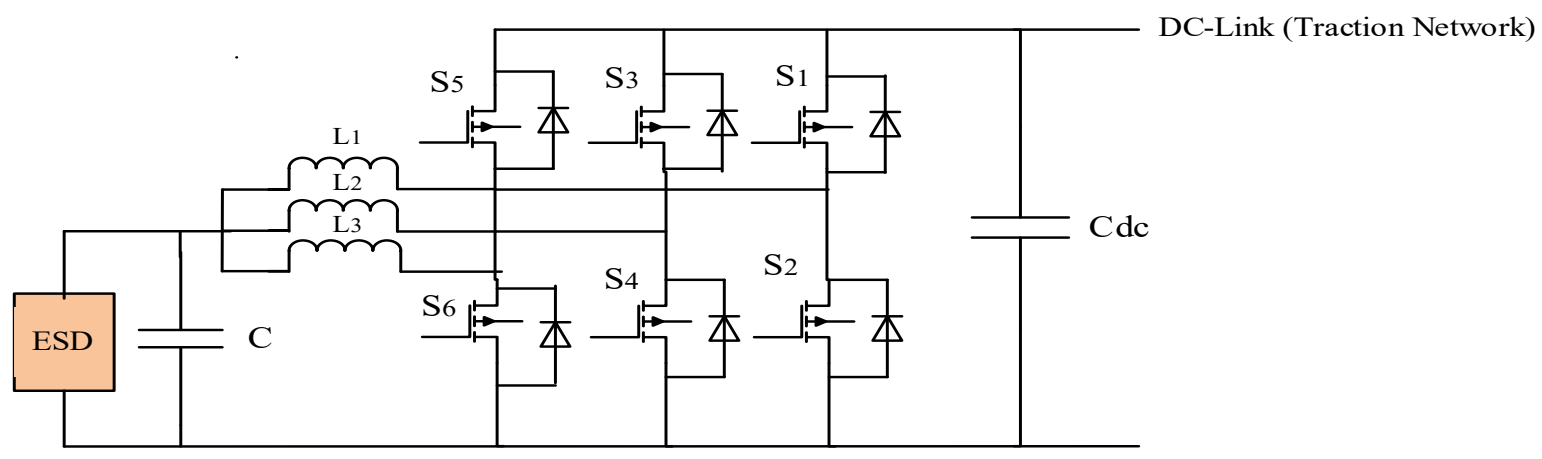

Fig. 16: Multiphase Buck-Boost Bi-directional DC-DC Converter [168], [172].

The idea of this topology is to lower the output current ripple and to have a frequency $\mathrm{N}$ times of a single-phase arrangement. This topology increases the reliability of energy flow that if one of the phases fails, others can continue to conduct though the total power capability is lowered by one third of the 
initial total power given that the number of the phases is three. Smaller number of filter components is required leading to reduce the weight. Moreover, switching losses are reduced compared to the singlephase buck-boost converter [62], [177]-[179].

However, due to increase in the number of switches, this topology requires a complex control strategy and more expensive compared to the single-phase buck-boost converter [168].

\subsection{Cascaded Buck-Boost Bi-directional DC-DC converter}

Fig. 17 shows two non-isolated buck-boost bi-directional DC-DC converters connected in cascaded form by means of an inductor. This topology enables the converter to have a high voltage gain ratio and a low current stress.

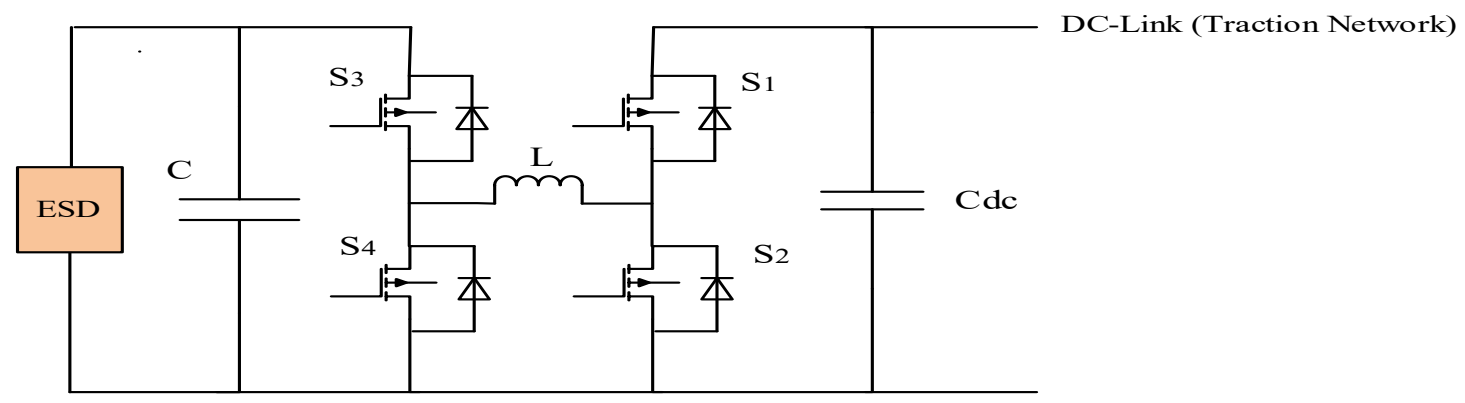

Fig. 17: Cascaded Buck-Boost DC-DC converter [62], [172].

The energy storage device is thus connected to the DC bus via S3 and S4 whereas S1 and S2 are connected to the DC-link traction network [172]. This type of converter is commonly used in electric vehicle (EV) applications.

This topology has a high-power capability due to low filter current stresses and low current ripples when compared to the single non-isolated buck-boost converter. Moreover, the voltage transfer ratio is high for the same switching frequency of a single buck-boost converter. However, the drawback is that it is costlier because of the used of greater number of switches, [172], [180]-[182].

\subsection{Dual Active Full-Bridge Bi-directional DC-DC Converter}

This is an isolated bidirectional DC-DC converter which is formed by connecting two full-bridge converters with a high frequency transformer in between them as shown in Fig. 18. Other components 
in the circuit are the capacitors which are connected at both sides of the DC buses, and an inductor connected to the primary side of the transformer.

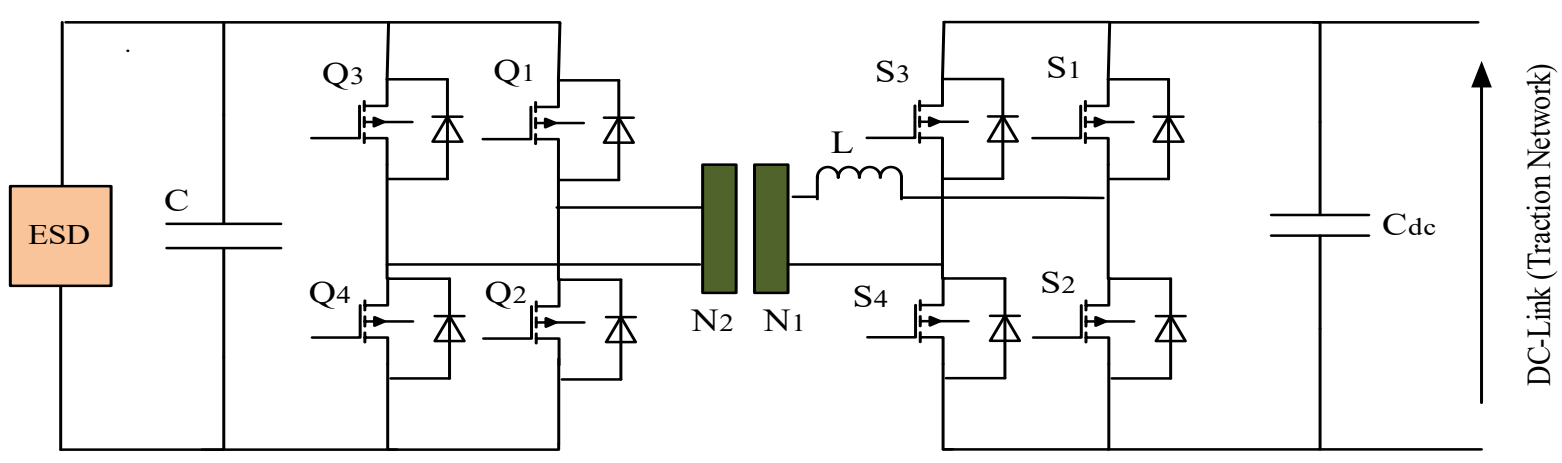

Fig. 18: Dual Active Full-Bridge Bi-directional DC-DC Converter [62], [172].

The high frequency (HF) transformer provides the required galvanic isolation and hence enables the control of the amount of power to be transferred on both sides of the converter. When the energy flows from DC-link (DC bus 1) to the ESS (ESS charging mode), the converter connected to the primary side of the HF transformer acts as an inverter while the converter at the secondary side of the transformer becomes a full wave rectifier. In reverse energy flow direction (ESS discharging mode), the former becomes the rectifier while the latter becomes the inverter [172], [183], [184].

The advantage of this converter is that it has high efficiency of about $95 \%$ or more, therefore it is suitable for high power applications. Another advantage is that as it can operate at a high frequency and high power density is attained when a small size of the HF transformer is required. Moreover, the ESS is highly protected from the magnetic interference and from the DC link because of the galvanic isolation provided by the converter. However, the converter has the disadvantage of its dimensions which are heavier and larger in size due to the transformer and many components involved. The converter also has many switches and hence a complex control strategy is required compared to the other simple topologies. Therefore, the design and execution of such a converter is complicated [168], [185], [186]. 
4.5 Dual Active Half-Bridge Bi-directional DC-DC Converter. In this type of topology, two transistor switches from the two converters of the dual active full bridge are replaced with capacitors and hence each converter becomes a half bridge as shown in Fig. 19. The idea of this topology is to reduce the number of the semiconductor switches used.

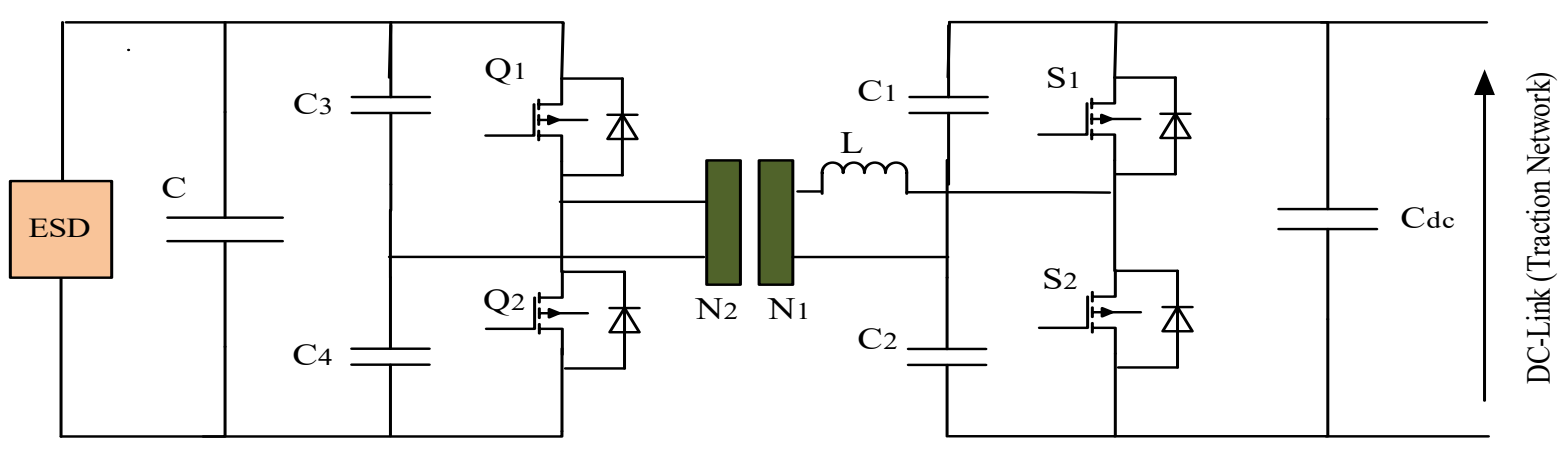

Fig. 19: Dual Active Half-Bridge Bi-directional DC-DC Converter [62], [168].

This type of converter is commonly used in low power applications because of the less power transfer between the two sides of the converter when compared to the dual active full bridge. The converter operates in buck mode when energy flow from the DC-link (high voltage side) to the ESS DC bus (low voltage side) and in this case transistors S3 and S4 are conducting. When the energy flows in reverse direction, the converter operates in boost mode with the same transistors. The two capacitors on both sides of the HF transformer are called balancing capacitors which perform the functions of circulating the transformer winding currents during the operation, [62], [168], [187].

This converter topology has the advantage of providing fewer current ripples on the secondary side of the HF transformer (the ESS DC bus) and hence fewer current stresses in the switches. Moreover, it has a reduced number of transistors compared to the full bridge converter for the same power rating. However, this converter has a drawback of allowing load currents to circulate through the capacitors as mentioned previously. As for the transformer design and dimension, it has less power transfer ratio compared to the dual active full bridge [172], [188], [189]. 


\section{Energy Storage Systems Control and Energy Management}

As discussed earlier, the energy storage system consists of three components namely the energy storage device itself (ESD) which can be a supercapacitor, battery, flywheel or hybrid ESS, then a bidirectional dc-dc converter and a controller. The need for the control and energy management of the energy storage system applied to urban rail transit system is highly crucial because of the frequent and numerous vehicles acceleration and braking operations which result in a very high rate of charging and discharging cycles. The control and energy management of the ESS must provide an efficient, optimal recovery in re-using the regenerative braking energy while ensuring safe and reliable operations of the energy storage devices as well as the bidirectional DC-DC converter [10], [190]. Depending on what is required to be achieved in the traction network - energy saving or voltage stabilization, that is the indicator which control strategy should be applied to the ESS [62], [191]-[194].

In General, control of the ESS in recovering the braking energy is divided into two categories. The first category is the energy flow management among the energy storage devices, trains and the traction substations, and the second category is the control of the bidirectional DC-DC power converter that manages the energy flow to and from the energy storage device, [193]. The control strategies governing these two categories are applied onto a controller which provide the control actions and receive the required input parameters as shown in Fig. 4 in section 3 to ensure the overall control and energy management are achieved, [195]-[199].

In the following subsections, the controls for both energy storage devices and bidirectional DC-DC converters are presented. Some related research studies applying such control strategies are also presented. The aims of these energy storage and DC-DC converters controls are to achieve an efficient, optimal control and energy management for the ESS in urban railway systems.

\subsection{Energy Storage Device Control}

The control and energy management for the energy storage device in electrified urban railway system is to regulate the amount of regenerative braking energy to be stored and to determine when to reuse it. These are governed by number of control strategies depending on the operating modes of the vehicles. 
The control and energy management systems are also to ensure the energy storage devices are well protected against the full charge/discharge as well as preventing the entire system from oscillation [193]. For the normal operating mode, the energy storage devices are prepared to store the braking energy and also release the energy during the acceleration period and when the vehicle is passing through gaps (where no catenary line connection presence), [101], [200].

The manufacturers of energy storage products such as supercapacitors or batteries for energy savings and voltage regulation to be used in railway applications, provide only products' specifications, drawings, functions and their advantages. However, they do not provide how to control the devices i.e., which control strategy or control technique is suitable for the optimal control and energy management. There are also no documentations on how to interface the storage devices to the traction network and which type of power converter to be used. The only solution provided to this is by the academic researchers who deal with the energy storage control strategies and the types of power converter topologies to be used [6], [201].

\subsection{Bidirectional DC-DC Converter Control}

The common control task in the bidirectional DC-DC converter as applied to the ESS for recuperating of regenerative braking energy is to control the power flow in both directions between the traction network and the energy storage device. The energy storage device cannot be connected directly to the traction DC-link for capturing the regenerative braking energy and releasing it back to enhance acceleration. This is because of their varying input and output conditions that are not suitable for railway applications [10]. However, if the energy storage device is connected directly to the DC-link, its utilization would be very minimal. Therefore, there is need for a power conversion system in the form of a bidirectional DC-DC converter to interface the energy storage device to the DC-link in order to manage the energy flow between the two (the DC-link and the storage device) [193].

Urban railway system is characterised as one of the high levels of power fluctuations resulting into intermittent operating conditions that require applications of fast response power converters to absorb the high spikes of the regenerative braking currents [193]. Moreover, during the operations, the DC- 
link and the energy storage system both have varying voltage levels, and to overcome this a bidirectional power converter is required to serve as an interface between the two. These two main issues highly affect the steady and dynamic performance of the bidirectional DC-DC converter during system operation [193], [194]. Hence, there is a need for an efficient control strategy to ensure a stable operation of the bidirectional DC-DC converter in all working conditions and free from interferences. The converter must be controlled in order to supply the required voltages and currents to the energy storage device according to the designed energy management control strategy [195]. Fig. 23 shows the general structure of a feedback control system to control the bidirectional DC-DC converter.

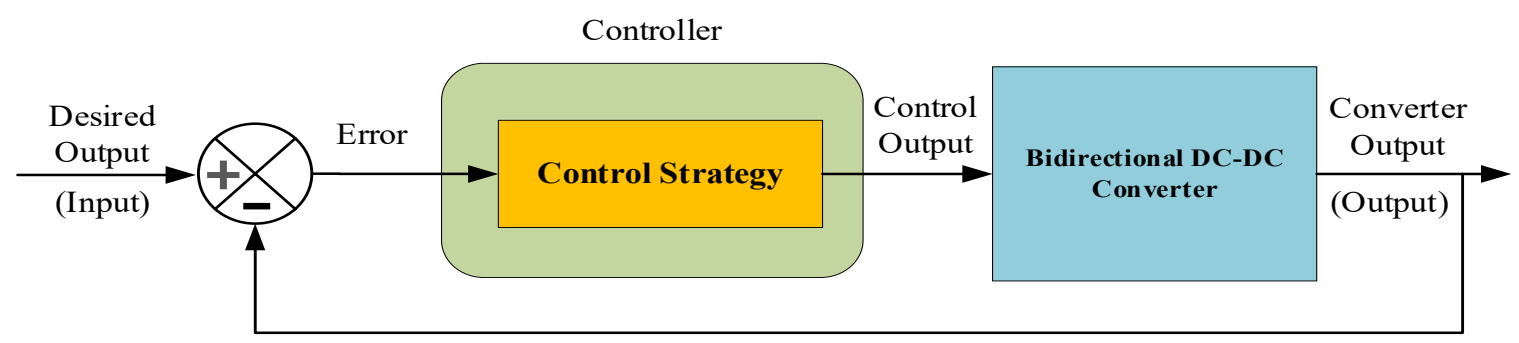

Fig. 23: General Structure of Feedback Control System for the Bidirectional DC-DC Converter [172].

The choice for the converter control method depends on the type of topology to be used and the nature of the control tasks required for a particular application. Therefore, for both isolated and non-isolated topologies and depending on an application's control task, the commonly control strategies used for the converter control in the recovery of regenerative braking energy in urban railway systems are listed in the next subsections and some related applications of such control methods done in regenerative braking energy recovery as well as other areas. Generally, in regenerative braking applications, two main parameters become the target control variables for the DC-DC converter and these are the energy storage device current $\left(I_{E S D}\right)$ and the traction DC-link voltage (also called network voltage, $V_{D C-\text {-ink }}$ ) [196], [197]. 


\subsubsection{Proportional Integral Derivative (PID) Control Method}

Due to its simplicity in design and implementation, PID control method is the most common, classic and traditional control strategy that is used to control various control problems for decades especially in the industry. In fact, over $90 \%$ of control loops found in the industries are controlled by using the PID or PI algorithms [202]. This control strategy is applied to either linear or nonlinear controllers in order to control and coordinate a closed loop control system to meet the required control targets. It plays a vital role in the control of processes, motor drive systems, power converters, and etc, [172]. Fig. 24 shows the PID feedback control system for the bidirectional DC-DC converter.

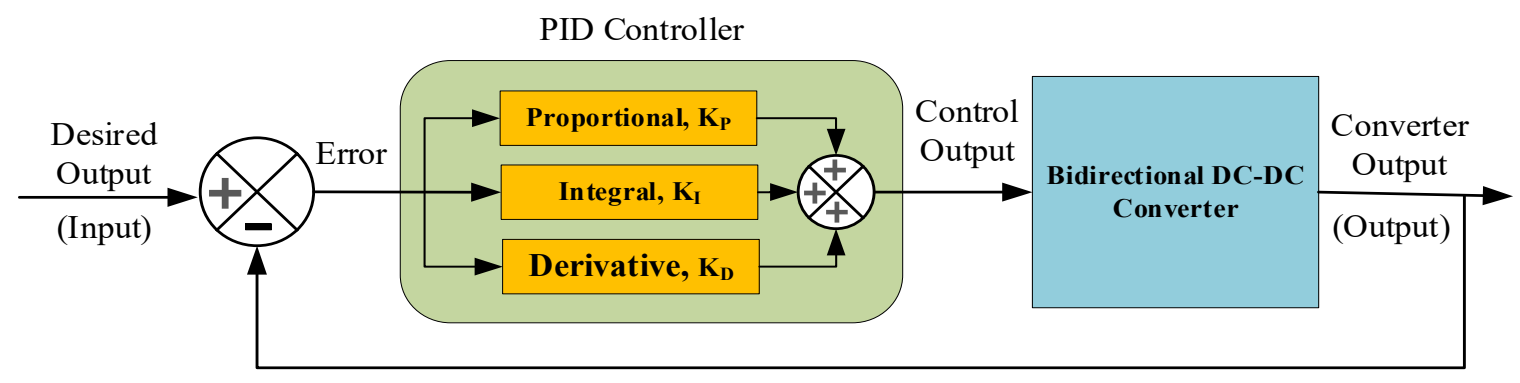

Fig. 24: PID Controller for the Converter Feedback Control System, [172], [203].

The basic principle of PID controller operation can be described by the following three-term control actions and with the controller transfer function:

$$
\begin{gathered}
G_{c}(s)=K_{P}+\frac{K_{I}}{s}+K_{D} s \\
u(t)=K_{p} e(t)+K_{I} \int e(t) d t+K_{D} \frac{d e(t)}{d t}
\end{gathered}
$$

It could be seen from Eq. (1), the PID controller consists of three terms and these are the $K_{P}$ which is the proportional compensation, $K_{I}$ the integral compensation, and $K_{D}$ the derivative compensation. The controller output equation in time domain, $u(t)$ in Eq. (2) shows the total sum for the control actions of the three-part on the error signal. With these three gains, a PID controller has been proved to guarantee an optimal control performance for a given closed - loop control system by ensuring high level of error reduction while maintaining a target level of stability and damping ratio, [204]. 
Advantages and Disadvantages: One of the major advantages of the PID control method is, it can be used for various converter topologies as well as for most control problems. It has a simple functionality as well as easier to implement. Moreover, it can be used in combination with other control strategies to make the control scheme to be more robust and optimal control performances, [172]. On the other hand, one of the limitations of this control method is that it is a compulsory requirement to determine the dynamic model of the system to be controlled in order to design and implement the PID control strategy. Moreover, the models developed in most cases are based on assumptions which the parameters are not easy to measure and are in fact varying during working condition, [203], [204]. There are two main control issues with regard to PI control method for bidirectional DC-DC converter during charging and discharging of energy storage devices applications. During the discharging process (boost mode), the converter has nonminimum phase behaviour as its output voltage to duty transfer function has a RightHand Plane (RHP) zero and a pole P is in the Left-Hand Plane (LHP), [205]. During the charging process, (buck mode), a zero is in the Left-hand Plane while a pole P is in the RHP. The effect of RHP zero presents an undershoot in step response which limits the achievement of high dynamic performance of the system leading to instability while the LHP zero presents an unstable open-loop system [193], [205].

Applications: The most common control method usually applied to bidirectional DC-DC converter for recuperating of regenerative braking energy is the double closed - loop proportional - integral (PI) control strategy, in which the inner loop controls the current and the outer loop controls the voltage. This is because of the strategy has a simple functionality, parameter settlings, and easier to implement. In [193], hierarchical control strategies were proposed consisting of upper and lower levels. The upperlevel control strategy was to control the supercapacitor energy management system while the lowerlevel control strategy was for the bidirectional DC-DC converter. The state machine control strategy was proposed for the energy management system whereas the double closed-loop PI control strategy was proposed for the bidirectional power converter. The outcome of the framework shows an outstanding performance and high disturbance rejection. In [195], the control of supercapacitor energy storage system was studied to provide an efficient energy management in traction network applications. 
In the proposed control strategy, the researcher considered the effect of the inductor impedance on the stability of the system. In [197], a polynomial control strategy was proposed to control a bidirectional DC-DC converter between the DC-link and supercapacitor applied in a hybrid vehicle for power management applications. This polynomial strategy was compared to the conventional PI control strategy and the result exhibits that the system operated with a better performance and the strategy appears to be more precise and powerful compared to proportional integral control. In [206], the researchers outlined the classical linear control technique used to control the bidirectional DC-DC converters for energy storage systems which consists of two PI regulators (double closed-loop control) for controlling the voltage and current. This technique is easier to implement due to its simplicity but lacking in performance.

\subsubsection{Sliding Mode Control Method}

Bidirectional DC-DC converters are inherently variable structure systems in their operations which constantly make their topologies to be changing from one form to another. As a result, they contain nonlinear elements in their dynamic equation which make the converters to be nonlinear systems. Moreover, the converters have an inherent chattering characteristic which is difficult to eliminate. The theory-based controllers, like the PID, require accurate mathematical models of the target control/plant and the controllers are also sensitive to parameters' variations. In using such controllers for the design of nonlinear system, the system must first be linearized around its equilibrium point using method such as Taylor's series, [207]. Hence, the models derived with such methods are approximate of the actual model due to the series of estimation within the process. The models derived from such methods do not account for perturbation and disturbances. Therefore, such controllers are not suitable for optimal control of nonlinear systems such as bidirectional dc-dc converters. In order to reliably control such nonlinear variable structure systems and by accounting for the perturbation and disturbance, there is a need to adopt nonlinear control strategies such as the sliding mode control, [172].

Sliding mode control is a type of nonlinear control strategies that can be used to control either linear or nonlinear systems because of its simplicity, fast and finite-time response, highly resistance to parameters' variations, external perturbations and disturbances. The principle of sliding mode control 
is to specify a virtual surface known as sliding surface where the system trajectory converges at an equilibrium point and a switching control input is applied to maintain the state trajectory on the sliding surface. The following equations show the principle of sliding mode control where the tracking error for a given system is calculated using the state vector $x$ and reference vector $x_{r}$, [208], [209].

$$
\bar{x}=x-x_{r}
$$

To design the sliding mode controller, the following equation is applied [208]:

$$
u=\frac{1}{2}[1+\operatorname{sign}(s)]
$$

From Eq. (4), $u$ signifies the output controller action which is a function of $s$, the sliding surface.

$$
s=c^{T} \bar{x}
$$

Where c signifies the positive coefficient. The Lyapunov function is defined as shown in Eq. (6).

$$
V(s)=0.5 s^{2}
$$

The sliding mode controller is designed in such a way that the derivative of $\mathrm{V}(\mathrm{s})$ is always negative when the sliding surface, $\mathrm{s}$ is not zero, [208]. Fig. 25 shows a sliding mode feedback control system for the bidirectional DC-DC converter where the controller is seen to contain the sliding surface as the first block that receives the error signal and then the control law which in this case is the Lyapunov Stability Function that determines the switching functions for the converter.

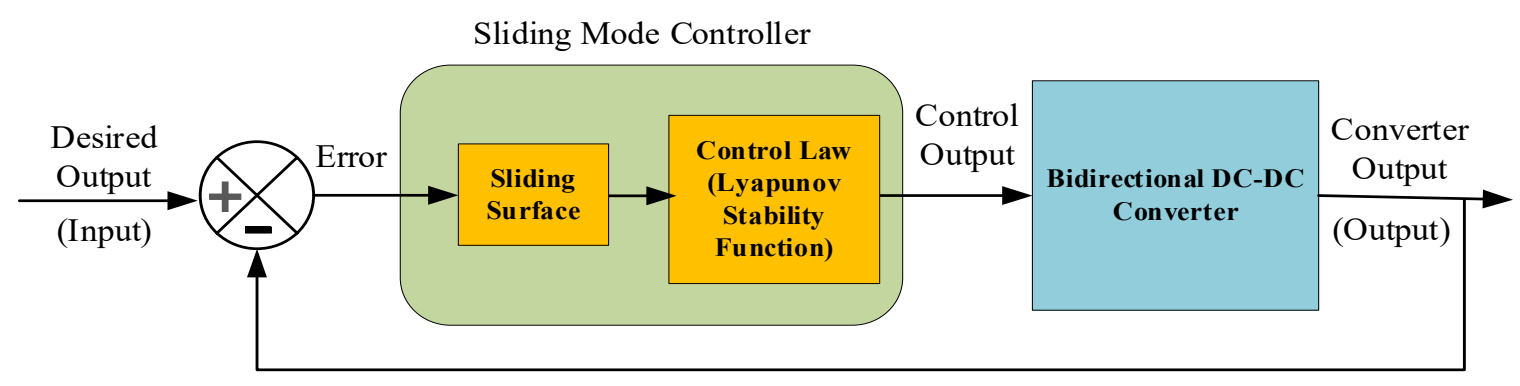

Fig. 25: Sliding Mode Controller for the Converter Feedback Control System, [172], [203]. 
Advantages and Disadvantages: The advantages of the SMC include having fast response, easier to implement, highly robust against parameter changes and external perturbation and disturbances, [10], [11], capability of system order reduction, it does not require accurate mathematical models of the target control/plant, it can be designed to have first - order response irrespective of the system, suitable for systems with inherent variable structure like power converters. On the other hand, one main drawback of this control strategy is that it chatters along the sliding surface when trying to move to the sliding regime. It requires at least the knowledge of the range of system's parameter variation for its effective implementation, [172], [204], [209].

Applications: In [210], a sliding mode control strategy was applied to an electric drive in railway regenerative braking energy applications where the strategy was based on Lyapunov stability theorem designed and simulated in order to realize the system stability in all operating conditions. The strategy was applied to a bidirectional DC-DC converter (for charging/discharging the supercapacitor), and a unidirectional for charging the battery from the supercapacitor. The result revealed that the system stability was achieved together with the energy management system. In [211], a sliding mode control was used to control a coupled - inductor bidirectional DC-DC converter interfacing the supercapacitor energy storage system for the purpose of improving the converter's performances. In this paper, a numerical application was used to a DC tramway system with stationary supercapacitor storage system (SESS). The results showed that the sliding mode control applied was highly resistive to external perturbations and disturbances. In [212], a sliding mode control was used to control a bidirectional DCDC converter interfacing hybrid supercapacitor and battery energy storage system for recuperating of train kinetic energy based on kinetic energy estimation and supercapacitor internal voltage observation. The sliding control method improved the system stability and the DC-link voltage fluctuations/dynamics. The control method enabled the supercapacitor and battery currents to track their references effectively. In a related application, a single degree sliding mode control strategy was presented for controlling a bidirectional DC-DC converter in a standby renewable energy source which a solution based on adaptive equations was offered to overcome the problem of recalculation of the design equations in every cycle operation. However, the method presented, the converter losses were 
not taken into account. Moreover, there was a chattering problem due to the first-degree level of the switching function used as against the second-degree level, [213].

\subsubsection{Model Predictive Control (MPC) Method}

MPC, also known as receding horizon optimization control (RHC), Dynamical Matrix Control (DMC) or Generalized Predictive Control (GPC) is one of the powerful advanced control methods that utilizes optimization control of tracking with constraints which is highly suitable for the control of power electronic converters and electric drives, [214]. It has been in industrial process applications since in the eighty's (1980s) though the practical application of Dynamic Matrix Control started at early 1970's by Shell Oil, [215]. It has a proven successful industrial application because of its stability proofs, excellent resource, and etc. Due to its excellent characteristics such as its simplicity, practicality, ease of implementation, and richness make it a successful method in control design. Moreover, it is highly suitable for systems or processes with problems that include time delays, variable control objectives, constraints contain in both manipulated and controlled variables, and with multiple number of controlled and manipulated variables, [216]. The principle of model predictive control strategy is that it uses a detailed nonlinear dynamic model of the system to be controlled and based on a predefined cost function of the system variables, a prediction of the system's behaviour in the future is made for all possible input states. It has a fast-dynamic response and the state variables of the system follow a predefined value. It is also easier to execute once a cost function is established, [172], [204]. In terms of its application in power electronic converters, the design of the MPC controllers begins with the computation of future inputs sequence, and it is the first array of the future control inputs that is applied.

The principles of MPC operation can be demonstrated by solving the optimization in a receding horizon as demonstrated in Eq. 7 below, [215], [216]:

$$
\min J=\sum_{\tau=t+1}^{\infty}(y(\tau))^{2}+r(u(\tau)-u(\tau-1))^{2}
$$

Subject to: $|u(\tau)| \leq u_{o}$

$$
x(t+1)=A x(t)+B u(t)
$$




$$
y(t)=C x(t)
$$

Eq. 7a represents the infinite horizon optimal control while equations Eq. 7c and Eq. $7 d$ represent the system model with state vector $\mathrm{x}$, input vector $\mathrm{u}$, and output vector $\mathrm{y}$. This set of equations is for the discrete MPC. The continuous MPC is similar in principle with the discrete MPC except that it is based on a continuous time model as described by equations Eq. 8,[215],[216].

$$
\begin{gathered}
\min J=\int_{0}^{T}\left(\left|y_{r}(t+\tau)-y(t+\tau)\right|_{Q}^{2}+|u(t+\tau)|_{R}^{2}\right) d \tau \\
\text { Subject to: } g(u(t+\tau), x(t+\tau)) \leq 0 \\
\dot{x}=A x+B u \\
y=C x
\end{gathered}
$$

Fig. 26 shows a model predictive feedback control system for the bidirectional DC-DC converter in which the model predictive controller's optimization function and other elements to process the error as well as to send the control command to the converter. After beginning with the discrete time model of the

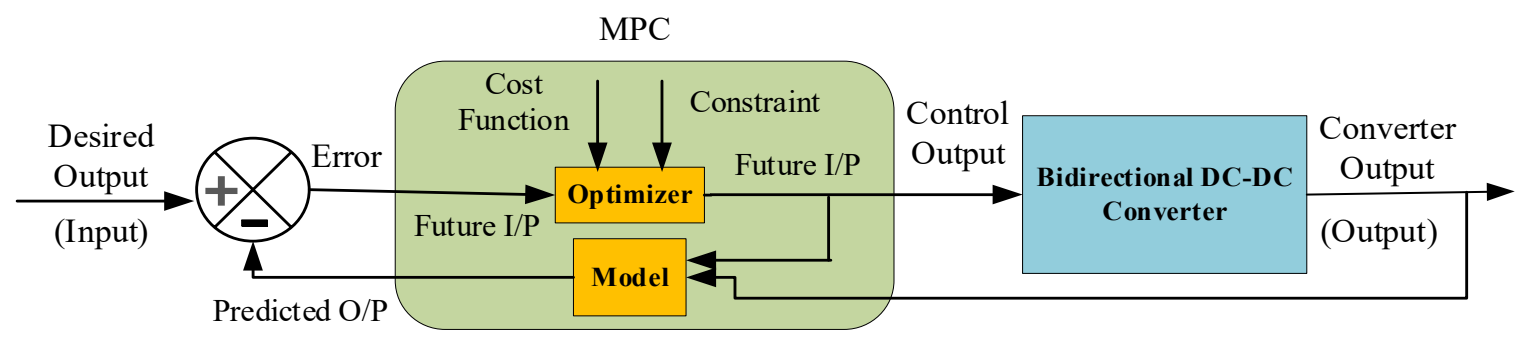

Fig. 26: MPC Controller for the Converter Feedback Control System [172], [204].

system, To begin with, the model of the system is first discretized and then the optimization and prediction systems are designed. At the prediction stage, measurements are obtained from the previous defined model while the future predicted value is being provided by a function of current values of the control variables for each mode of the converter operation. At the end of the MPC cycle operation, all predictions are sent to the optimization block where the solution of the optimization problem is done 
online using the predicted values and the predefined cost function. Finally, the MPC provides the required optimal control actions with continuous cycle operations, [172].

Advantages and Disadvantages: MPC is a simple control strategy that is highly robust and is capable of handling multiple objectives. It is easy to maintain and modify the models or the specifications without necessarily redesigning the complete system. It explicitly accommodates constraints and use explicit model. It has clear tunning parameters which include the prediction horizon and optimization problem setup MPC compared to other control strategies, depends on the accuracy of the discrete-time model of the system to execute the MPC strategy. It also depends on the tuning of the MPC feedback control performance which is also a challenging task as it requires infinite prediction horizon or terminal constraints. Moreover, during its design process, all states may not be available, therefore, there is a need for an integrator feedback in order to handle the steady state error, and finally there is large angle deviation as a result of soft constraints and linearized model deficiencies, [172], [215],[216].

Applications: In [217], an explicit model predictive control was used to control the bidirectional DCDC converter for supercapacitor energy storage system in Light Rail Vehicle in order to achieve real time control of the system and to reduce the amount of online computation. The optimal control problem with the system parameters and the constraints of the duty cycle are derived from the model that is based on v-resolution method which capable of capturing the hybrid nature of the supercapacitor in the form of piece wise affine. The model predictive control law was computed using multi-parameter programming. In [218], a model predictive control was used to control three-level bidirectional DC-DC converter for supercapacitor energy storage system in order to address the converter's high voltage stress and large output current ripple. In this strategy, the DC-bus voltage and flying capacitor voltage are the control objectives, and the MPC optimizes the objectives using prediction modelling and reducing the objective function. The results showed that the high voltage stress has been reduced and the low output current ripple for the supercapacitor energy storage system have been achieved. In another application, a model predictive control strategy was used to control a bidirectional DC-DC converter for a battery energy storage system (BESS) in renewable energy system. The purpose of the strategy, was to overcome the fluctuation problem of the energy source output, and resulting a 
smoothed output as well as a stable DC-bus voltage, [219]. In [220], MPC strategy was applied to control a bidirectional DC-DC converter that links a battery bank to the DC bus for the purpose of maintaining the DC bus voltage in a specified range. The results showed that the control strategy proved to reduce to minimize the DC bus voltage fluctuations by keeping the DC bus voltage within the predefined rated range. In [221], an accurate MPC was used to control a bidirectional DC-DC converter connected to DC distributed power systems. The outcome of the control strategy showed that the converter has achieved the desired transient response as well the required stability.

\subsubsection{Fuzzy Logic Control (FLC) Method}

Fuzzy logic control (FLC), does not require an accurate mathematical model, and it is capable of working with both linear and nonlinear systems with imprecise inputs, and it is highly resistant to disturbance as compared to most nonlinear control strategies, [204],[209].

The fuzzy logic concept was first developed by Prof. L.A. Zadeh in the year 1965 from the University of California, USA. However, it was not practically implemented until in the year 1974 by Dr. E. H. Mamdani, a Prof. in London University, UK who used the concept into practice in controlling an automatic steam engine. Later in the year of 1976, the industrial implementation took place by the Blue Circle in England and SIRA in Denmark in controlling cement kiln. From 1980 onwards, several applications of FLC continued to diverge in other sectors which include but not limited to automobile manufacturing, automatic controls, manufacturing/process industries, academic institutions, hospitals, and etc, [203]. The principle of fuzzy logic control is based on fuzzy sets where a smooth transition of such sets take place from membership to non-membership not in a sudden manner. The first step in designing FLC is, to specify the input and output variables which are the state variables, their errors, and error variations with respect to their accumulation, [209]. In the operation of DC-DC power converters, the FLC input variables consist of output voltage/current error and/or accumulation/variation of the error. The FLC technique consists of the following consecutive steps which need to be implemented one after the other: 
a. Fuzzification: is a process of converting crisp also called classic data (data understandable by computer machines) into the fuzzy data called membership functions (MFs)

b. Fuzzy Inference Process: provides the fuzzy output by working on the MFs and the control rules.

c. Defuzzification: is a step calculating each output which a different approach is used and the results are placed in table called the lookup table. For each application process, an output is picked up from the table based on the current input.

As a DC-DC converter is a nonlinear and time varying system, and in order to use the fuzzy control method for the converter control, the dynamic model, parameters or working conditions are not required but rather a well-defined qualitative knowledge of the system dynamics is required. As shown in Fig. 27, fuzzy control technique is explained [172], [203].

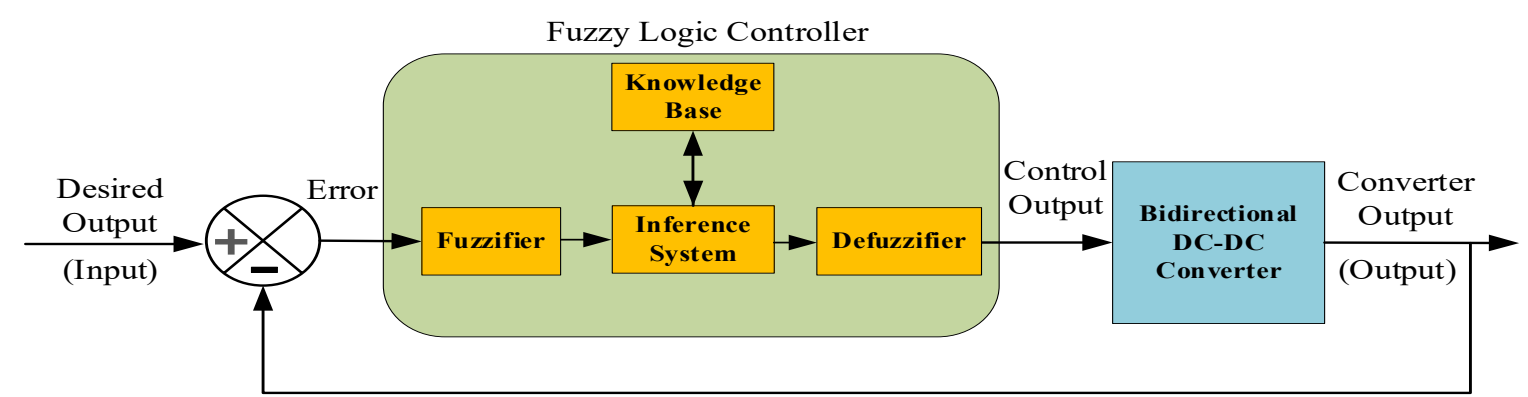

Fig. 27: Fuzzy Controller for the Converter Feedback Control System [172], [204].

Advantages and Disadvantages: The main advantage of the fuzzy controllers is that no prior knowledge is needed about the system parameters which applicable for those systems whose dynamic models are difficult or impossible to be obtained. They can be used for both linear and nonlinear control systems which makes them become robust controllers. The FLCs are almost resistant to system parameter fluctuations since they do not take into account their values. However, one of the major drawbacks of FLCs is that they are wholly dependent on human knowledge and expertise as there is a need for regular updating of the fuzzy rules. Moreover, the controllers require manual tuning and time-consuming retuning processes. There is a trade-off in the case of the controller performance robustness since in most cases it is not taken into consideration in the fuzzy logic tuning process, [ 202], [203], [209]. 
Applications: In one of the fuzzy control applications, an energy consumption reduction from the substation for an electric elevator was achieved while ensuring the charging and discharging of the electric double layer capacitor (EDLC) are regulated. In that system, the EDLC stores the braking energy of the elevator, and then releases it back when the elevator accelerates during its operation, hence reduces the energy being drawn from the supply. With the help of the fuzzy control strategy, the EDLC stabilizes the DC-link voltage due to fluctuations caused by the power supply voltage variations, [222]. In [223], a fuzzy logic control strategy was used to control a bidirectional DC-DC converter for the purpose of optimizing battery performance in electric vehicle applications. The result of this control strategy enables the bidirectional DC-DC to have $90 \%$ efficiency and could regulate the battery charging and discharging current, while maintaining the output voltage at a constant value. In another application of electric vehicle systems, a comparison of FLC strategy was done against the Proportional Integral (PI). The fuzzy control proved to have better control performances over the PI control strategy, [224]. In [225], a fuzzy logic based control strategy was applied to a proposed bidirectional DC-DC in electric vehicle for the purpose of efficient energy management.

\subsubsection{Artificial Neural Network (ANN) Method}

Unlike the traditional linear control systems, in which the key requirement of the controller design and implementation is that the plant/process's mathematical model is mandatory and it must be in the form of algebraic and differential equations. These controllers suffer several drawbacks because of the assumptions made, parameter variations, nonlinear systems approximated to linear and time - invariant systems. Thus, these control challenges could be solved effectively by an artificial intelligence-based control strategies called the Artificial Neural Network (ANN) control. The ANN control is another intelligent control strategy that could deal with nonlinear systems or whose models cannot be obtained, and are highly insensitive to parameter variations. The strategy is based on learning the system/process by studying previous data provided by the system then it develops an appropriate control action to provide an optimal control in the system, [172], [204]. Fig. 28 shows ANN feedback control system for a bidirectional DC-DC converter. 


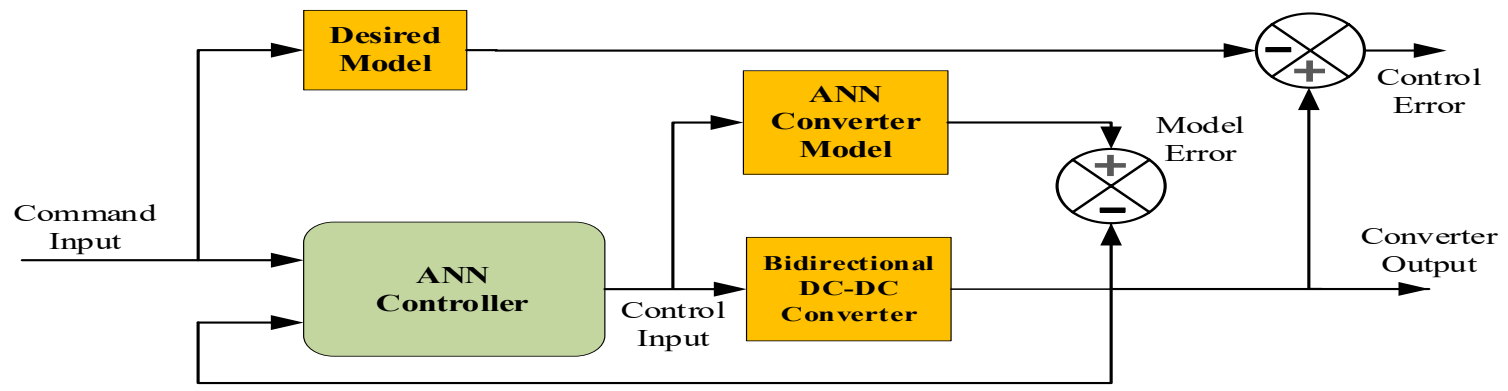

Fig. 28: ANN Controller for the Converter Feedback Control System [204].

Advantages and Disadvantages: The main advantage of using artificial neural control methods is that does not require detailed information about the system or its analytical model (mathematical model) to be known. Instead, the control methods are based on learning by studying the previous data in controlling the system. Other advantages are, they are capable of handling large and complicated systems with complex control problems. Their design is based on linguistic information provided by the expert knowledge or real data of the system/plant. Controllers based on ANN do not require much tuning effort compared to the classical controllers. In addition to the linguistic information process design, a response-based information can be used in conjunction to carry out the design. An improved performance is achieved when ANN controllers are tuned appropriately. On the other hand, some of their disadvantages are similar to those of FLC strategies as both of them are intelligent-based control techniques. Other disadvantage is their designs are wholly dependent on linguistic information obtained from human knowledge and expertise or by using clustering method, and such information need to be updated from time to time, [172], [204].

Applications: In [226], an artificial neural network control method was applied to a boost converter in order to improve its transient response performance by regulating the output voltage. The result of the simulation showed a fast-dynamic response which reduced the percent overshoot. In [227], ANN control was combined with an FLC strategy was applied to control the temperature of the water. The ANN control was combined in order to overcome the control problem which could not be fully solved by only using FLC control method. An improved performance was achieved by combining the two control strategies. In [228], a new ANN control strategy called Neural Network Predictor was applied 
to control a multiple outputs DC-DC converter and the dynamic characteristics of this new method were compared to a traditional PID feedback control. The results of the new control method showed improved performances in terms of the convergence time of the output voltage, the undershoot voltage, and the overshoot voltage. In [229], an ANN control was applied to control a static DC-DC converter for an onboard electrical energy management in electric vehicle. In this method, the parameters update has been done by Levenberg-Marquardt method while the network validation by the model assumption Nonlinear Autoregressive with Exogenous input (NARX). The comparison between the ANN method and the classical linear control method showed that the ANN control method has a better control system stability.

Table 4 presents the summary of the control methods discussed in this section

Table 4: A suumary of comparisons of control methods for bidirectional DC-DC converters and their applications in electric vehicle and railway

\begin{tabular}{|c|c|c|c|c|c|}
\hline $\mathbf{S} / \mathbf{N}$ & Control Methods & Advantages & Disadvantages & Applications Examples References & References \\
\hline 1 & $\begin{array}{l}\text { Proportional Integral } \\
\text { Derivative (PID) } \\
\text { Control }\end{array}$ & $\begin{array}{l}\text { - It's simple and easy to implement } \\
\text { - Can combine with other control } \\
\text { methods for robust \& optimal control } \\
\text { - Proved to be efficient in providing } \\
\text { acceptable control perofrmances }\end{array}$ & $\begin{array}{l}\text { - Mandatory requirement to determine the } \\
\text { mathematical model for the plant/process } \\
\text { for the PID controller design \& } \\
\text { implementation } \\
\text { - Senstive to Parameters Variation } \\
\text { - Not sutable for the control nonlinear } \\
\text { systems } \\
\text { - Mandatory to define control } \\
\text { specifications of the control objective }\end{array}$ & [193], [195], [197], [206] & $\begin{array}{c}\text { [10], [62], [94], [102], [103], } \\
\text { [104], [105], [106], [107], } \\
\text { [108], [109], [110] }\end{array}$ \\
\hline 2 & Slide Mode Control & $\begin{array}{l}\text { - Fast dyanmic response } \\
\text { - Easier to Implement } \\
\text { - Highly Robust against parameter } \\
\text { variation \& external pertubation and } \\
\text { disturbances } \\
\text { - Suitable for systems with inherent variable } \\
\text { structure } \\
\text { - Doesn't require system model } \\
\text { - Capability of system order reduction }\end{array}$ & $\begin{array}{l}- \text { - Inherent chattering issue } \\
\cdot \text { Requires knowledge of systems } \\
\text { parameter variation }\end{array}$ & [210], [211[, [212], [213] & $\begin{array}{c}\text { [6], [10], [62], [120], [121], } \\
\text { [122], [123], [124], [125], } \\
{[126],[127],[128],[129] .}\end{array}$ \\
\hline 3 & $\begin{array}{l}\text { Model Predictive } \\
\text { Control (MPC) }\end{array}$ & $\begin{array}{l}\text { - Highly robust } \\
\text { - Simple control strategy } \\
\text { - Fast dynamic response } \\
\text { - Easier to maintain and modify model/specs } \\
\text { - Optimize control of tracking with constraints } \\
\text { - Capable of handling multiple objectives }\end{array}$ & $\begin{array}{l}\text { - Detail model required for its design } \\
\cdot \text { - Requires infinite prediction } \\
\text { horison/terminal constrsints for its tuning } \\
\text { process } \\
\text { - Unavailability of all state variables during } \\
\text { its design }\end{array}$ & & $\begin{array}{c}\text { [10], [39], [75], [86], [130], } \\
\text { [131], [132], [133], [134], } \\
\text { [135], [136], [137]. }\end{array}$ \\
\hline 4 & Fuzzy Logic Control & $\begin{array}{l}\text { - It doesn't require system's dynamic model } \\
\text { for tis design } \\
\text { - Fast dynamic response } \\
\text { - No prior knowledge required for the system } \\
\text { parameters } \\
\text { - Highly robust } \\
\text { - Highly resistant to system parameter } \\
\text { changes }\end{array}$ & $\begin{array}{l}- \text { Requires regular updating of fuzzy rules } \\
\text { - Requires manual tuning \& time } \\
\text { consuming retuning }\end{array}$ & [222], [223], [224], [225] & $\begin{array}{c}\text { [139], [140], [141], [142], } \\
{[143] .}\end{array}$ \\
\hline 5 & $\begin{array}{l}\text { Artificial Neural } \\
\text { Network (ANN) } \\
\text { Control }\end{array}$ & $\begin{array}{l}\text { - It doesn't require system's dynamic model } \\
\text { for tis design } \\
\text { - Capable of handling system with complex } \\
\text { control problems } \\
\text { - Requires less tunning effort } \\
\text { - Fast dynamic response } \\
\text { - Design based on linguistic information }\end{array}$ & $\begin{array}{l}- \text { Design dependent on linguistic } \\
\text { information as obtained from human } \\
\text { knowledge \& expertise } \\
\text { - Information provided needs to be updated } \\
\text { from time to time. }\end{array}$ & [226], [227], [228], [229] & $\begin{array}{c}\text { [10], [39], [75], [86], [130], } \\
\text { [131], [132], [133], [134], } \\
\text { [135], [136], [137]. }\end{array}$ \\
\hline
\end{tabular}




\subsubsection{Other Potential Control Methods}

Some other potential control methods worth to be mentioned, and which are used in the control of bidirectional DC-DC converter are Dynamic Evolution Control, Backstepping Control and Boundary Control.

In dynamic evolution control, the aim is to minimize the error state by ensuring that the error is brought down zero level with respect to the time increase. One main advantage of this method is that no expert knowledge of the system model parameters is required [172]. In reference [230], it was used to control a bidirectional DC-DC converter that interfaced a supercapacitor energy storage system in a fuel cell electric vehicle system. The supercapacitor served as a secondary power supply to enhance the efficiency of the system by improving the fuel cell dynamic response. The bidirectional converter managed the power flows between the supercapacitor and the fuel cell DC-link.

The backstepping control method is a nonlinear control strategy which employs the use of Lyapunov second method that enables it to provide robust control and stability of the control system. One main advantage of this method is that, it tracks the error to zero level irrespective of the external disturbances and variations in the parameters [204].

A boundary control strategy is also used in the control of bidirectional DC-DC converters because it has large signal trajectories. Boundary control is based on a technique applied to inverse problems with respect to control theory [172].

\section{Discussion and Recommendation}

Energy storage systems prove to be a viable solution among other methods for the utilization of regenerative braking energy in electrified urban railway system, which they are used in either onboard or stationary applications to maximise the use of such energy. The major features that make ESSs to have special priority over other methods are, the recovering of the train's kinetic energy during dynamic braking (regenerative braking), they assist the vehicle with the stored regenerated energy during its acceleration process hence reducing of the energy consumption from the traction substation, a vehicle with onboard ESSs can freely move without having to be connected to the catenary line supply or in 
the event of power outage or failure. The ESSs allow for peak power shaving hence power and size of the substations are reduced. As a system, it consists of three main components and those are the energy storage device itself, the bidirectional electronic DC-DC power converter, and a controller. The detail discussion and recommendation of energy storage technologies, topologies of DC-DC converter and control methods are presented below.

\subsection{Energy Storage Technologies}

In general, there are three storage devices available for the energy storage system in urban railway applications. They are supercapacitors, batteries and flywheels. The important key performance indicators used in describing and comparing the performances of the energy storage technologies are energy and power densities, efficiency, lifecycle, response rate, durability, and self-discharge rate. As discussed, and presented in the advantages, disadvantages, techno-economic comparisons, and Ragone plot, the energy and power densities are the most critical indicators to consider in making a selection for an energy storage device in regenerative braking applications especially in onboard ESS applications. Among the three storage devices, batteries possess the highest energy densities (especially the lithium-ion then followed by sodium sulphur), followed by supercapacitors and then flywheels. The compactness of Li-ion batteries makes them highly suitable for onboard applications over supercapacitors and flywheels. However, batteries present a very low power densities compared to supercapacitors and flywheels, and they have a long charging time. On the other hand, supercapacitors have a high-power density, long life cycle, and able to withstand high rate of charging and discharging cycles. Flywheels are known to have both high energy density as well as high power density compared to batteries which can also be applicable for regenerative braking energy recovery.

In urban rail transit systems, there are frequent and numerous trains acceleration and braking operations especially during the peak periods, and resulting into frequent and numerous charging and discharging cycles. The characteristics of regenerative braking energy is for a short duration and high peak currents. With these urban rail features, it can be concluded that among the three energy storage devices, only supercapacitor seems to be a more suitable option for such applications because of its high-power 
density, being able to absorb high and frequent charging and discharging cycles for such short durations, and also having a long-life cycle without failure.

\subsection{Power Electronic Converter Topologies}

For the bidirectional DC-DC power converter topologies, the selection of a particular topology depends on the energy storage technology and installation configuration to be used. For instance, in onboard applications, the size and weight of the converter need to be considered as smaller size and less heavier converters are required. However, these considerations do not matter in the case of stationary/wayside installation. The choice of the topology also depends on whether a galvanic isolation is required or not. The parameters that are considered in choosing a particular converter topology for an energy storage technology and for a given application are the efficiency, transfer voltage ratio, operating temperature range, galvanic isolation, number of transistor switches, magnitude of converter output ripple, and etc.

For a non-isolated application, three converters are presented, the buck-boost DC-DC converters, interleaved buck-boost and cascaded buck-boost. Among these converters, cascaded buck-boost DCDC converter can be considered to be the most suitable for recuperating of regenerative braking energy because of the advantages they have over the buck-boost and interleaved DC-DC converters. Although the cascaded buck-boost converter has twice number of power semiconductor switched over the conventional bidirectional buck-boost converter, it has the best performances in terms of high voltage gain ratio, very fewer current ripples and inductor current stresses. This also result in less current stresses in the semiconductor switches as well as other passive components. The interleaved buck-boos converter also has good performances but it has high number of switches and inductors, all of which make it heavier, expensive and requires a complex control algorithm over the cascaded.

For the isolated applications, the bidirectional dual active half-bridge DC-DC converter should be selected over the full-bridge because the former has a half of the switches' quantity for the same power rating, having low transistor current stresses and low current ripples at the low voltage side. 


\subsection{Control for the Bi-directional DC-DC Converter}

The classical linear PID control method is limited in providing the optimal control required especially for systems like power converters which are nonlinear in their dynamic state and with high parameter variations during their operations. The sliding mode control method provides a better control over the classical PID method because it can deal with the nonlinearity issues but still the inherent chattering problem exists. The MPC also provides a better control but requires a well informative nonlinear dynamic of the converter in order to predict the future state for every switching vector. However, both FLC and ANN employ the learning methods from the knowledge of the converter dynamics in their control strategies which enable them to provide a highly robust control without the need to have the model of the converter. Therefore, among these control methods outlined for the DC-DC power converter, both FLC and ANN control methods can provide the best control compared to other methods due to the stated features.

The recommendations derived from this review paper are as follows:

\section{The storage technologies}

Generally, the supercapacitors are the best for onboard applications over batteries and flywheels because of their fast response to high rate of charging and discharging cycles, having high power density, and long-life cycles. However, Li-ion battery are able to compete in the future if its power density can be increased to the required level. The flywheels also have high energy and power densities but are limited to a number of applications because of the risk of explosion and shattering and they are heavier. On the other hand, a hybrid combination of supercapacitor and Li-ion energy technologies can give the best performance for onboard applications especially when catenary-free driving is required but by compromising the cost, complex control strategies, and weight of the system.

As for the wayside applications, supercapacitor storage is recommended over batteries and flywheels due to its outstanding features such as fast response rate to charging and discharging, high power density, and etc. The second suitable storage device are batteries since there is no restriction for space 
in wayside application, however, their lifetime limitation will be highly affected due to the characteristics of regenerative braking operations which have fast and high cycling frequency. For flywheels, they can also be used like the supercapacitors but for safety reasons, their use in such wayside application is also limited.

\section{The bidirectional DC-DC converter topologies}

The recommended topology according to this review is the cascaded configuration for non-isolated onboard and wayside ESSs applications. When isolation is required for wayside ESSs application, then a dual-active half-bridge DC-DC converter is recommended over the full-bridge configuration.

\section{The control methods of bidirectional power converter}

The FLC and ANN methods are hereby recommended to be used separately or combined over the classical linear PID control, sliding control, and MPC because of their excellent features. The FLC and ANN are suitable for systems like electronic power converter whose dynamic model are highly nonlinear, and for their ability to provide optimal control with no model of the converter required. Moreover, they are highly resistant to system parameter fluctuations compared to the other control methods.

\section{Challenges and Future Research Direction}

The most widely used ESSs in railway regenerative braking energy recovery are batteries and supercapacitors due to their simple implementation, accessibility, and weight, compared to flywheels and the rest of the energy storage technologies. However, they too have their associated issues which include but not limited to overcharging, over-discharging, internal self-discharge, short circuit, temperature, and etc [39], [83]. The bidirectional DC-DC converter, being a variable structure nonlinear dynamical system, is highly affected by the urban railway intermittent operating nature due to the shocking regenerative braking current, wide range variation of train load current, energy storage device voltage and the traction network voltage. All of these, highly influence both the steady and dynamic performances of the converter , [193]. Furthermore, the converter has some control challenges during the charging and discharging of the ESS. During the discharging operation, the converter has a 
nonminimum phase behaviour as its output voltage to duty transfer function has a right-hand plane zero while pole in the left-hand plane. While in the charging mode, the behaviour reverses. The overall effect leads to system's instability and limitation to achieving high dynamic system performance, [193], [205].

It could be observed that the majority of the literature in ESSs applications for the regenerative braking energy recovery in urban rail transit are concerned mostly with the energy management issues for the storage devices in terms overcharging and over discharging $\left(\mathrm{SOC}_{\min }, \mathrm{SOC}_{\max }, \mathrm{I}_{\text {esdmax }}\right.$, and $\mathrm{V}_{\text {esdmax }}$ ) rather than optimal control of the bidirectional DC-DC converter that manages the power flow. In such studies, the converter operations were assumed to be ideal whereas those are not the case in real practice.

Therefore, a deeper research work and analyses are needed for the bidirectional DC-DC power converter that link the traction network and the energy storage device in terms of suitable topology selection and the most efficient control strategy in recuperating the regenerative braking energy for ESSs application in urban railway system. These research work and analyses are important so that the braking energy is harvested maximally while ensuring the best energy management condition in the entire system. The future direction of these studies is to take into account the analyses and designs of both classical and intelligent control strategies for the bidirectional DC-DC converter in regenerative braking energy recovery applications, simulations and hardware experiments, and then comparisons of their performances. It is hoped that an optimal and robust control strategy in terms of the improved converter dynamic performances as well highly efficient energy management system can be recommended.

\section{Conclusion}

In this paper, comprehensive reviews of the ESS technologies, relevant topologies of bidirectional DCDC converters and control schemes being used in railway systems for regenerative braking energy recovery and management have been presented. Unlike most studies and reviews which are limited to only the ESS characteristics, configurations, advantages and disadvantages, this paper also reviewed in detail the applications of the storage technologies, power converters and control strategies in both academic research studies and commercial implementations. For each of these components, the most suitable technology has been recommended although, in most cases, this depends on the type of 
application and ESS installation configuration. The energy storage technologies (supercapacitors, batteries, and flywheels) have been analysed and discussed in terms of their working principle, advantages, disadvantages, and applications. Their comparisons in terms of energy and power densities have been graphically represented and analysed by means of a Ragone plot. Moreover, the techno economic comparisons of the storage devices have been presented and analysed in terms of key performance parameters like efficiency, durability, energy density, power density, self-discharge, cost per $\mathrm{kW}$, cost per $\mathrm{kWh}$. For the energy storage technologies, their applications in terms of installation configurations which could be either stationary (wayside/trackside) ESS installation or onboard installation also have been discussed.

This study concludes that among the storage technologies, supercapacitor appears to be the most suitable choice in terms of regenerative braking energy recovery and management for all types of applications, followed by Lithium-ion batteries and then flywheels. For the bidirectional DC-DC converter topology selection, cascaded BDC is recommended for non-isolated type while dual active bridge (DAB) BDC is selected in the case of isolated type. It has been proven that in terms of the control methods for the bidirectional DC-DC converter, FLC and ANN have been recommended over the other control strategies for robust and stable control in regenerative braking energy recovery and management.

Thus, the key contribution of this paper is the comprehensive reviews and analyses given for the energy storage system components in the recovery of regenerative braking in urban railway applications. The review also highlighted the key performance indicators, important parameters, possible solutions and recommendations for the three ESS components which may assist the researchers, academicians, manufacturers and other stakeholders in improving the energy efficiency and economic benefits in urban railway applications to the next level.

\section{Acknowledgements}

The authors acknowledge the Ministry of Education, Malaysia for supporting this work under Universiti Tenaga Nasional with grant code LRGS/1/2018/UNITEN/01/1/2. Special thanks to those who contributed to this project directly or indirectly. 
Authors Contributions: All the authors mentioned actively participated in the development and writing of the paper.

Conflicts of Interest: The authors declare no conflict of interest

\section{DATA AVAILABILITY STATEMENT}

Data sharing not applicable to this article as no datasets were generated or analysed during the current study.

\section{ORCID}

Danlami Sadiq https://orcid.org/0000-0002-2948-9108 Azri H. Hasani https://orcid.org/0000-0002$\underline{0285-2747}$

\section{References}

[1] Y. Chenyihsu and A. Whalley, "Green infrastructure: The effects of urban rail transit on air quality,” Am. Econ. J. Econ. Policy, vol. 4, no. 1, pp. 58-97, 2012, doi: 10.1257/pol.4.1.58.

[2] X. Bao, "Urban Rail Transit Present Situation and Future Development Trends in China: Overall Analysis Based on National Policies and Strategic Plans in 2016-2020," Urban Rail Transit, vol. 4, no. 1, pp. 1-12, 2018, doi: 10.1007/s40864-018-0078-4.

[3] D. Brenna, Morris; Foiadelli, Federica; Zaninelli, Electrical Railway Transportation Systems, First Edit. New Jersey, USA: John Wiley \& Sons, Inc., 2018.

[4] A. González-Gil, R. Palacin, P. Batty, and J. P. Powell, "A systems approach to reduce urban rail energy consumption," Energy Convers. Manag., vol. 80, pp. 509-524, 2014, doi: 10.1016/j.enconman.2014.01.060.

[5] M. Popescu and A. Bitoleanu, "A review of the energy efficiency improvement in DC railway systems," Energies, vol. 12, no. 6, 2019, doi: 10.3390/en12061092.

[6] M. Khodaparastan, A. A. Mohamed, and W. Brandauer, "Recuperation of regenerative braking energy in electric rail transit systems," IEEE Trans. Intell. Transp. Syst., vol. 20, no. 8, pp. 2831-2847, 2019, doi: 10.1109/TITS.2018.2886809.

[7] K. Keskin and A. Karamancioglu, "Energy-efficient train operation using nature-inspired algorithms," J. Adv. Transp., vol. 2017, 2017, doi: 10.1155/2017/6173795.

[8] G. Xu, F. Li, J. Long, and D. Han, "Train movement simulation by element increment method," J. Adv. Transp., vol. 50, no. 8, pp. 2060-2076, 2016, doi: 10.1002/atr.1445.

[9] Y. Zhou, Y. Bai, J. Li, B. Mao, and T. Li, "Integrated Optimization on Train Control and Timetable to Minimize Net Energy Consumption of Metro Lines," J. Adv. Transp., vol. 2018, 2018, doi: 10.1155/2018/7905820.

[10] A. González-Gil, R. Palacin, and P. Batty, "Sustainable urban rail systems: Strategies and technologies for optimal management of regenerative braking energy," Energy Convers. Manag., vol. 75, pp. 374-388, 2013, doi: 10.1016/j.enconman.2013.06.039.

[11] M. Günay, M. E. Korkmaz, and R. Özmen, "An investigation on braking systems used in railway vehicles,” Eng. Sci. Technol. an Int. J., vol. 23, no. 2, pp. 421-431, 2020, doi: 10.1016/j.jestch.2020.01.009.

[12] "Regenerative braking | Climate Technology Centre \& Network." https://www.ctc-n.org/ctcnpoolparty/regenerative-braking-2 (accessed Aug. 24, 2020). 
[13] R. C. Sharma, M. Dhingra, and R. K. Pathak, "Braking systems in railway vehicles," Int. J. Eng. Res. Technol., vol. 4, no. 1, pp. 206-211, 2015.

[14] H. Kumar, S. K. Yadav, K. Sahay, and S. S. Kumar, "Investigation on Recuperation of Regenerative Braking Energy using ESS in (Urban) Rail Transit System," Proc. - 2019 Int. Conf. Electr. Electron. Comput. Eng. UPCON 2019, pp. 1-6, 2019, doi: 10.1109/UPCON47278.2019.8980241.

[15] H. Alnuman, D. Gladwin, and M. Foster, "Electrical modelling of a DC railway system with multiple trains," Energies, vol. 11, no. 11, 2018, doi: 10.3390/en11113211.

[16] H. Alnuman, D. T. Gladwin, and M. P. Foster, "Development of an Electrical Model for Multiple Trains Running on a DC 4th Rail Track," Proc. - 2018 IEEE Int. Conf. Environ. Electr. Eng. 2018 IEEE Ind. Commer. Power Syst. Eur. EEEIC/I CPS Eur. 2018, 2018, doi: 10.1109/EEEIC.2018.8494511.

[17] P. Suresh Kumar, S. Joshi, N. Prasanthi Kumari, S. Nair, and S. Chatterjee, "Modification of existing regenerative braking system for electric vehicle," Int. J. Innov. Technol. Explor. Eng., vol. 8, no. 11, pp. 1675-1682, 2019, doi: 10.35940/ijitee.K1512.0981119.

[18] G. Scheepmaker and R. M. P. Goverde, "Effect of regenerative braking on energy-efficient train control," no. July 2015, p. 13, 2016.

[19] H. Hayashiya et al., "Review of regenerative energy utilization in traction power supply system in Japan: Applications of energy storage systems in d.c. traction power supply system," Proc. IECON 2017 - 43rd Annu. Conf. IEEE Ind. Electron. Soc., vol. 2017-Janua, pp. 39183923, 2017, doi: 10.1109/IECON.2017.8216670.

[20] X. Feng, H. Zhang, Y. Ding, Z. Liu, H. Peng, and B. Xu, "A review study on traction energy saving of rail transport," Discret. Dyn. Nat. Soc., vol. 2013, 2013, doi: 10.1155/2013/156548.

[21] C. Wei, Y. Wang, and L. Yang, "Research of regenerative braking energy utilization in urban rail transit," AIP Conf. Proc., vol. 2066, no. January, 2019, doi: 10.1063/1.5089048.

[22] W. Kampeerawat and T. Koseki, "A strategy for utilization of regenerative energy in urban railway system by application of smart train scheduling and wayside energy storage system," Energy Procedia, vol. 138, pp. 795-800, 2017, doi: 10.1016/j.egypro.2017.10.070.

[23] Q. Gu, T. Tang, and Y. D. Song, "A survey on energy-saving operation of railway transportation systems," Meas. Control, vol. 43, no. 7, pp. 209-211, 2010, doi: $10.1177 / 002029401004300704$.

[24] Y. Lu, Y. Zhao, X. Zhao, G. Li, and C. Zhang, "Status analysis of regenerative braking energy utilization equipments in urban rail transit," 2017 IEEE Transp. Electrif. Conf. Expo, AsiaPacific, ITEC Asia-Pacific 2017, 2017, doi: 10.1109/ITEC-AP.2017.8080771.

[25] H. Hayashiya, "Recent Trend of Regenerative Energy Utilization in Traction Power Supply System in Japan," Urban Rail Transit, vol. 3, no. 4, pp. 183-191, 2017, doi: 10.1007/s40864017-0070-4.

[26] H. Liu, M. Zhou, X. Guo, and Z. Zhang, "Timetable Optimization for Regenerative Energy Utilization in Subway Systems,” vol. 20, no. 9, pp. 3247-3257, 2019.

[27] T. Yuksel, "A Survey on Energy-Efficient Timetable Optimization Model Based on the Utilization of Regenerative Braking," 2018.

[28] X. Yang, X. Li, B. Ning, and T. Tang, "Transportmetrica B : Transport Dynamics An optimisation method for train scheduling with minimum energy consumption and travel time in metro rail systems," no. August, 2015, doi: 10.1080/21680566.2015.1007577.

[29] W. Kampeerawar, T. Koseki, and F. Zhou, "Efficient Urban Railway Design integrating Train 
Scheduling, Onboard Energy Storage, and Traction Power Management," 2018 Int. Power Electron. Conf. (IPEC-Niigata 2018 -ECCE Asia), pp. 3257-3264, 2018, doi: 10.23919/IPEC.2018.8507499.

[30] A. Nasri, M. Fekri Moghadam, and H. Mokhtari, "Timetable optimization for maximum usage of regenerative energy of braking in electrical railway systems," SPEEDAM 2010 - Int. Symp. Power Electron. Electr. Drives, Autom. Motion, pp. 1218-1221, 2010, doi: 10.1109/SPEEDAM.2010.5542099.

[31] D. Cornic, R. Senior, and D. Engineer, "Efficient recovery of braking energy through a reversible dc substation THE RAILENERGY PANEL 3 R \& D PROGRAM : INNOVATIVE ENERGY," 2010.

[32] S. Mayrink, J. G. Oliveira, B. H. Dias, L. W. Oliveira, J. S. Ochoa, and G. S. Rosseti, "Regenerative braking for energy recovering in diesel-electric freight trains: A technical and economic evaluation," Energies, vol. 13, no. 4, 2020, doi: 10.3390/en13040963.

[33] A. M. S. Omar, A. A. A. Samat, S. S. M. Isa, S. A. Shamsuddin, N. F. Jamaludin, and M. F. Khyasudeen, "New model of inverting substation for DC traction with regenerative braking system," AIP Conf. Proc., vol. 1875, no. August 2017, 2017, doi: 10.1063/1.4998387.

[34] S. S. Fazel, Saman Firouzian, and B. K. Shandiz, "Energy-Efficient Emplacement of Reversible DC Traction Power Subestations in Urban Rail Trasport through Regenerative Energy Recovery," Int. J. Railw. Res., vol. 1, no. 2, pp. 11-22, 2014.

[35] M. Khodaparastan and A. Mohamed, "Modeling and Simulation of a Reversible Substation for Recuperation of Regenerative Braking Energy in Rail Transit Systems," ITEC 2019 - 2019 IEEE Transp. Electrif. Conf. Expo, 2019, doi: 10.1109/ITEC.2019.8790530.

[36] D. Ramsey, T. Letrouve, A. Bouscayrol, and P. Delarue, "Quantification of the recoverable braking energy in a reversible railway DC traction power substation," 2019 21st Eur. Conf. Power Electron. Appl. EPE 2019 ECCE Eur., pp. 1-10, 2019, doi: 10.23919/EPE.2019.8915386.

[37] D. Roch-dupré, A. P. Cucala, R. R. Pecharromán, Á. J. López-lópez, and A. Fernándezcardador, "Electrical Power and Energy Systems Simulation-based assessment of the installation of a Reversible Substation in a railway line, including a realistic model of large tra ffi c perturbations," Electr. Power Energy Syst., vol. 115, no. August 2019, p. 105476, 2020 , doi: 10.1016/j.ijepes.2019.105476.

[38] G. Zhang, J. Qian, and X. Zhang, "applied sciences Application of a High-Power Reversible Converter in a Hybrid Traction Power Supply System,” 2017, doi: 10.3390/app7030282.

[39] M. Chymera, A. Renfrew, and M. Barnes, "Energy Storage Devices in Railway Systems," N/a, vol. 00, no. 0, pp. 1-19, 2005, doi: 10.1093/tse/tdaa016.

[40] N. Ghaviha, J. Campillo, M. Bohlin, and E. Dahlquist, "Review of Application of Energy Storage Devices in Railway Transportation," Energy Procedia, vol. 105, pp. 4561-4568, 2017, doi: 10.1016/j.egypro.2017.03.980.

[41] M. Ceraolo, G. Lutzemberger, E. Meli, L. Pugi, A. Rindi, and G. Pancari, "Energy storage systems to exploit regenerative braking in DC railway systems: Different approaches to improve efficiency of modern high-speed trains," J. Energy Storage, vol. 16, pp. 269-279, 2018, doi: 10.1016/j.est.2018.01.017.

[42] Z. Gao, Q. Lu, C. Wang, J. Fu, and B. He, "Energy-storage-based smart electrical infrastructure and regenerative braking energy management in AC-Fed railways with neutral zones," Energies, vol. 12, no. 21, 2019, doi: 10.3390/en12214053.

[43] M. Ogasa, "Application of energy storage technologies for electric railway vehicles-examples 
with hybrid electric railway vehicles," IEEJ Trans. Electr. Electron. Eng., vol. 5, no. 3, pp. 304-311, 2010, doi: 10.1002/tee.20534.

[44] H. Alnuman and D. T. Gladwin, "Energy storage application into a double DC electric railway," Energy Procedia, vol. 151, pp. 12-16, 2018, doi: 10.1016/j.egypro.2018.09.020.

[45] A. Ovalle, J. Pouget, S. Bacha, L. Gerbaud, E. Vinot, and B. Sonier, "Energy storage sizing methodology for mass-transit direct-current wayside support: Application to French railway company case study," Appl. Energy, vol. 230, no. August, pp. 1673-1684, 2018, doi: 10.1016/j.apenergy.2018.09.035.

[46] Y. J. Jia, J. J. Wang, and G. K. Xie, "Analysis and Research on Energy Absorption and Utilization System of Regenerative Braking in Rail Transit Based on Super Capacitor," $J$. Phys. Conf. Ser., vol. 1345, no. 6, 2019, doi: 10.1088/1742-6596/1345/6/062034.

[47] C. Sumpavakup, S. Suwannakijborihan, T. Ratniyomchai, and T. Kulworawanichpong, "Peak Demand Cutting Strategy with an On-Board Energy Storage System in Mass Rapid Transit," Iran. J. Sci. Technol. - Trans. Electr. Eng., vol. 42, no. 1, pp. 49-62, 2018, doi: 10.1007/s40998-018-0048-6.

[48] T. Ratniyomchai and T. Kulworawanichpong, "A Demonstration Project for Installation of Battery Energy Storage System in Mass Rapid Transit," Energy Procedia, vol. 138, pp. 93-98, 2017, doi: 10.1016/j.egypro.2017.10.065.

[49] R. Barrero, X. Tackoen, and J. Van Mierlo, "Stationary or onboard energy storage systems for energy consumption reduction in a metro network," Proc. Inst. Mech. Eng. Part F J. Rail Rapid Transit, vol. 224, no. 3, pp. 207-225, 2010, doi: 10.1243/09544097JRRT322.

[50] J. Chen, H. Hu, Y. Ge, K. Wang, W. Huang, and Z. He, “An Energy Storage System for Recycling Regenerative Braking Energy in High-Speed Railway," IEEE Trans. Power Deliv., vol. 8977, no. c, pp. 1-1, 2020, doi: 10.1109/tpwrd.2020.2980018.

[51] M. Domínguez, A. P. Cucala, A. Fernández, R. R. Pecharromán, and J. Blanquer, "Energy efficiency on train control : design of metro ATO driving," 9th World Congr. Railw. Res., pp. $1-12,2011$.

[52] T. Suzuki, H. Hayashiya, T. Yamanoi, and K. Kawahara, "Application examples of energy saving measures in Japanese DC feeding system," 2014 Int. Power Electron. Conf. IPECHiroshima - ECCE Asia 2014, pp. 1062-1067, 2014, doi: 10.1109/IPEC.2014.6869718.

[53] C. Sumpavakup, T. Ratniyomchai, and T. Kulworawanichpong, "Optimal energy saving in DC railway system with on-board energy storage system by using peak demand cutting strategy," J. Mod. Transp., vol. 25, no. 4, pp. 223-235, 2017, doi: 10.1007/s40534-017-0146-6.

[54] R. Teymourfar, B. Asaei, H. Iman-Eini, and R. Nejati Fard, "Stationary super-capacitor energy storage system to save regenerative braking energy in a metro line," Energy Convers. Manag., vol. 56, pp. 206-214, 2012, doi: 10.1016/j.enconman.2011.11.019.

[55] R. D. White, “AC 25kV 50 Hz electrification supply design,” IET Semin. Dig., vol. 2011, no. 14203, pp. 92-130, 2011, doi: 10.1049/ic.2011.0181.

[56] Siemens, "DC traction power supply | Rail Electrification | Global." https://www.mobility.siemens.com/global/en/portfolio/rail/electrification/dc-traction-powersupply.html (accessed Aug. 25, 2020).

[57] Siemens, "AC traction power supply | Rail Electrification | Global." https://www.mobility.siemens.com/global/en/portfolio/rail/electrification/ac-traction-powersupply.html (accessed Aug. 25, 2020).

[58] F. Schmid and C. J. Goodman, "Overview of electric railway systems," IET Conf. Publ., vol. 
2014, no. CP690, 2014, doi: 10.1049/cp.2014.1430.

[59] T. Authority, E. Systems, H. Voltage, and E. Supply, "AC / DC RAILWAY ELECTRIFICATION AND PROTECTION."

[60] Toshiba, "Railway Systems | Toshiba Infrastructure Systems \& Solutions Corporation." https://www.toshiba.co.jp/infrastructure/en/railway/index.htm (accessed Aug. 25, 2020).

[61] M. Elbelkasi, E. Badran, and M. Abdel-Rahman, "Overview of DC and AC Electric Railway Systems Considering Energy Efficiency Enhancement Methods," Port-Said Eng. Res. J., vol. 0, no. 0, pp. 0-0, 2019, doi: 10.21608/pserj.2019.18206.1012.

[62] G. Abad, Power Electronics and Electric Drives for Tractiion Applications, First Edit. The Atrium, West Sussex, UK: John Wiley \& Sons Ltd, 2017.

[63] D. Serrano-Jiménez, L. Abrahamsson, S. Castaño-Solís, and J. Sanz-Feito, "Electrical railway power supply systems: Current situation and future trends," Int. J. Electr. Power Energy Syst., vol. 92, pp. 181-192, 2017, doi: 10.1016/j.ijepes.2017.05.008.

[64] A. Verdicchio, P. Ladoux, H. Caron, and C. Courtois, "New Medium-Voltage DC Railway Electrification System," IEEE Trans. Transp. Electrif., vol. 4, no. 2, pp. 591-604, 2018, doi: 10.1109/TTE.2018.2826780.

[65] J. Srivastava, V. Kumar Singh, and A. Singhal, "Review on Railway Traction Power Supply System,” J. Environ. Sci. , Comput. Sci. Eng. Technol., vol. 2, no. 4, pp. 1236-1250, 2013.

[66] R. D. White, "Electrification traction and signalling compatibility," no. March, pp. 132-164, 2013, doi: 10.1049/ic.2006.0683.

[67] B. Bhargava, "Railway electrification systems and configurations," 1999 IEEE Power Eng. Soc. Summer Meet. PES 1999 - Conf. Proc., vol. 1, pp. 445-450, 1999, doi: 10.1109/PESS.1999.784389.

[68] F. Schmid and C. J. Goodman, "Electric railway systems in common use," IET Semin. Dig., vol. 2011, no. 14203, pp. 1-15, 2011, doi: 10.1049/ic.2011.0174.

[69] P. Laconte, "Transportation networks in urban Europe," Ekistics, vol. 59. Athens Center of Ekistics, pp. 93-113, doi: 10.2307/43623137.

[70] L. He, Q. Liang, and S. Fang, "Challenges and Innovative Solutions in Urban Rail Transit Network Operations and Management: China's Guangzhou Metro Experience," Urban Rail Transit, vol. 2, no. 1, pp. 33-45, 2016, doi: 10.1007/s40864-016-0036-y.

[71] A. S. I. Almselati, R. A. O. K. Rahmat, and O. Jaafar, "An overview of urban transport in Malaysia,” Social Sciences, vol. 6, no. 1. pp. 24-33, 2011, doi: 10.3923/sscience.2011.24.33.

[72] J. Zhang, Y. Li, Y. Wang, and B. Li, "Overview of urban rail transit energy feedback traction power supply system,” J. Phys. Conf. Ser., vol. 1549, no. 4, 2020, doi: 10.1088/1742$6596 / 1549 / 4 / 042051$.

[73] M. Połom, M. Tarkowski, and K. Puzdrakiewicz, "Urban Transformation in the Context of Rail Transport Development: The Case of a Newly Built Railway Line in Gdańsk (Poland)," $J$. Adv. Transp., vol. 2018, pp. 1-15, 2018, doi: 10.1155/2018/1218041.

[74] A. González-Gil, R. Palacin, and P. Batty, "Optimal energy management of urban rail systems: Key performance indicators," Energy Convers. Manag., vol. 90, pp. 282-291, 2015, doi: 10.1016/j.enconman.2014.11.035.

[75] S. Koohi-Fayegh and M. A. Rosen, "A review of energy storage types, applications and recent developments," J. Energy Storage, vol. 27, no. October 2019, p. 101047, 2020, doi: 10.1016/j.est.2019.101047. 
[76] F. Meishner and D. U. Sauer, "Wayside energy recovery systems in DC urban railway grids," eTransportation, vol. 1, p. 100001, 2019, doi: 10.1016/j.etran.2019.04.001.

[77] A. Mohamed, A. Reid, and T. Lamb, "White Paper on Wayside Energy Storage for Regenerative Braking Energy Recuperation in the Electric Rail System," no. November 2018, 2018.

[78] L. Galaï-Dol, A. De Bernardinis, A. Nassiopoulos, A. Peny, and F. Bourquin, "On the Use of Train Braking Energy Regarding the Electrical Consumption Optimization in Railway Station," Transp. Res. Procedia, vol. 14, pp. 655-664, 2016, doi: 10.1016/j.trpro.2016.05.321.

[79] R. Transportation, S. Committee, I. Vehicular, and T. Society, IEEE Guide for Wayside Energy Storage Systems for DC Traction Applications IEEE Vehicular Technology Society IEEE Guide for Wayside Energy Storage Systems for DC Traction Applications. 2017.

[80] International Union Of Railwats, "Technologies and Potential Developments for Energy Efficiency and CO2 Reductions in Rail Systems," p. 188, 2016, [Online]. Available: https://uic.org/IMG/pdf/27_technologies_and_potential_developments_for_energy_efficienc y_and_co2_reductions_in_rail_systems._uic_in_colaboration.pdf.

[81] Los Angeles County Metropolitan Transportation Authority, "Sustainable Rail Plan," no. May, 2013, [Online]. Available:

http://media.metro.net/about_us/sustainability/images/sustainable_rail_plan_final_clean_subm itted.pdf.

[82] B. Y. Jiang, J. Liu, W. Tian, M. Shahidehpour, and M. Krishnamurthy, "Energy Harvesting for the Electrification of Railway Stations," no. September, pp. 39-48, 2014.

[83] M. Faisal, M. A. Hannan, P. J. Ker, A. Hussain, M. Bin Mansor, and F. Blaabjerg, "Review of energy storage system technologies in microgrid applications: Issues and challenges," IEEE Access, vol. 6, pp. 35143-35164, 2018, doi: 10.1109/ACCESS.2018.2841407.

[84] T. M. Gür, "Review of electrical energy storage technologies, materials and systems: Challenges and prospects for large-scale grid storage," Energy Environ. Sci., vol. 11, no. 10, pp. 2696-2767, 2018, doi: 10.1039/c8ee01419a.

[85] M. Aneke and M. Wang, "Energy storage technologies and real life applications - A state of the art review," Appl. Energy, vol. 179, pp. 350-377, 2016, doi:

10.1016/j.apenergy.2016.06.097.

[86] M. A. Hannan, M. M. Hoque, A. Mohamed, and A. Ayob, "Review of energy storage systems for electric vehicle applications: Issues and challenges," Renew. Sustain. Energy Rev., vol. 69, no. December 2016, pp. 771-789, 2017, doi: 10.1016/j.rser.2016.11.171.

[87] A. Czerwiński, J. Wróbel, J. Lach, K. Wróbel, and P. Podsadni, "The charging-discharging behavior of the lead-acid cell with electrodes based on carbon matrix," J. Solid State Electrochem., vol. 22, no. 9, pp. 2703-2714, 2018, doi: 10.1007/s10008-018-3981-4.

[88] P. T. Moseley, D. A. J. Rand, and B. Monahov, "Designing lead-acid batteries to meet energy and power requirements of future automobiles," J. Power Sources, vol. 219, no. December, pp. 75-79, 2012, doi: 10.1016/j.jpowsour.2012.07.040.

[89] K. C. Divya and J. Østergaard, "Battery energy storage technology for power systems-An overview," Electr. Power Syst. Res., vol. 79, no. 4, pp. 511-520, 2009, doi: 10.1016/j.epsr.2008.09.017.

[90] M. C. Kocer et al., "Assessment of battery storage technologies for a Turkish power network," Sustain., vol. 11, no. 13, 2019, doi: 10.3390/su11133669.

[91] D. Pavlov, Lead-Acid Batteries: Science and Technology - A handbook of lead-acid battery 
technology and its influence on the product. Amsterdam, The Netherlands: John Fedor, 2017.

[92] A. Czerwiński, S. Obrębowski, and Z. Rogulski, "New high-energy lead-acid battery with reticulated vitreous carbon as a carrier and current collector," J. Power Sources, vol. 198, pp. 378-382, 2012, doi: 10.1016/j.jpowsour.2011.09.081.

[93] P. Ruetschi, "Aging mechanisms and service life of lead-acid batteries," J. Power Sources, vol. 127, no. 1-2, pp. 33-44, 2004, doi: 10.1016/j.jpowsour.2003.09.052.

[94] A. Okui, S. Hase, H. Shigeeda, T. Konishi, and T. Yoshi, "Application of energy storage system for railway transportation in Japan," 2010 Int. Power Electron. Conf. - ECCE Asia -, IPEC 2010, pp. 3117-3123, 2010, doi: 10.1109/IPEC.2010.5542321.

[95] S. L. I. Tsai, P.J; Chan, "Nickel-based Batteries: materials and chemistry," in Electricity Transmission, Distribution and Storage Systems, no. March 1899, Woodhead Publishing Limited, 2013, pp. 1-494.

[96] Y. Zhu, W. H. Zhu, Z. Davis, and B. J. Tatarchuk, "Simulation of Ni-MH Batteries via an Equivalent Circuit Model for Energy Storage Applications," Adv. Phys. Chem., vol. 2016, 2016, doi: 10.1155/2016/4584781.

[97] Y. Shen, F. Peng, S. Kontos, and D. Noréus, "Improved NiMH performance by a surface treatment that creates magnetic Ni-clusters," Int. J. Hydrogen Energy, vol. 41, no. 23, pp. 9933-9938, 2016, doi: 10.1016/j.ijhydene.2016.01.145.

[98] G. Li et al., "Advanced intermediate temperature sodium-nickel chloride batteries with ultrahigh energy density," Nat. Commun., vol. 7, pp. 1-6, 2016, doi: 10.1038/ncomms10683.

[99] M. Sanders, The Rechargeable Battery Market and Main Trends 2016 - 2025. Novi, Michigan, USA, 2017.

[100] "Nice Trams Project in France Near the Italian Border - Railway Technology." https://www.railway-technology.com/projects/nice-trams/ (accessed Aug. 26, 2020).

[101] T. Ratniyomchai, S. Hillmansen, and P. Tricoli, "Recent developments and applications of energy storage devices in electrified railways," IET Electr. Syst. Transp., vol. 4, no. 1, pp. 920, 2014, doi: 10.1049/iet-est.2013.0031.

[102] Y. Miao, P. Hynan, A. Von Jouanne, and A. Yokochi, "Current li-ion battery technologies in electric vehicles and opportunities for advancements," Energies, vol. 12, no. 6, pp. 1-20, 2019, doi: $10.3390 /$ en 12061074.

[103] J. Jaguemont, L. Boulon, and Y. Dubé, "A comprehensive review of lithium-ion batteries used in hybrid and electric vehicles at cold temperatures," Appl. Energy, vol. 164, pp. 99-114, 2016, doi: 10.1016/j.apenergy.2015.11.034.

[104] "Advantages \& Limitations of the Lithium-ion Battery - Battery University." https://batteryuniversity.com/learn/archive/is_lithium_ion_the_ideal_battery (accessed Aug. 26, 2020).

[105] Y. Zou, X. Hu, H. Ma, and S. E. Li, "Combined State of Charge and State of Health estimation over lithium-ion battery cell cycle lifespan for electric vehicles," J. Power Sources, vol. 273, pp. 793-803, 2015, doi: 10.1016/j.jpowsour.2014.09.146.

[106] N. Nitta, F. Wu, J. T. Lee, and G. Yushin, "Li-ion battery materials: Present and future," Mater. Today, vol. 18, no. 5, pp. 252-264, 2015, doi: 10.1016/j.mattod.2014.10.040.

[107] S. Chauque, F. Y. Oliva, A. Visintin, D. Barraco, E. P. M. Leiva, and O. R. Cámara, "Lithium titanate as anode material for lithium ion batteries: Synthesis, post-treatment and its electrochemical response," J. Electroanal. Chem., vol. 799, no. September, pp. 142-155, 2017, doi: 10.1016/j.jelechem.2017.05.052. 
[108] M. A. Hannan, M. M. Hoque, A. Hussain, Y. Yusof, and P. J. Ker, "State-of-the-Art and Energy Management System of Lithium-Ion Batteries in Electric Vehicle Applications: Issues and Recommendations," IEEE Access, vol. 6, pp. 19362-19378, 2018, doi: 10.1109/ACCESS.2018.2817655.

[109] T. Konishi and M. Tobita, "Fixed energy storage technology applied for DC electrified railway (traction power substation)," Electr. Syst. Aircraft, Railw. Sh. Propulsion, ESARS, 2012, doi: 10.1109/ESARS.2012.6387438.

[110] H. Hayashiya et al., "Lithium-ion battery installation in traction power supply system for regenerative energy utilization: Initial report of effect evaluation after half a year operation," 16th Int. Power Electron. Motion Control Conf. Expo. PEMC 2014, pp. 119-124, 2014, doi: 10.1109/EPEPEMC.2014.6980621.

[111] S. Tewari and N. Mohan, "Value of NAS energy storage toward integrating wind: Results from the wind to battery project," IEEE Trans. Power Syst., vol. 28, no. 1, pp. 532-541, 2013, doi: 10.1109/TPWRS.2012.2205278.

[112] C. . S.-K. Menictas, Advances in Batteries for Medium and Large-Scale Energy Storage. Woodhead Publishing Limited, 2014.

[113] “NAS Battries | Products | NGK INSULATORS, LTD.” https://www.ngkinsulators.com/en/product/nas/ (accessed Aug. 26, 2020).

[114] X. Luo, J. Wang, M. Dooner, and J. Clarke, "Overview of current development in electrical energy storage technologies and the application potential in power system operation," Appl. Energy, vol. 137, pp. 511-536, 2015, doi: 10.1016/j.apenergy.2014.09.081.

[115] P. M. Diaz and H. J. El-Khozondar, "Electrical energy storage technologies and the application potential in power system operation: A mini review," IEEE 7th Palest. Int. Conf. Electr. Comput. Eng. PICECE 2019, 2019, doi: 10.1109/PICECE.2019.8747172.

[116] D. Kumar, S. B. Kuhar, and D. K. Kanchan, "Room temperature sodium-sulfur batteries as emerging energy source," J. Energy Storage, vol. 18, no. March, pp. 133-148, 2018, doi: 10.1016/j.est.2018.04.021.

[117] A. Kumar et al., "High-energy density room temperature sodium-sulfur battery enabled by sodium polysulfide catholyte and carbon cloth current collector decorated with $\mathrm{MnO} 2$ nanoarrays," Energy Storage Mater., vol. 20, no. November 2018, pp. 196-202, 2019, doi: 10.1016/j.ensm.2018.11.031.

[118] P. Sharma and T. S. Bhatti, "A review on electrochemical double-layer capacitors," Energy Convers. Manag., vol. 51, no. 12, pp. 2901-2912, 2010, doi: 10.1016/j.enconman.2010.06.031.

[119] M. Khodaparastan and A. Mohamed, "Supercapacitors for electric rail transit systems," 2017 6th Int. Conf. Renew. Energy Res. Appl. ICRERA 2017, vol. 2017-Janua, pp. 896-901, 2017, doi: 10.1109/ICRERA.2017.8191189.

[120] P. Svasta, R. Negroiu, and A. Vasile, "Supercapacitors - An alternative electrical energy storage device," Proc. - 2017 5th Int. Symp. Electr. Electron. Eng. ISEEE 2017, vol. 2017Decem, pp. 1-5, 2017, doi: 10.1109/ISEEE.2017.8170626.

[121] A. Bostrom, A. Von Jouanne, T. K. A. Brekken, and A. Yokochi, "Supercapacitor energy storage systems for voltage and power flow stabilization," 2013 lst IEEE Conf. Technol. Sustain. SusTech 2013, pp. 230-237, 2013, doi: 10.1109/SusTech.2013.6617326.

[122] J. Partridge and D. I. Abouelamaimen, "The role of supercapacitors in regenerative braking systems," Energies, vol. 12, no. 14, 2019, doi: 10.3390/en12142683. 
[123] F. Ciccarelli, D. Iannuzzi, and D. Lauria, "Supercapacitors-based energy storage for urban mass transit systems," Proc. 2011 14th Eur. Conf. Power Electron. Appl. EPE 2011, 2011.

[124] "Siemens.com/mobility Increasing energy efficiency Optimized traction power supply in mass transit systems - PDF Free Download." https://docplayer.net/89948259-Siemens-commobility-increasing-energy-efficiency-optimized-traction-power-supply-in-mass-transitsystems.html (accessed Aug. 26, 2020).

[125] "Siemens installing Sitras supercap-based stationary energy storage unit for TriMet light right substation - Green Car Congress." https://www.greencarcongress.com/2013/06/sitras20130603.html (accessed Aug. 26, 2020).

[126] and I. A. Sekijima, Y., M. Inui, Y. Monden, "Regenerated energy train A: brake motor train B: acceleration," Japanese Railw. Eng. 46, 2005.

[127] H. M. Lee, "A study on development of ESS installed in DC railway system," ICCAS 2010 Int. Conf. Control. Autom. Syst., pp. 804-806, 2010.

[128] "Bombadier Mitrac Energy Saver/EcoActive Technologies." [Online]. Available: https://www.bombardier.com/content/dam/Websites/bombardiercom/supportingdocuments/BT/Bombardier-Transport-ECO4-MITRAC_Energy_Saver-EN.pdf.

[129] M. Steiner, M. Klohr, and S. Pagiela, "Energy storage system with Ultracaps on board of railway vehicles," 2007 Eur. Conf. Power Electron. Appl. EPE, 2007, doi: 10.1109/EPE.2007.4417400.

[130] "Carbon Fiber Flywheels | Beacon Power." https://beaconpower.com/carbon-fiber-flywheels/ (accessed Aug. 27, 2020).

[131] M. Khodaparastan and A. Mohamed, "Flywheel vs. Supercapacitor as wayside energy storage for electric rail transit systems," Inventions, vol. 4, no. 4, 2019, doi: 10.3390/inventions4040062.

[132] M. E. Amiryar and K. R. Pullen, "A review of flywheel energy storage system technologies and their applications," Appl. Sci., vol. 7, no. 3, 2017, doi: 10.3390/app7030286.

[133] S. M. Mousavi G, F. Faraji, A. Majazi, and K. Al-Haddad, "A comprehensive review of Flywheel Energy Storage System technology,” Renew. Sustain. Energy Rev., vol. 67, pp. 477490, 2017, doi: 10.1016/j.rser.2016.09.060.

[134] A. A. K. Arani, H. Karami, G. B. Gharehpetian, and M. S. A. Hejazi, "Review of Flywheel Energy Storage Systems structures and applications in power systems and microgrids," Renew. Sustain. Energy Rev., vol. 69, no. September 2016, pp. 9-18, 2017, doi: 10.1016/j.rser.2016.11.166.

[135] A. Rupp, H. Baier, P. Mertiny, and M. Secanell, "Analysis of a flywheel energy storage system for light rail transit," Energy, vol. 107, pp. 625-638, 2016, doi: 10.1016/j.energy.2016.04.051.

[136] M. Khodaparastan and A. Mohamed, "Modeling and Simulation of Regenerative Braking Energy in DC Electric Rail Systems," 2018 IEEE Transp. Electrif. Conf. Expo, ITEC 2018, no. 2, pp. 1117-1122, 2018, doi: 10.1109/ITEC.2018.8450133.

[137] F. Castro, L. S. B. Ng, and G. Thompson, "LA METRO RED LINE WAYSIDE ENERGY STORAGE SUBSTATION REVENUE SERVICE REGENERATIVE ENERGY SAVING RESULTS," pp. 1-5, 2014.

[138] H. Moghbelli and S. Sabzi, "Analysis and simulation of hybrid electric energy storage (HEES) systems for high power applications," ASEE Annu. Conf. Expo. Conf. Proc., vol. 122nd ASEE, no. 122nd ASEE Annual Conference and Exposition: Making Value for Society, 2015, doi: 
$10.18260 / \mathrm{p} .23548$.

[139] H. Moghbeli, H. Hajisadeghian, and M. Asadi, "Design and simulation of hybrid electrical energy storage (HEES) for Esfahan urban railway to store regenerative braking energy," 7 th Power Electron. Drive Syst. Technol. Conf. PEDSTC 2016, no. Pedstc, pp. 93-98, 2016, doi: 10.1109/PEDSTC.2016.7556844.

[140] T. Zimmermann, P. Keil, M. Hofmann, M. F. Horsche, S. Pichlmaier, and A. Jossen, "Review of system topologies for hybrid electrical energy storage systems," J. Energy Storage, vol. 8, pp. 78-90, 2016, doi: 10.1016/j.est.2016.09.006.

[141] A. Fitri Desanti, Y. Uta Nugraha, M. Nur Yuniarto, and A. Wikarta, "Review of the Topology and Energy Management Hybrid Energy Storage on Electric Vehicle," IOP Conf. Ser. Mater. Sci. Eng., vol. 694, no. 1, 2019, doi: 10.1088/1757-899X/694/1/012006.

[142] M. Ogasa and Y. Taguchi, "Electronics Technologies Battery Tram,” 2007.

[143] M. Meinert, "New mobile energy storage system for rolling stock," 2009 13th Eur. Conf. Power Electron. Appl. EPE '09, no. Dlc, 2009.

[144] K. Fleurbaey et al., "Lithium-ion Capacitor - Electrical and Thermal Characterization of Advanced Rechargeable Energy Storage Component," Eur. Electr. Veh. Congr., no. December, pp. 1-11, 2014.

[145] F. Ciccarelli, D. Iannuzzi, D. Lauria, and P. Natale, "Optimal Control of Stationary LithiumIon Capacitor-Based Storage Device for Light Electrical Transportation Network," IEEE Trans. Transp. Electrif., vol. 3, no. 3, pp. 618-631, 2017, doi: 10.1109/TTE.2017.2739399.

[146] J. Ronsmans, B. Lalande, and J. S. R. M. N. V, "Capacitors," 2015.

[147] N. Omar et al., "Lithium-ion capacitor - Advanced technology for rechargeable energy storage systems," 2013 World Electr. Veh. Symp. Exhib. EVS 2014, pp. 1-11, 2014, doi: 10.1109/EVS.2013.6914718.

[148] I. Hadjipaschalis, A. Poullikkas, and V. Efthimiou, "Overview of current and future energy storage technologies for electric power applications," Renew. Sustain. Energy Rev., vol. 13, no. 6-7, pp. 1513-1522, 2009, doi: 10.1016/j.rser.2008.09.028.

[149] H. Chen, T. N. Cong, W. Yang, C. Tan, Y. Li, and Y. Ding, "Progress in electrical energy storage system: A critical review," Prog. Nat. Sci., vol. 19, no. 3, pp. 291-312, 2009, doi: 10.1016/j.pnsc.2008.07.014.

[150] A. Burke and M. Miller, "The power capability of ultracapacitors and lithium batteries for electric and hybrid vehicle applications," J. Power Sources, vol. 196, no. 1, pp. 514-522, 2011, doi: 10.1016/j.jpowsour.2010.06.092.

[151] H. Ibrahim, A. Ilinca, and J. Perron, "Energy storage systems-Characteristics and comparisons," Renew. Sustain. Energy Rev., vol. 12, no. 5, pp. 1221-1250, 2008, doi: 10.1016/j.rser.2007.01.023.

[152] A. Chatzivasileiadi, E. Ampatzi, and I. Knight, "Characteristics of electrical energy storage technologies and their applications in buildings," Renew. Sustain. Energy Rev., vol. 25, pp. 814-830, 2013, doi: 10.1016/j.rser.2013.05.023.

[153] S. M. Schoenung and W. Hassenzahl, "Characteristics and Technologies for Long-vs. ShortTerm Energy Storage A Study by the DOE Energy Storage Systems Program SAND20010765," Sandia Natl. Lab. U.S. Dept. Energy, no. March, p. 46 pp., 2001.

[154] B. Battke, T. S. Schmidt, D. Grosspietsch, and V. H. Hoffmann, "A review and probabilistic model of lifecycle costs of stationary batteries in multiple applications," Renew. Sustain. Energy Rev., vol. 25, pp. 240-250, 2013, doi: 10.1016/j.rser.2013.04.023. 
[155] T. Christen and M. W. Carlen, "Theory of ragone plots," J. Power Sources, vol. 91, no. 2, pp. 210-216, 2000, doi: 10.1016/S0378-7753(00)00474-2.

[156] R. S. and S. Board, "Research Programme: Energy Storage Systems for Railway Applications, Phase2: OHL Electrification Gaps," 2010. [Online]. Available: https://www.rssb.co.uk.

[157] P. V. Radu, A. Szelag, and M. Steczek, "On-board energy storage devices with supercapacitors for metro trains-case study analysis of application effectiveness," Energies, vol. 12, no. 7, 2019, doi: 10.3390/en12071291.

[158] R. Barrero, X. Tackoen, and J. Van Mierlo, "Supercapacitors on-board light rail vehicles: Enhanced energy storage systems for improved vehicle efficiency," in Proceedings of the ASME/IEEE/ASCE Joint Rail Conference, JRC 2008, 2008, pp. 371-379.

[159] F. Fan, B. G. Stewart, and A. T. P. Calculation, "Power Flow Simulation of DC Railway Power Supply Systems with Regenerative Braking,” pp. 5-10, 2020.

[160] P. V. Radu, M. Lewandowski, and A. Szelag, "On-board and wayside energy storage devices applications in urban transport systems-case study analysis for power applications," Energies, vol. 13, no. 8, 2020, doi: 10.3390/en13082013.

[161] C. Wu, S. Lu, F. Xue, L. Jiang, and M. Chen, "Optimal Sizing of On-Board Energy Storage Devices for Electrified Railway Systems," IEEE Trans. Transp. Electrif., vol. 7782, no. c, pp. 1-1, 2020, doi: 10.1109/tte.2020.2996362.

[162] M. Ceraolo and G. Lutzemberger, "Stationary and on-board storage systems to enhance energy and cost efficiency of tramways," J. Power Sources, vol. 264, pp. 128-139, 2014, doi: 10.1016/j.jpowsour.2014.04.070.

[163] D. Roch-dupré, Á. J. López-lópez, R. R. Pecharromán, A. P. Cucala, and A. Fernándezcardador, "Electrical Power and Energy Systems Analysis of the demand charge in DC railway systems and reduction of its economic impact with Energy Storage Systems," vol. 93, pp. 459467, 2017, doi: 10.1016/j.ijepes.2017.06.022.

[164] P. Radcliffe, J. S. Wallace, and L. H. Shu, "Stationary applications of energy storage technologies for transit systems," EPEC 2010 - IEEE Electr. Power Energy Conf. "Sustainable Energy an Intell. Grid," 2010, doi: 10.1109/EPEC.2010.5697222.

[165] D. Iannuzzi, F. Ciccarelli, and D. Lauria, "Stationary ultracapacitors storage device for improving energy saving and voltage profile of light transportation networks," Transp. Res. Part C, vol. 21, no. 1, pp. 321-337, 2012, doi: 10.1016/j.trc.2011.11.002.

[166] G. Réchard and R. Gouttefangeas, "ScienceDirect ScienceDirect Recovering energy from Symposium train braking for Heating traction grid use Assessing the Gabriel feasibility the heat demand-outdoor Kong demand forecast temperature function for a long-term district heat," Energy Procedia, vol. 143, pp. 61-66, 2017, doi: 10.1016/j.egypro.2017.12.648.

[167] S. Lin, W. Song, and Z. Feng, "Simulation research on rail transit traction grid voltage stabilization and its energy saving effects based on BESS," pp. 431-436, 2014, doi: 10.12720/sgce.3.4.431-436.

[168] I. Župan and A. Lasić, "Power converter circuits for recuperation of the regenerative braking energy in rail vehicles," pp. 174-179, 2019.

[169] S. Chakraborty et al., "DC-DC Converter Topologies for Electric Vehicles, Plug-in Hybrid Electric Vehicles and Fast Charging Stations: State of the Art and Future Trends," no. April, 2019, doi: 10.3390/en12081569.

[170] S. Kale, "DC TO DC CONVERTERS AND ITS APPLICATION FOR RAILWAY SYSTEMA REVIEW," vol. 10, no. 4, pp. 13-21, 2019. 
[171] M. Z. Hossain and N. A. Rahim, "Recent progress and development on power DC-DC converter topology , control, design and applications : A review," Renew. Sustain. Energy Rev., vol. 81, no. January 2017, pp. 205-230, 2018, doi: 10.1016/j.rser.2017.07.017.

[172] S. A. Gorji, H. G. Sahebi, M. Ektesabi, and A. B. Rad, "Topologies and Control Schemes of Bidirectional DC - DC Power Converters : An Overview," IEEE Access, vol. 7, pp. 117997118019, 2019, doi: 10.1109/ACCESS.2019.2937239.

[173] V. F. Pires, E. Romero-cadaval, D. Vinnikov, I. Roasto, and J. F. Martins, "Power converter interfaces for electrochemical energy storage systems - A review," vol. 86, pp. 453-475, 2014, doi: 10.1016/j.enconman.2014.05.003.

[174] S. De Breucker, "Impact of DC-DC Converters on Li-ion Batteries," Katholieke Universiteit Leuven - Faculty of Engineering, 2012.

[175] I. I. V. Jagadeesh, "Review and comparative analysis on dc-dc converters used in electric vehicle applications Review and comparative analysis on dc-dc converters used in electric vehicle applications," 2019, doi: 10.1088/1757-899X/623/1/012005.

[176] L. Caricchi, F.: Crescimbinii, F; Giulii, F; Solero, "Study of Bi-Directional Buck-Boost Converter Topologies for Application in Electrical Vehicle Motor Drives," IEEE Trans. Ind. Electron., pp. 287-293, 1998.

[177] "Benefits of multiphasing buck converters - Part 1|EE Times." https://www.eetimes.com/benefits-of-multiphasing-buck-converters-part-1/\# (accessed Aug. $27,2020)$.

[178] O. García, P. Zumel, A. De Castro, and J. A. Cobos, "Automotive DC - DC Bidirectional Converter Made With Many Interleaved Buck Stages,” vol. 21, no. 3, pp. 578-586, 2006.

[179] Y. Wang, L. Xue, S. Member, C. Wang, and S. Member, "Interleaved High-Conversion-Ratio Bidirectional DC - DC Converter for Distributed Energy-Storage Systems - Circuit Generation, Analysis , and Design," vol. 31, no. 8, pp. 5547-5561, 2016.

[180] D. Ravi, B. M. Reddy, S. L. Shimi, and P. Samuel, "Bidirectional dc to dc Converters : An Overview of Various Topologies , Switching Schemes and Control Techniques," vol. 7, pp. 360-365, 2018.

[181] H. Lee, "High-Efficiency Bidirectional Buck - Boost Converter for Photovoltaic and Energy Storage Systems in a Smart Grid,” vol. 34, no. 5, pp. 4316-4328, 2019.

[182] D. Yuan, S. Gu, J. Liu, Y. Zhang, and C. Lv, "Energy Procedia Design and analysis of emergency self-traction system for urban rail transit vehicles," vol. 16, pp. 585-591, 2012, doi: 10.1016/j.egypro.2012.01.094.

[183] M. H. Kheraluwala, R. W. Gascoigne, D. M. Divan, E. D. Baumann, and E. F. O. F. Highpower-density, "Performance Characterization," vol. 28, no. 6, pp. 1294-1301, 1992.

[184] J. Kan, Y. Wu, Y. Tang, B. Zhang, and Z. Zhang, "Dual Active Full-bridge Bidirectional Converter for V2G Charger Based on High-frequency AC Buck-boost Control Strategy," pp. 46-50, 2016.

[185] S. Inoue and H. Akagi, "A Bidirectional DC - DC Converter for an Energy,” vol. 22, no. 6, pp. 2299-2306, 2007.

[186] Y. Miura, M. Kaga, Y. Horita, and T. Ise, "Bidirectional Isolated Dual Full-bridge dc-de Converter with Active Clamp for EDLC Yushi Miura Masato Kaga Yasuhisa Horita Toshifumi Ise," pp. 1136-1143, 2010.

[187] H. P. System, B. Zhao, S. Member, Q. Song, W. Liu, and Y. Sun, "Overview of Dual-ActiveBridge Isolated Bidirectional DC - DC Converter for," IEEE Trans. Power Electron., vol. 29, 
no. 8, pp. 4091-4106, 2014, doi: 10.1109/TPEL.2013.2289913.

[188] S. Park and Y. Song, "An Interleaved Half-Bridge Bidirectional DC-DC Converter for Energy Storage System Applications," pp. 0-5, 2011.

[189] X. Xu, A. M. Khambadkone, and R. Oruganti, "A Soft-Switched Back-to-B ack Bi-directional DC / DC Converter with a FPGA based Digital Control for Automotive applications O2LrCoss3," pp. 262-267, 2007.

[190] R. Barrero, X. Tackoen, and J. Van Mierlo, "Improving energy efficiency in public transport: Stationary supercapacitor based energy storage systems for a metro network," 2008 IEEE Veh. Power Propuls. Conf. VPPC 2008, 2008, doi: 10.1109/VPPC.2008.4677491.

[191] F. Ciccarelli, D. Iannuzzi, K. Kondo, and L. Fratelli, "Line-Voltage Control Based on Wayside Energy Storage Systems for Tramway Networks," IEEE Trans. Power Electron., vol. 31, no. 1, pp. 884-899, 2016, doi: 10.1109/TPEL.2015.2411996.

[192] W. Liu, J. Xu, and J. Tang, "Study on control strategy of urban rail train with on-board regenerative braking energy storage system," Proc. IECON 2017 - 43rd Annu. Conf. IEEE Ind. Electron. Soc., vol. 2017-Janua, pp. 3924-3929, 2017, doi: 10.1109/IECON.2017.8216671.

[193] F. Zhu, Z. Yang, H. Xia, and F. Lin, "Hierarchical Control and Full-Range Dynamic Performance Optimization of the Supercapacitor Energy Storage System in Urban Railway," IEEE Trans. Ind. Electron., vol. 65, no. 8, pp. 6646-6656, 2018, doi: 10.1109/TIE.2017.2772174.

[194] S. I. Serna-Garc, D. G. Lez Montoya, and C. A. s. Ramos-Paja, "Control of a charger/discharger DC/DC converter with improved disturbance rejection for bus regulation," Energies, vol. 11, no. 3, 2018, doi: 10.3390/en11030594.

[195] W. Lhomme, P. Delarue, P. Barrade, A. Bouscayrol, and A. Rufer, "Design and control of a supercapacitor storage system for traction applications," Conf. Rec. - IAS Annu. Meet. (IEEE Ind. Appl. Soc., vol. 3, pp. 2013-2020, 2005, doi: 10.1109/IAS.2005.1518724.

[196] J. P. Villegas Ceballos, S. I. Serna-Garcés, D. González Montoya, C. A. Ramos-Paja, and J. D. Bastidas-Rodríguez, "Charger/discharger DC/DC converter with interleaved configuration for DC-bus regulation and battery protection," Energy Sci. Eng., vol. 8, no. 2, pp. 530-543, 2020, doi: 10.1002/ese3.534.

[197] M. B. Camara, H. Gualous, F. Gustin, A. Berthon, and B. Dakyo, "DC/DC converter design for supercapacitor and battery power management in hybrid vehicle applicationspolynomial control strategy," IEEE Trans. Ind. Electron., vol. 57, no. 2, pp. 587-597, 2010, doi: 10.1109/TIE.2009.2025283.

[198] F. Lin, X. Li, Y. Zhao, and Z. Yang, "Control strategies with dynamic threshold adjustment for supercapacitor energy storage system considering the train and substation characteristics in urban rail transit," Energies, vol. 9, no. 4, 2016, doi: 10.3390/en9040257.

[199] F. Ciccarelli, D. Iannuzzi, and P. Tricoli, "Speed-based supercapacitor state of charge tracker for light railway vehicles," Proc. 2011 14th Eur. Conf. Power Electron. Appl. EPE 2011, 2011.

[200] L. Battistelli, M. Fantauzzi, D. Iannuzzi, and D. Lauria, "Energy management of electrified mass transit systems with Energy Storage devices," SPEEDAM 2012 - 21st Int. Symp. Power Electron. Electr. Drives, Autom. Motion, pp. 1172-1177, 2012, doi: 10.1109/SPEEDAM.2012.6264499.

[201] G. Graber, V. Galdi, V. Calderaro, and A. Piccolo, "Sizing and energy management of onboard hybrid energy storage systems in urban rail transit," 2016 Int. Conf. Electr. Syst. Aircraft, Railw. Sh. Propuls. Road Veh. Int. Transp. Electrif. Conf. ESARS-ITEC 2016, 2017, 
doi: 10.1109/ESARS-ITEC.2016.7841408.

[202] L. D. S. Coelho and M. W. Pessôa, "A tuning strategy for multivariable PI and PID controllers using differential evolution combined with chaotic Zaslavskii map," Expert Syst. Appl., vol. 38, no. 11, pp. 13694-13701, Oct. 2011, doi: 10.1016/j.eswa.2011.04.156.

[203] S. Z. Bai, Ying; Roth, Classical and Modern Controls with Microcontroller, Design, Implementaion, and Applications. (C) Springer Nature Switzerland AG 2019, 2019.

[204] H. M. Rashid, Power Electronics Handbook, 4th Editio. Joe Hayton, 2018.

[205] M. A. A. Mohamed, Q. Guan, and M. Rashed, "Control of DC-DC Converter for Interfacing Supercapcitors Energy storage to DC Micro Grids," in 2018 IEEE International Conference on Electrical Systems for Aircraft, Railway, Ship Propulsion and Road Vehicles \& International Transportation Electrification Conference (ESARS-ITEC), 2018, pp. 1-8.

[206] D. Iannuzzi, "Improvement of the energy recovery of traction electrical drives using supercapacitors," 2008 13th Int. Power Electron. Motion Control Conf. EPE-PEMC 2008, pp. 1469-1474, 2008, doi: 10.1109/EPEPEMC.2008.4635475.

[207] K. Filsoof and P. W. Lehn, "A Bidirectional Multiple-Input Multiple-Output Modular Multilevel DC-DC Converter and its Control Design," vol. 8993, no. c, 2015, doi: 10.1109/TPEL.2015.2448112.

[208] Q. Xu, N. Vafamand, L. Chen, and S. Member, "Review on Advanced Control Technologies for Bidirectional DC / DC Converters in DC Microgrids," vol. 6777, no. c, 2020, doi: 10.1109/JESTPE.2020.2978064.

[209] V. S. C. Raviraj and P. C. Sen, "Comparative Study of Proportional - Integral, Sliding Mode, and Fuzzy Logic Controllers for Power Converters," vol. 33, no. 2, pp. 518-524, 1997.

[210] S. Sabzi, M. Asadi, and H. Moghbeli, "Regenerative energy management of electric drive based on Lyapunov stability theorem," J. Mod. Power Syst. Clean Energy, vol. 7, no. 2, pp. 321-328, 2019, doi: 10.1007/s40565-018-0497-y.

[211] F. Ciccarelli and D. Lauria, "Sliding-mode Control of Bidirectional dc-dc Converter for Supercapacitor Energy Storage Applications," pp. 1119-1122, 2010.

[212] M. Fallah, M. Asadi, and H. Moghbeli, "Energy management and control system of DC-DC converter with super-capacitor and battery for recovering of train kinetic energy," vol. 014104, 2018, doi: $10.1063 / 1.5004619$.

[213] S. I. Serna-Garcés, D. G. Montoya, and C. A. Ramos-Paja, "Sliding-mode control of a charger/discharger DC/DC converter for DC-bus regulation in renewable power systems," Energies, vol. 9, no. 4, 2016, doi: 10.3390/en9040245.

[214] L. Wang, Model Predictive Control System Design and Implementation, vol. 53, no. 9. Springer-Verlag London Limited, 2013.

[215] EE392m-Spring 2005 Gorinevasky, "Model Predictive Control Lecture Note Part 1: The Concept," 2005. Accessed: May 21, 2021. [Online]. Available: https://web.stanford.edu/class/archive/ee/ee392m/ee392m.1056/Lecture14_MPC.pdf.

[216] J. H. Lee, "A Lecture on Model Predictive Control Prepared for Pan American Advanced Studies Institute Program on Process Systems Engineering," Geogia. Accessed: May 21, 2021. [Online]. Available: http://cepac.cheme.cmu.edu/pasilectures/lee/LecturenoteonMPC-JHL.pdf.

[217] J. Liu, Q. Yan, X. Qu, and F. Jiang, Explicit Model Predictive Control of Bidirectional DC / DC Converter for Ultracapacitors Energy Storage Unit Applied to Light Rail Vehicle, vol. 47, no. 3. IFAC, 2014. 
[218] T. Da, Zhang; Yanggang, Ou; Caixue, Chen; Tuo, Zheng; Wendeng, "Model Predictive Control of Three-level Bidirectional DC-DC Converter based on Supercapacitor Energy Storage System," Conference, pp. 19-23.

[219] Y. Shan et al., "Model Predictive Control of Bidirectional DC - DC Converters and AC / DC Interlinking Converters - A New Control Method for PV-Wind-Battery Microgrids," vol. 10, no. 4, pp. 1823-1833, 2019.

[220] A. Pirooz and R. Noroozian, "Model predictive control of classic bidirectional DC-DC converter for battery applications," 7th Power Electron. Drive Syst. Technol. Conf. PEDSTC 2016, no. Pedstc, pp. 517-522, 2016, doi: 10.1109/PEDSTC.2016.7556914.

[221] M. Ebad and B. Song, "Accurate Model Predictive Control of Bidirectional DC-DC Converters for DC Distributed Power," pp. 1-8, 2012.

[222] N. Jabbour, C. Mademlis, and I. Kioskeridis, "Improved performance in a supercapacitorbased energy storage control system with bidirectional DC-DC converter for elevator motor drives," 7th IET Int. Conf. Power Electron. Mach. Drives, PEMD 2014, pp. 1-6, 2014.

[223] K. B. Adam and M. Ashari, "Design of bidirectional converter using fuzzy logic controller to optimize battery performance in Electric Vehicle," 2015 Int. Semin. Intell. Technol. Its Appl. ISITIA 2015 - Proceeding, pp. 201-205, 2015, doi: 10.1109/ISITIA.2015.7219979.

[224] K. Arpita and P. Usha, "Fuzzy logic controlled Bi-directional DC-DC Converter for Electric Vehicle Applications," vol. 12, no. 3, pp. 51-55, 2017, doi: 10.9790/1676-1203045155.

[225] R. L. Narayana, G. S. Mahesh, K. Reddy, and C. T. Yuvaraj, "A Fuzzy Logic Based Controller for the Bidirectional Converter in an Electric Vehicle," no. 1, pp. 58-62, 2019, doi: 10.35940/ijeat.A1039.109119.

[226] B. S. Dhivya, V. Krishnan, and R. Ramaprabha, "Neural network controller for boost converter," Proc. IEEE Int. Conf. Circuit, Power Comput. Technol. ICCPCT 2013, pp. 246251, 2013, doi: 10.1109/ICCPCT.2013.6529052.

[227] B. Dai, R. Chen, and R. C. Chen, "Temperature control with fuzzy neural network," Proc. 2017 IEEE 8th Int. Conf. Aware. Sci. Technol. iCAST 2017, vol. 2018-Janua, no. iCAST, pp. 452-455, 2017, doi: 10.1109/ICAwST.2017.8256499.

[228] F. Kurokawa, H. Maruta, K. Ueno, and T. Mizoguchi, "A New Digital Control DC-DC Converter with Neural Network Predictor Fujio Kurokawa,” pp. 522-526, 2010.

[229] M.-F. H. G. A. B. J.N, "DC to DC converter with neural network control for on-board electrical energy management," 2004, [Online]. Available:

https://ieeexplore.ieee.org/document/1375618/authors\#authors.

[230] A. S. Samosir and A. H. M. Yatim, "A novel control strategy of bidirectional dc-dc converter for interfacing ultracapacitor to fuel cell electric vehicles system based on dynamic evolution control," Int. Rev. Electr. Eng., vol. 5, no. 1, pp. 64-69, 2010. 